Florida International University FIU Digital Commons

\title{
Novel Insights into the Mechanisms of Regulation of Tyrosine Kinase Receptors by Ras Interference 1
}

Adriana Galvis

Florida International University, agalv004@fiu.edu

DOI: 10.25148 /etd.FI14040866

Follow this and additional works at: https://digitalcommons.fiu.edu/etd

Part of the Biochemistry Commons, Biology Commons, and the Molecular Biology Commons

\section{Recommended Citation}

Galvis, Adriana, "Novel Insights into the Mechanisms of Regulation of Tyrosine Kinase Receptors by Ras Interference 1" (2014). FIU Electronic Theses and Dissertations. 1176.

https://digitalcommons.fiu.edu/etd/1176 


\title{
FLORIDA INTERNATIONAL UNIVERSITY \\ Miami, Florida
}

\section{NOVEL INSIGHTS INTO THE MECHANISMS OF REGULATION OF TYROSINE KINASE RECEPTORS BY RAS INTERFERENCE 1}

\author{
A dissertation submitted in partial fulfillment of the \\ requirements for the degree of \\ DOCTOR OF PHILOSOPHY \\ in \\ BIOLOGY
}

by

Adriana Galvis

2014 
To: Dean Kenneth G. Furton

College of Arts and Sciences

This dissertation, written by Adriana Galvis, and entitled Novel Insights into the Mechanisms of Regulation of Tyrosine Kinase Receptors by Ras interference 1, having been approved in respect to style and intellectual content, is referred to you for judgment.

We have read this dissertation and recommend that it be approved.

$\begin{array}{r}\hline \text { Lidia Kos } \\ \hline \text { Ophelia Weeks } \\ \hline \text { John Makemson }\end{array}$

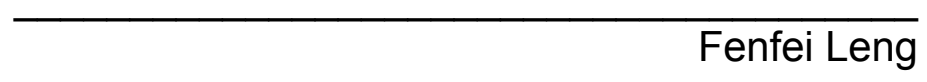

Alejandro Barbieri, Major Professor

Date of Defense: March 21, 2014

The dissertation of Adriana Galvis is approved.

$\begin{array}{r}\text { Dean Kenneth G. Furton } \\ \text { College of Arts and Sciences } \\ \hline \begin{array}{r}\text { Dean Lakshmi N. Reddi } \\ \text { University Graduate School }\end{array}\end{array}$

Florida International University, 2014 


\section{DEDICATION}

I want to dedicate this dissertation, and everything it represents, to my family. To my husband, my parents, and my siblings. I can't thank you enough for the love and support; you made this journey a lot easier. Thanks for helping me make this dream come true.

Quiero dedicarle esta tesis, y todo lo que representa, a mi familia. A mi esposo, mis papas y mis hermanos. No tengo como agradecerles por todo el amor y el apoyo; ustedes hicieron de este, un camino mucho mas facil de recorrer. Muchas gracias por ayudarme a hacer este sueño realidad. 


\section{ACKNOWLEDGMENTS}

I would like to thank Dr. Alejandro Barbieri for his mentorship and support during the past 8 years.

To Dr. Lidia Kos, Dr. Ophelia Weeks, Dr. John Makemson and Dr. Fenfei Leng for their guidance and input on this project.

To Adriana Marcano, Nathalie Rivero, and Dr. Horacio Priestap (RIP) for their help on specific areas of my research.

To former and current members of Barbieri's lab for their generosity and feedback.

To my friends, especially Monica Isola, Nicole Fresard, Ana Paula Benaduce and Monica Rodriguez for encouraging me throughout this journey.

To the MBRS RISE program, to Florida International University and their staff, especially to Dr. Mo Donelly, for their sponsorship and support. 


\section{ABSTRACT OF THE DISSERTATION \\ NOVEL INSIGHTS INTO THE MECHANISMS OF REGULATION OF TYROSINE \\ KINASE RECEPTORS BY RAS INTERFERENCE 1}

\section{by}

Adriana Galvis

Florida International University, 2014

Miami, Florida

\section{Professor Alejandro Barbieri, Major Professor}

Receptor-tyrosine kinases (RTKs) are membrane bound receptors characterized by their intrinsic kinase activity. RTK activities play an essential role in several human diseases, including cancer, diabetes and neurodegenerative diseases. RTK activities have been regulated by the expression or silencing of several genes as well as by the utilization of small molecules.

Ras Interference 1 (Rin1) is a multifunctional protein that becomes associated with activated RTKs upon ligand stimulation. Rin1 plays a key role in receptor internalization and in signal transduction via activation of Rab5 and association with active form of Ras. This study has two main objectives: (1) It determines the role of Rin1 in the regulation of several RTKs focusing on insulin receptor. This was accomplished by studying the Rin1-insulin receptor interaction using a variety of biochemical and morphological assays. This study shows a novel interaction between the insulin receptor and Rin1 through the Vps9 domain. Two more RTKs (epidermal growth factor receptor and nerve growth 
factor receptor) also interacted with the $\mathrm{SH} 2$ domain of Rin1. The effect of the Rin1-RTK interaction on the activation of both Rab5 and Ras was also studied during receptor internalization and intracellular signaling. Finally, the role of Rin1 was examined in two differentiation processes (adipogenesis and neurogenesis). Rin1 showed a strong inhibitory effect on 3T3-L1 preadipocyte differentiation but it seems to show a modest effect in PC12 neurite outgrowth. These data indicate a selective function and specific interaction of Rin1 toward RTKs. (2) It examines the role of the small molecule Dehydroleucodine $(\mathrm{DhL})$ on several key signaling molecules during adipogenesis. This was accomplished by studying the differentiation of 3T3-L1 preadipocytes exposed to different concentrations of DhL in different days of the adipocyte formation process. The results indicate that DhL selectively blocked adipocyte formation, as well as the expression of PPARy, and C/EBPa. However, DhL treatment did not affect Rin1 or Rab5 expression and their activities.

Taken together, the data indicate a potential molecular mechanism by which proteins or small molecules regulate selective and specific RTK intracellular membrane trafficking and signaling during cell growth and differentiation in normal and pathological conditions. 


\section{TABLE OF CONTENTS}

CHAPTER

PAGE

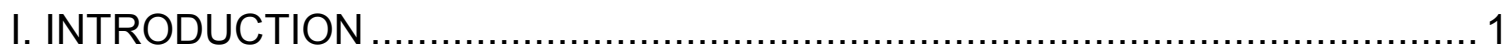

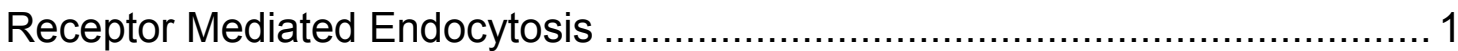

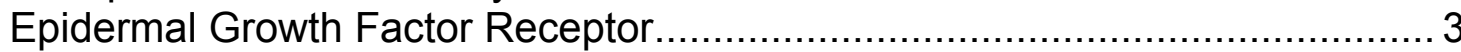

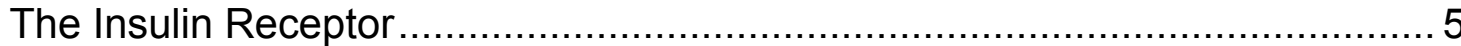

The Nerve Growth Factor Receptor ......................................................... 7

Signal Transduction and Endocytosis ................................................ 8

Hyperproliferative Diseases and Cancer................................................. 10

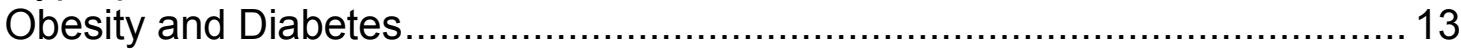

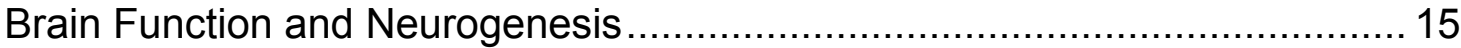

Natural products: Phytochemicals..................................................... 17

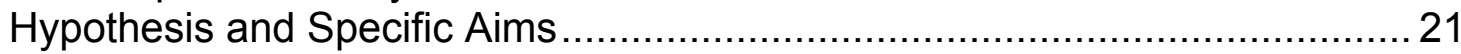

II. MECHANISM OF INTERACTION BETWEEN RIN1 AND RTKS AND ITS

EFFECTS TOWARD THE ACTIVITY OF RAB5 AND RAS............................. 39

III. THE ROLE OF RIN1 (AND RIN1-LIKE MOLECULES) IN SIGNALING TRANSDUCTION PATHWAYS INVOLVED IN CELL DIFFERENTIATION. ......66

IV. EXAMINING THE EFFECT OF DEHYDROLEUCODINE IN

DIFFERENTIATION OF ADIPOSE CELLS. ..................................................... 80

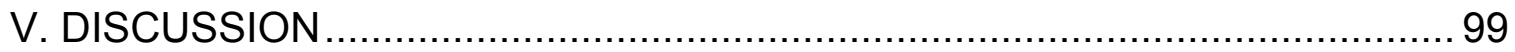

FUTURE WORK

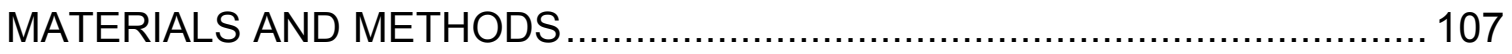

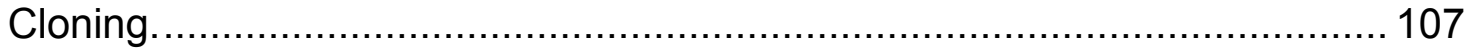

Construction of recombinant retroviruses and stable cell lines expressing

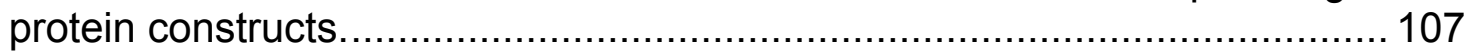

Rin1 depletion in 3T3-L1 cells.......................................................... 107

Lysate preparation, SDS-PAGE and Western blotting.............................. 108

GST-fused protein purification. ............................................................ 108

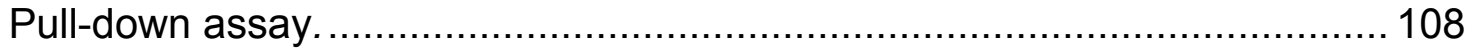

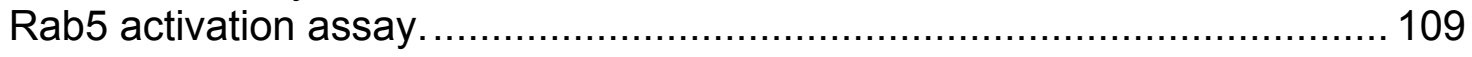

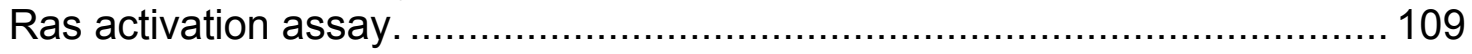

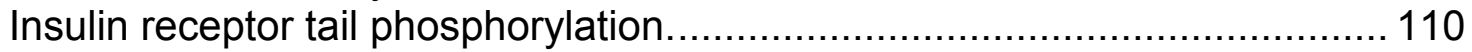

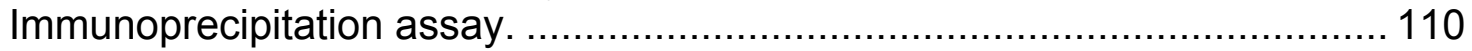

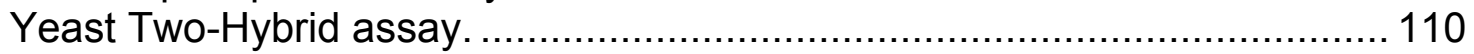

Tyrosine kinase receptor-depending signaling ............................................ 111

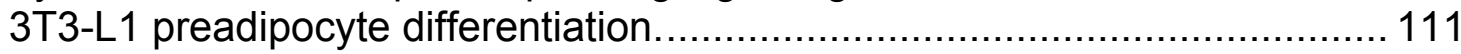

High-performance liquid chromatography analysis. ................................. 112 
Gas chromatography (GC)/flame ionization detector (FID) and GC/ mass spectrometry (MS) analysis of DhL derivatives........................................ 113

DhL derivatives: compound identification................................................ 113

Effect of DhL in Rin and Rab5 expression and activation. ......................... 114

Adipogenesis quantification. ............................................................ 114

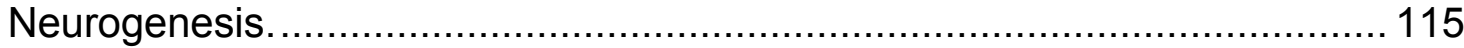

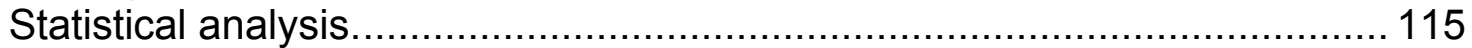

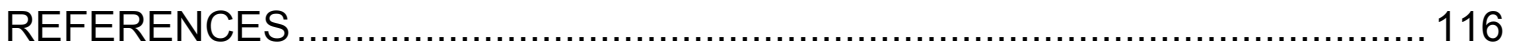

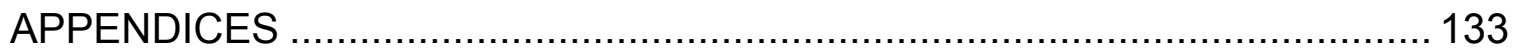

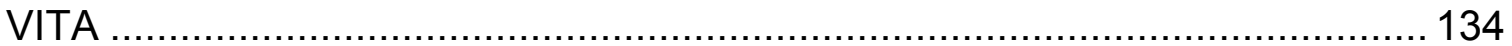




\section{LIST OF FIGURES}

FIGURE

PAGE

Figure 1.1. Receptor mediated endocytosis. ........................................... 24

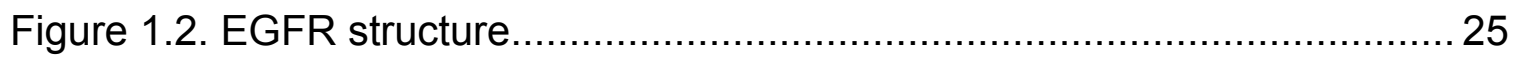

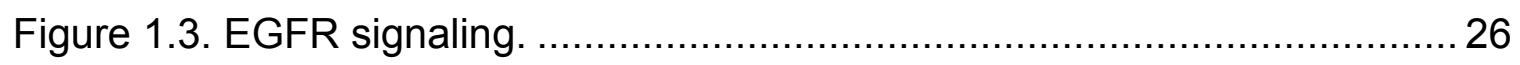

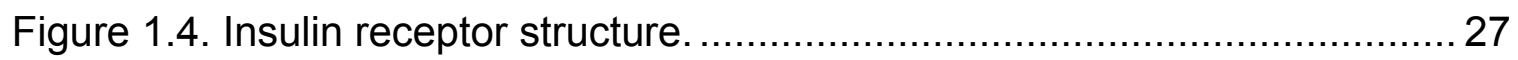

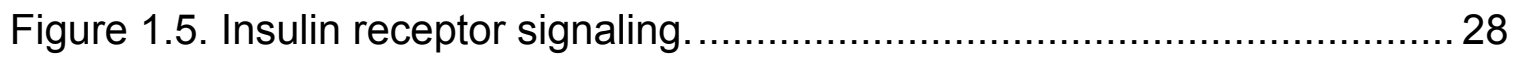

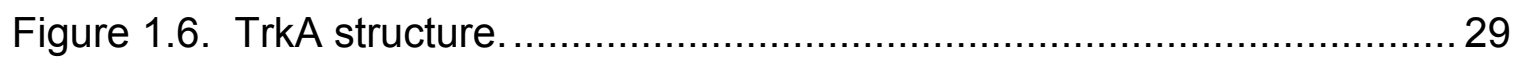

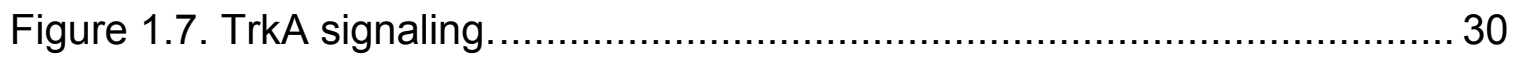

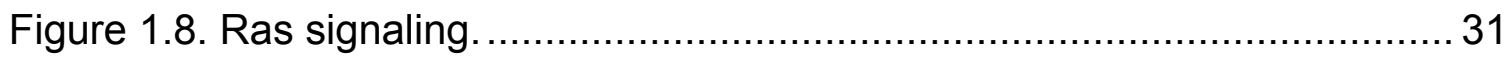

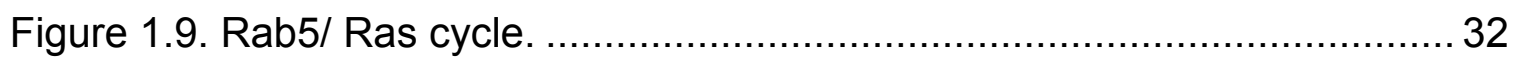

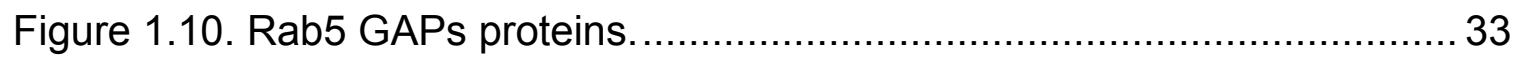

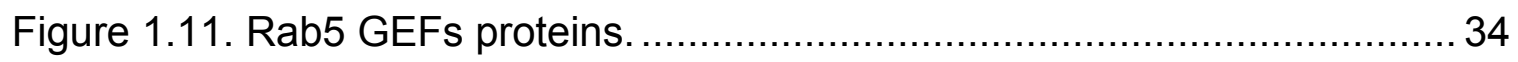

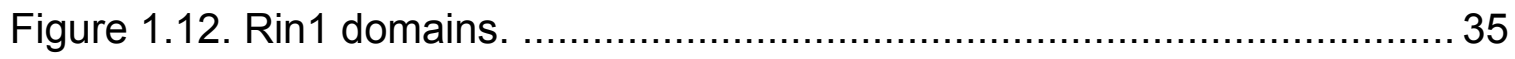

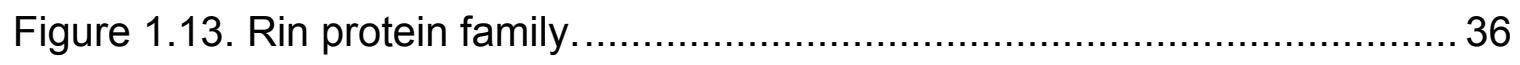

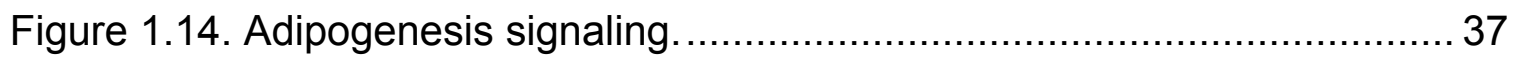

Figure 1.15. Transcription factors involved in adipogenesis............................ 38

Figure 2.1. Immunoprecipitation assay between Rin1 (WT and domains) and

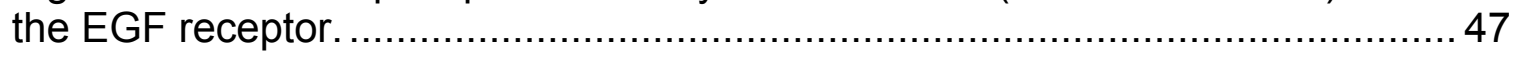

Figure 2.2. GST-pulldown assay between EGF receptor and Rin1 mutants. ..... 48

Figure 2.3. Immunoprecipitation assay between Rin1 (WT and domains) and

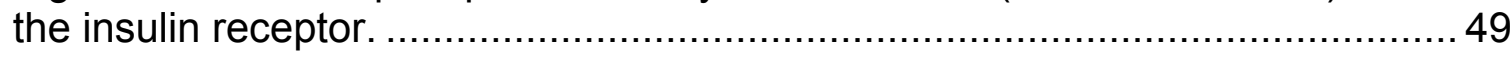

Figure 2.4. Yeast two hybrid system using Rin1 constructs and the insulin receptor cytoplasmic tail. 
Figure 2.5. GST-pulldown assay between the insulin receptor and Rin1 mutants.

Figure 2.6. GST-pulldown assay between the NGF receptor and Rin1 mutants. 52

Figure 2.7. Rab5 activation in NR6 cells overexpressing EGFR and Rin proteins 53

Figure 2.8. Rab5 activation in NIH3T3 cells overexpressing Rin1...................54

Figure 2.9. Ras activation in NR6 cells overexpressing Rin1........................ 55

Figure 2.10. EGFR signaling in NR6 cells overexpressing Rin1 ......................56

Figure 2.11. EGFR signaling in NR6 cells overexpressing Rin2 ....................57

Figure 2.12. EGFR signaling in NR6 cells overexpressing Rin3 .....................58

Figure 2.13. IR signaling in NIH3T3 cells overexpressing Rin1_.....................59

Figure 2.14. IR signaling in NIH3T3 cells overexpressing Rin2 .......................60

Figure 2.15. IR signaling in NIH3T3 cells overexpressing Rin3.......................61

Figure 2.16. IR signaling in NIH3T3 cells overexpressing Rin1:R94A mutant....62 Figure 2.17. IR signaling in NIH3T3 cells overexpressing Rin1: Y561F mutant. 63 Figure 2.18. IR signaling in NIH3T3 cells overexpressing Rin1: T580A mutant. 64 Figure 2.19. IR signaling in NIH3T3 cells overexpressing Rin1:R629A mutant. . 65 Figure 3.1. Rab5/ Rin1 endogenous expression during 3T3-L1 differentiation...71

Figure 3.2. Lipid droplet quantification in cells overexpressing Rin proteins

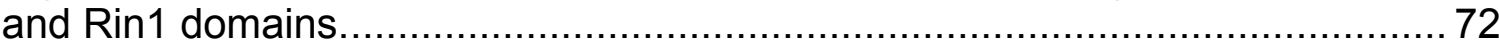

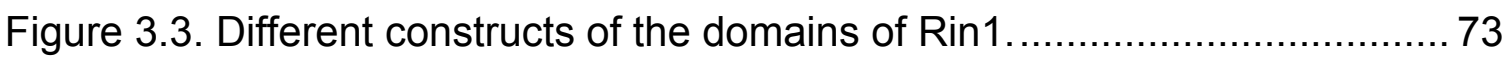

Figure 3.4. Adipogenic markers expression in cells overexpressing Rin1.........74

Figure 3.5. Adipogenic markers expression in cells overexpressing the

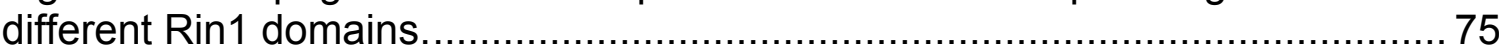

Figure 3.6. Lipid droplet quantification in cells overexpressing Rin1 mutants.... 76 
Figure 3.7. Adipogenic markers expression in cells overexpressing the different Rin1 mutants.

Figure 3.8. CREB activation in cells overexpressing Rin1 and control cells.......78

Figure 3.9. Effect of Rin proteins in PC12 differentiation................................ 79

Figure 4.1. Dehydroleucodine inhibited adipogenesis of 3T3-L1

preadipocytes without reducing cell viability.............................................. 89

Figure 4.2. Dehydroleucodine blocked the formation of lipid droplet by

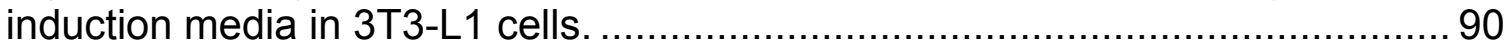

Figure 4.3. Dehydroleucodine attenuated the expression of PPARy during

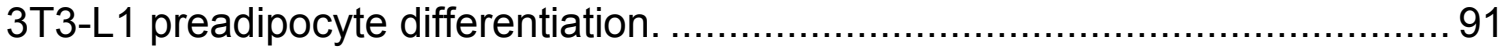

Figure 4.4. Dehydroleucodine selectively alters the expression of PPARY, C-EBPa and AMPKa.

Figure 4.5. Dehydroleucodine blocked adipocyte differentiation in a time-dependent manner.

Figure 4.6. Dehydroleucodine alters the expression of FAS............................ 94

Figure 4.7. GC analysis of dehydroleucodine and 11,13-dihydrodehydroleucodine epimers.

Figure 4.8. 11,13-Dihydro-dehydroleucodine inhibited 3T3-L1 preadipocyte differentiation

Figure 4.9. Effect of dehydroleucodine in Rab5 expression and activation. .......97

Figure 4.10. Effect of dehydroleucodine in Rin1 expression............................98 


\section{ABBREVIATIONS}

ALS: Amyotrophic lateral sclerosis

AP2: Adaptor protein 2

BAT: Brown adipose tissue

BDNF: Brain-derived neurothropic factor

BSA: Bovine serum albumin

BCL-2: B-cell lymphoma 2

C/EBPa: CCAAT/ enhancer- binding protein

$\mathrm{Ca}^{+2}:$ Calcium

CREB: CAMP response element-binding protein

DhL: Dehydroleucodine

EEA1: Early endosome antigen 1

EGF: Epidermal growth factor

EGFR: Epidermal growth factor receptor

Erk: Extracellular signal regulated kinase

FGF: Fibroblast growth factor

FGFR: Fibroblast growth factor receptor

FL: Full length

GAP: GTPase activating protein

GDP: Guanosine di phosphate

GEF: Guanine nucleotide exchange factor

GPCR: G-protein coupled receptor

Grb2: Growth factor receptor bound protein 2 
GSK3: Glycogen synthase kinase 3

GTP: Guanosine tri phosphate

IAPs: Inhibitor of apoptosis proteins

IGF: Insulin-like growth factor

IGFR: Insulin-like growth factor receptor

IR: Insulin receptor

IRS: Insulin receptor substrate

JNK: c-Jun kinase

MACS: Macrochepaly, alopecia, cutis laxa and scoliosis

MAPK: Mitogen activated protein kinase

NF-kB: Nuclear factor kappa-light-chain-enhancer of activated B cells

NGF: Nerve growth factor

NGFR: Nerve growth factor receptor

PBS: Phosphate buffered saline

PC12: Rat adrenal pheochromocytoma 12

PLC: Phospholipase C

PDGF: Platelet-derived growth factor

PDGFR: Platelet-derived growth factor receptor

PI3K: Phosphoinositide 3 Kinase

PKC: Protein kinase C

PPARY: Peroxisome proliferator-activated receptor

RA: Ras association domain

Rabex-5: Rabaptin-5 associated exchange factor for Rab5 
Rap6: Rab5 activating protein 6

Ras: Rat sarcoma

Rin: Ras interference

Rin1: Ras interference 1

RTK: Receptor-tyrosine kinases

SDS-PAGE: Sodium dodecyl sulfate polyacrylamide gel electrophoresis

SH2: SRC homology 2

Src: Sarcoma

STAM: Signal-transducing adaptor molecule

TBC: Tre-2/Bub2/Cdc16 domain

TGF: Transforming growth factor

TGFa: Transforming Growth Factor alpha

Trk: Tropomyosin-receptor-kinase

UCP-1: Uncoupling protein-1

VPS9: Vacuolar protein sorting 9

WAT: White adipose tissue

WT: Wild type 


\section{INTRODUCTION}

Endocytosis is the process by which cells internalize molecules from the extracellular environment (Besterman and Low, 1983). There are two different types depending on the size of the internalized particles. Phagocytosis refers to the invagination of particles larger than 250 nanometers, while pinocytosis refers to particles less than 100 nanometers (Besterman and Low, 1983). The second category can be further divided in to macropinocytosis and receptor-mediated endocytosis. The former requires actin cytoskeleton reorganization and provides a way to internalize, non-selectively, large quantities of solute molecules and membrane (Lim and Gleeson, 2011). Once inside the cell, these molecules are delivered into the lysosome, a compartment in which digestive enzymes break them down into metabolites that are released into the cytosol as they are needed for cell metabolism. Insulin (Maxfield et al., 1978) and growth factors such as brain-derived neurothropic factor (BDNF) (Patapoutian and Reichardt, 2001), fibroblast growth factor (FGF) (Ornitz and Itoh, 2001), platelet-derived growth factor (PDGF) (Hannink and Donoghue, 1989), insulin-like growth factor (IGF) (Hoppener et al., 1985), epidermal growth factor (EGF) (Harris et al., 2003), and

nerve growth factor (NGF) (Alleva and Santucci, 2001) are examples of molecules that use this process for their internalization.

\section{Receptor Mediated Endocytosis}

Receptor-mediated endocytosis is initiated when a ligand binds to its receptor (Figure 1.1), which in turns initiates a series of protein-protein 
interactions responsible for numerous cellular processes including cell proliferation, differentiation, growth, homeostasis, and apoptosis through the regulation of target genes. Receptor mediated endocytosis can be a constitutive or an activated process as in the case of transferrin (Goldstein et al., 1985) and EGF (Barbieri et al., 2003; Dunn and Hubbard, 1984; Schlessinger, 1981), respectively.

Receptor-tyrosine kinases (RTKs) are internalized by receptor-mediated endocytosis. They are membrane-bound receptors characterized by their intrinsic kinase activity. They share a common structure characterized by 1) an extracellular region that interacts directly with the ligand; 2) a hydrophobic region that transverses the lipid bilayer; and 3) a cytoplasmic region that interacts with cytosolic molecules. Activated RTKs are responsible for multiple cellular processes including cell growth and apoptosis (Carpenter and Cantley, 1996; Riese and Stern, 1998; Zhou et al., 2000). Examples of this type of receptor are fibroblast growth factor receptor (FGFR), platelet-derived growth factor receptor (PDGFR), insulin-like growth factor receptor (IGFR), the epidermal growth factor receptor (EGFR), insulin receptor (IR), and the nerve growth factor receptor (NGFR). In general, the ligand binds to the extracellular domain of the receptor, triggering receptor dimerization, which in turn activates specific catalytic sites on the cytoplasmic face of the receptor, resulting in autophosphorylation of the receptor's cytoplasmic tail and activation of multiple signal transduction cascades through protein-protein interactions (Hubbard and Miller, 2007). 


\section{Epidermal Growth Factor Receptor}

The EGFR belongs to a family composed of four types of receptors: ERBB1 (EGFR), ERBB2, ERBB3, and ERBB4. From these, ERBB2 does not bind any known EGF-like ligand; ERBB3 is kinase inactive, and ERBB4 is the only one autonomous (Bublil and Yarden, 2007). Upon ligand stimulation, ERBB4 is the only one that does not have to form a dimer and that ERBB2 and ERBB3 homodimers are not feasible because they lack ligand binding and kinase activity, respectively. As mentioned before, EGFR has the three different domains characteristic of RTKs: a ligand-binding extracellular domain, a hydrophobic transmembrane domain, and the tyrosine kinase activity cytoplasmic domain (Figure 1.2) (Carpenter, 1987; Downward et al., 1984; Hunter and Cooper, 1985).

The EGFR family recognizes different types of ligands including EGF, Transforming Growth Factor-alpha (TGF-alpha), amphiregulin, betacellulin, epiregulin, and epigen (Nair, 2005). These receptors have a diffuse distribution on the cell surface when the ligand is not present. Upon EGF stimulation, the receptors cluster (homo or heteridimerization) in clathrin-coated pits to be internalized (Heath et al., 2003). Even though EGFR signaling is downregulated by the receptor internalization and targeting to the endosomal compartment (Holbro and Hynes, 2004), it is now known that it continues generating signals until its degradation in the lysosome (Avraham and Yarden, 2011). At physiological levels of EGF (low doses $1-2 \mathrm{ng} / \mathrm{ml}$ ), the receptor is internalized mainly through clathrin-coated pits (Sigismund et al., 2008). The process of 
internalization is triggered by the direct interaction of the receptor tail with the adaptor protein AP2, which recruits clathrin to the plasma membrane creating the coated pit. The GTPase Dynamin is the one responsible for the vesicle fission from the plasma membrane forming the clathrin-coated vesicle (Schmid, 1997). Once inside the cell, the coat dissemble takes place, and the vesicle fuses with the early endosome continuing with the internalization process and the signaling cascade activated by the ligand-receptor complex (Kaksonen et al., 2006).

Epidermal growth factor receptor signaling activates different types of transcription factors including c-jun, c-fos, c-myc, and NF-kB, (Holbro and Hynes, 2004). Transcription factor regulation is done by the activation of key signaling pathways such as Erk and Akt, among others (Avraham and Yarden, 2011). Epidermal growth factor receptor signaling plays a key regulatory role in biological processes such as migration, proliferation, and resistance to apoptosis (Wieduwilt and Moasser, 2008). It is also a prominent regulator of cell lineage determination in different types of tissue (Figure 1.3). Overexpression of EGFR has been found in different types of cancer, specifically in breast and ovarian tumors (Nair, 2005). Recent studies have demonstrated the crosstalk between EGFR and GPCR (G-protein coupled receptors) and its importance in several cancers such as astrioglioma cells and ovarian cancer cells. The crosstalk between EGFR and GPCR is the result of EGFR activation by GPCR agonists (Gschwind et al., 2001). Aberrant EGFR activation through non-EGF may inactivate phosphatases that control the receptor intrinsic kinase activity, shifting the autophosphorylation/dephosphorylation equilibrium toward the active state 
(Fischer et al., 2003). Different key cytoplasmic proteins, such as Src and PKC, are involved depending on the system and the signaling context (Gschwind et al., 2001). In summary, GPCR-induced activation of EGFR and downstream signaling through Src and PKC regulation are found in more than 60 human carcinoma cell lines derived from different tissues (Fischer et al., 2003).

\section{The Insulin Receptor}

The insulin receptor exists as a dimer composed of two a (extracellular) and two $\beta$ (intracellular) subunits linked by a disulfide bond (Figure 1.4). There are two isoforms of the receptor that differ in 12 amino acids in the carboxyl terminus of the extracellular domain (the $\alpha$-subunit). Some studies suggest that one isoform may signal more efficiently to metabolic processes while the other to mitogenic events (Belfiore et al., 2009). Despite the fact that both isoforms can form hetero- or homodimers to initiate the signaling cascade, they have higher affinity for only one ligand molecule upon stimulation (Siddle, 2011). As in the case of EGFR, the insulin receptor gets internalized through clathrin-coated pits and clathrin-coated vesicles until its fusion with early endosome, late endosome and finally the lysosome where its degradation takes place (Ceresa et al., 1998). Once the receptor gets activated upon insulin stimulation, it will initiate the signaling cascade as with other types of RTKs, with the exception of the insulin receptor substrate (IRS) protein recruitment. The activated receptor will recruit and phosphorylate IRS proteins, which are responsible for amplifying the signal by the recruitment and activation of $\mathrm{SH} 2$ domain-containing proteins (Su et al., 2006). Ultimately these proteins will regulate the activity of several transcription 
factors including TORC1 and FOXO through the PI3K/ Akt and GRB2-SOS/Ras cascades (Figure 1.5) (Cheng et al., 2010).

Insulin signaling plays a major role in several biological processes including protein synthesis, lipid metabolism, glycolysis and glucose storage in muscle, liver and adipose tissue (Shaham et al., 2008). In muscle cells, insulin activates GLUT4 transporters from the cytoplasm to the plasma membrane increasing the intracellular concentration of glucose (Summers et al., 1998). In the liver, insulin stimulates glycogen synthesis by promoting the phosphorylation of glucose, confining it within the cell (Hua, 2010). In adipose tissue, insulin promotes the storage of lipids in the form of triglycerides by phosphorylating CREB protein and activating key adipogenic transcription factors such as PPARY and $\mathrm{C} / \mathrm{EBP} \alpha$ as explained below. Malfunction of these processes is associated with systemic disorders such as hypertension, obesity, diabetes, cardiovascular disease, infertility and neurodegeneration (Cheng et al., 2010; Reaven and Tsao, 2003; Stumvoll et al., 2005). Recent studies demonstrated a crosstalk between insulin-like growth factor receptor (IGFR) and EGFR and its role in some types of hyper-proliferative diseases such as pancreatic and breast cancer (Ueda et al., 2006). Insulin-like growth factor receptor, as well as the insulin receptor, is a member of the insulin-like growth factor receptor family. Both receptors have not only structural similarities, but also activate similar signaling cascades. It is believed the biological difference between the two receptors lies in its different tissue distribution and substrate recruitment (Werner et al., 2008). Depending on 
the tissue and signaling context, it would not be unexpected to see a crosstalk not only between EGFR and IGFR but also with the insulin receptor.

\section{The Nerve Growth Factor Receptor}

The nerve growth factor receptor family is composed of the tropomyosin receptor kinase (Trk) and the p75 protein receptor (Sofroniew et al., 2001). There are three different Trk receptors, each composed of a single trans-membrane region and a cytosolic kinase domain (Figure 1.6). Tropomyosin receptor kinase A (TrkA) gets activated primarily by NGF, TrkB by BDNF, and neurotrophin $4 / 5$ and TrkC by neurotrophin 3 . The Trk family of tyrosine kinase receptors regulates the development and maintenance of the peripheral and central nervous system (Brodeur et al., 2009). This study will focus on TrkA. Tropomyosin receptor kinase $A$ also uses the clathrin-mediated pathway for its internalization in the same way as EGFR and the insulin receptor (Grimes et al., 1996). The primary roles of NGF/TrkA signaling are to promote cell survival, neurite outgrowth, neuronal differentiation, and activity-dependent plasticity of sympathetic neurons (Brodeur et al., 2009). These biological processes are obtained by the activation of three major signaling pathways: PI3K/Akt, Erk, and Phospholipase C (PLC)/ protein kinase $C(P K C)$, respectively (Figure 1.7). Malfunction of these signaling pathways is related to various neurodegenerative diseases such as ALS (amyotrophic lateral sclerosis), Parkinson's, Huntington's and Alzheimer's diseases as well as in different types of cancer including thyroid carcinoma and neuroblastoma (Brodeur et al., 2009; Connor and Dragunow, 1998; Kruttgen et al., 2006; Siegel and Chauhan, 2000). 


\section{Signal Transduction and Endocytosis}

Different proteins are involved in the signaling cascades activated by RTKs. After receptor activation, multiple proteins are recruited and play key roles in the activated signal cascade (Perona, 2006). Studies have shown the important role the small GTPases Rab and Ras proteins play during receptormediated endocytosis, membrane trafficking, vesicle transport, and signal transduction (Figure 1.8) (Agola et al., 2011; Hancock, 2003). These proteins cycle between their active form, bound to GTP, and their inactive form, bound to GDP. Guanine nucleotide exchange factors (GEFs) promote the exchange from GDP to GTP, activating these small GTPases. On the other hand, GTPase activating proteins (GAPs) promote the hydrolization of GTP, inactivating them (Figure 1.9).

Studies have shown the important regulatory role of Rab5 in the endocytic rate and early endosome fusion (Bucci et al., 1992; Li et al., 1994; Li and Stahl, 1993; Roberts et al., 1999). As with other GTPases, Rab5 has a very low intrinsic GTPase activity, and depends on other enzymes such as GAPs to hydrolyze GTP, downregulating its activity. These enzymes share a common Tre2/Bub2/Cdc16 (TBC) catalytic domain responsible for GTP hydrolization. Examples of Rab5 GAP proteins are RabGap5, RN-tre (Pfeffer, 2005), and TBC2 (Chotard et al., 2010), among others (Figure 1.10). Multiple Rab5 GEFs have been identified. These proteins are characterized by sharing a highly conserved Vps9 (vacuolar protein sorting 9) domain that catalyzes the exchange from GDP to GTP, activating Rab5. Examples are the yeast homolog Vps9p (Hama et al., 
1999), Rabex-5 (Carney et al., 2006), Rin1 (Han and Colicelli, 1995; Tall et al., 2001), Alsin2 (Otomo et al., 2008), RME-6 (Sato et al., 2005), and Rap 6 (Hunker et al., 2006a; Sato et al., 2005) (Figure 1.11).

Several of these proteins contain, besides the Vps9, other domains that interact and sequester other signaling molecules. Thus, their localization on early endosomes allows them to increase endocytosis by the activation of Rab5, and to regulate specific signaling cascades. The same is the case of Ras Interference 1 (Rin1), which consists of four domains. First, the SH2 domain (SRC Homology 2) located at the amino-terminus mediates a direct interaction with RTKs such as the IR and EGFR (Barbieri et al., 2003). Second, the Proline Rich (PR) interacts with proteins such as the signal-transducing adaptor molecule (STAM) (Kong et al., 2007). Third, the Vps9 domain provides the site for the interaction and subsequent activation of Rab5, as explained above. Finally, the carboxy-terminus houses the Ras-Association (RA) domain, which interacts with the active form of Ras (Barbieri et al., 2003) (Figure 1.12). Ras Interference 1 competes with the Ras downstream effector Raf, inhibiting the its signaling cascade (Han and Colicelli, 1995). Thus, Rin1 is involved in both processes by its direct interaction through its three different domains with Rab5 (endocytosis) and Ras (cell signaling). Furthermore, it has been shown that several important residues of Rin1 play a key role in the activation of Rab5 (Galvis et al., 2009), and that it is potentiated by the interaction of Rin1 with the active form of Ras (Tall et al., 2001). 
Ras Interference 1 is part of a protein family composed of two other members: Rin2 and Rin3 (Figure 1.13). The former is also a Rab5-binding protein, but unlike Rin1, it has more affinity to Rab5-GTP; however, it also enhances the guanine nucleotide exchange activity of Rab5. Deficiency of Rin2 has been related to a disorder of elastic tissue known as macrochepaly, alopecia, cutis laxa and scoliosis syndrome (MACS) (Basel-Vanagaite et al., 2009). Ras Interference 2 has the same domain structure as Rin1, with an extra proline rich domain. The same structure is observed in Rin3, except that it is composed of three proline rich domains. It also binds the active form of Rab5 rather than the inactive one, just like Rin2 (Kajiho et al., 2003). It seems that Rin3 has a specific expression pattern restricted to mast cells, controlling basic functions as well as malfunction such as chronic inflammation and cell hyper proliferation (Janson et al., 2012).

\section{Hyperproliferative Diseases and Cancer}

Hyperproliferative diseases such as cancer are characterized by unregulated cell growth (Sebastian et al., 2006). Alterations in the equilibrium between cell proliferation and programmed cell death results in tumor formation as a consequence of uncontrolled cell division. Development and growth of cancer cells is produced by genetic modifications in signaling pathways that regulate cell proliferation, differentiation, survival and motility (Nicholson et al., 2001). In most cases these signaling pathways are activated by RTKs, and their role in cancer development is, at least in part, a result of the receptor abnormal expression and activation. Aberrant EGFR (and its downstream signaling) 
activation has been found in numerous types of cancer (Nair, 2005). The malfunction of EGFR has been supported by epidemiological evidence in human tumors, which demonstrated the contribution of abnormal EGFR expression and signaling in numerous epithelial malignancies including breast cancer (Suo and Nesland, 2002), squamous skin carcinomas (Merlino et al., 1985), renal carcinoma (Moch et al., 1997), head and neck tumors (Rogers et al., 2005), among others (Sebastian et al., 2006). The anomalous EGFR functioning includes activating mutations and receptor overexpression, which contributes to oncogenesis by inducing cell proliferation and apoptosis resistance (Henson and Gibson, 2006).

Overactivated receptors such as EGFR and IGFR transform a normal cell to a malignant one by providing sustained signals that promote cell proliferation, anti-apoptosis, angiogenesis and metastasis, which are the basics properties of cancer development and progression (Arteaga, 2002). The GTPase Ras is a key regulator of signal transduction within the cell. It is a small GTPase that modulates signal activation upon membrane receptor stimulation. It has three isoforms: H-Ras, K-Ras, and N-Ras, all of which are involved in different types of tumors when over activated (Colicelli, 2004). The main deregulated signaling pathways involved in oncogenesis are the Raf-Erk, PI3K-Akt, and Jak-Stat (Nair, 2005). The first one promotes cell proliferation and inhibits programmed cell death, by increasing the transcription of the BCL-2 family members and IAPs (inhibitor of apoptosis proteins) resulting in cell survival and proliferation (Henson and Gibson, 2006). The PI3K-Akt pathway also promotes cell survival and cell 
growth through the activation of anti-apoptotic genes such as NFkB and CREB. Akt also phosphorylates the GSK3 kinase, inhibiting it, blocking transcriptional activity and metabolism regulation (Henson and Gibson, 2006). Finally, the JakStat pathway promotes cell survival by the activation of survival genes through the translocation of Stat to the nucleus (Henson and Gibson, 2006).

Malfunction of Rab5 has been related to different types of cancer. Upregulation of Rab5 expression has been associated with thyroid autonomous adenomas (Stein et al., 2003), and Rab5 activation has been shown to promote focal adhesion disassembly, enhancing migration and invasion of cancer cells (Mendoza et al., 2013). Furthermore, Rin1 has also been related to multiple types of cancer. Rin1 localization has been shown to play an important role in colon cancer cells carcinogenesis (Inoue et al., 2011), while in breast cancer it seems to function as a tumor suppressor by negatively regulating tumor cell invasive growth (Milstein et al., 2007). On the other hand, on some non-small lung adenocarcinomas cell lines, upregulation of Rin1 expression seems to increase its proliferative properties (Tomshine et al., 2009). Taking these data together, it seems that the role of Rin1 in cancer progression is tissue-dependent and is related to the role of Rin1 as a Rab5 activator and a Ras effector.

Therefore, studying of the signaling pathways and its relationship with Rin1 is important to understand the molecular mechanisms of hyper proliferative diseases such as cancer. 


\section{Obesity and Diabetes}

Obesity is a medical condition characterized by the excess accumulation of body fat. Fat deposits can be subcutaneous (beneath the skin) or visceral (around internal organs). The former is related to many of the obese-related pathologies such as cancer, heart disease and diabetes, among others (Hassan et al., 2012). Diabetes is a metabolic disorder characterized by high blood glucose levels as a consequence of the inability of cells to absorb glucose. The high glucose levels happen because, at least in part, pancreatic beta cells are not able to produce insulin, or because cells cannot respond to the one produced properly, also known as insulin resistance (Guillausseau et al., 2008).

Adipogenesis is the formation of adipocytes (fat cells) from preadipocytes (Rosen and Spiegelman, 2000). Different types of hormones and signaling cascades, including insulin, regulate this process (Figure 1.14). There are two main types of adipose tissue: white fat (WAT) and brown (BAT) tissue. White fat tissue stores excess energy in the form of triglycerides in large lipid droplets. White adipose tissue storage is important because by storing lipid excess, it prevents lipid accumulation in other tissues (Koppen and Kalkhoven, 2010). In addition, lipases hydrolyze triglycerides of WAT tissue into fatty acids that can be oxidized to generate energy as needed (Koppen and Kalkhoven, 2010; Rosen and Spiegelman, 2006). Recent studies have shown that WAT is not only the primary lipid storage, but that it also functions as an endocrine organ releasing different types of adipokines that regulate immune responses, blood pressure, angiogenesis, bone mass, thyroid and reproductive functions (Trayhurn, 2005). 
On the other hand, BAT tissue is specialized in defense against cold and works as a protection against lipid accumulation by dissipating energy (instead of storing it) in the form of heat (Rosen and Spiegelman, 2000). This is achieved by an increase in the number of mitochondria present in this type of cell. Specifically, high expression of uncoupling protein (UCP)-1 dissipates the protein gradient across the inner mitochondrial membrane during the electron movement in the respiratory chain (Garlid et al., 1998). In BAT tissue, triglycerides are stored in multiple small lipid droplets (Cannon and Nedergaard, 2004). These two types of adipose tissue are found in multiple locations within the body. Usually they are found in areas rich in loose connective tissue (such as between muscle and dermis) and around major organs such as the heart and kidneys (Rosen and Spiegelman, 2000). White adipose tissue location has been associated with different types of diseases. Visceral adipose tissue is associated with an increase risk of cardiovascular malfunctions and insulin resistance, while subcutaneous tissue accumulation is not (Rosen and MacDougald, 2006).

Adipocyte differentiation occurs in two separate phases, each one marked and controlled by different transcription factors. The first phase is characterized by cell growth arrest followed by one or two rounds of mitosis known as clonal expansion. The second phase starts by a second round of growth arrest and is followed by the biochemical and morphological changes necessary to give rise to the adipocyte phenotype (Rosen and Spiegelman, 2000). The first factors to be activated during adipogenesis are the CCAAT/enhancer-binding proteins (C/EBP) $\beta$ and $y$ (Evans et al., 2004). The early and transient activation of 
$\mathrm{C} / \mathrm{EBP} \beta$ and $\mathrm{Y}$ is thought to be responsible for the clonal expansion, characteristic of the first phase, and for the induction of PPARY and C/EBPa expression (Lane et al., 1999). Peroxisome proliferator-activated receptor $\mathrm{y}$ is activated first and induces the expression of C/EBPa that at the same time, in a positive control, helps to maintain a high PPARy expression level. These two transcription factors mediate the expression of adipocyte-specific genes that lead to the adipogenic differentiation phenotype (Hwang et al., 1997). The function of Erk activity is not clear yet. Some studies suggest a key role in the clonal expansion in the first phase of differentiation. Then it must be downregulated because Erk activity leads to phosphorylation of PPARy, inhibiting adipocyte differentiation (Rosen and MacDougald, 2006) (Figure 1.15).

Malfunction in the equilibrium of adipose tissue can lead to numerous diseases including obesity, diabetes, insulin resistance, glucose intolerance, hypertension, nonalcoholic fatty liver and cardiovascular disease (Wang, 2010). Hence, it is necessary to study this biological process in detail as well as the proteins involved.

\section{Brain Function and Neurogenesis}

Neurogenesis is the process by which new neurons are formed in the nervous system (Gotz and Huttner, 2005). Long branches that develop from the cell body characterize neuron cells. During neurogenesis, intracellular organization and assembly of microtubules and filamentous proteins of the cytoskeleton such as Maps (microtubule associated proteins) are involved in neurite growth (Biocca et al., 1983). Nerve growth factor is an essential 
neurotrophin for cell differentiation and survival (Liu et al., 2007), it activates numerous signaling pathways by its binding to TrkA as explained above. Studies in PC (rat adrenal pheochromocytoma) 12 cells showed that the internalization of the TrkA/NGF complex and formation of the signaling endosome is essential for NFG-induced differentiation (Grimes et al., 1996). These signaling endosomes are involved in long distance retrograde transport in axons, compared with the short distance traveled by early endosomes in regular cells. Interestingly enough, a population of this neuronal signaling endosomes is also Rab5-positive (Liu et al., 2007). This suggests that Rab5 activity must be attenuated to prevent the transition to late endosomes and further degradation of the receptor complex terminating the signal. Low levels of Rab5-GTP found in differentiated PC12 cells suggest the NGF-induced signaling downregulation of Rab5 activity (Liu et al., 2007).

The ligand/receptor complex recruits proteins that activate the Ras and Rap1 GTPases, the ones that in turn activate Raf, PI3K, and PLC among other signaling proteins. These are the main pathways responsible for the transcription of specific genes that commit to the differentiation process (Faigle and Song, 2013; Wang et al., 2006).

Neurodegenerative diseases such as Parkinson's (Goedert, 2001), Alzheimer's (Hardy and Selkoe, 2002), and Amyotrophic Lateral Sclerosis (ALS) (Qiang et al., 2013) are characterized by a loss in the neuronal population within the nervous system. The cell loss is responsible for the cognitive and motor function damage that comes as symptoms of such diseases (Abdipranoto et al., 
2008). Studies have shown neurogenesis in the adult nervous system (Eriksson et al., 1998), demonstrating the ability of some neuronal populations in the adult brain to regenerate themselves. These findings may suggest another approach to understand and cure neurodegenerative diseases: instead of focusing on slowing cell loss, the control and cure of these diseases can be in enhancing neurogenesis to replenish the neuronal population lost.

\section{Natural products: Phytochemicals}

The importance of natural products in medicine as well as in the agroindustry has led to numerous studies on the synthesis and biological activities of these substances. Yet little is now known about their actual roles in nature, particularly their use as alternative medicine.

Many natural products show anti-obesity (Vasudeva et al., 2012) and antitumoral activities of varying mechanisms (Aravindaram and Yang, 2010). Possibly a method to find a more efficient way to treat diseases like obesity and cancer, and more important, to achieve the synergistic effects of natural products should be to search for treatments using multiple products and/ or products having multiple biological activities.

Sesquiterpene lactones are secondary metabolites found in most species

of Compositae (Asteraceae), and there are more than 6,000 sesquiterpene lactones with known structures. Parthenolide was first reported as a new sesquiterpene lactone from Feverfew (Tanacetum parthenium) (Pareek et al., 2011). Its organization revealed a structure of an alpha-methylene-gammalactone. One of the most important characteristics of sesquiterpene lactones is 
their anti-tumor activity (Zhang et al., 2005). Interestingly, a number of naturally occurring sesquiterpene lactones with the alpha-methylene-gamma-lactone (alpha-methylenenbutyrolactone) structure, such as parthenolide and helenalin, were reported to have potent cytotoxic activity toward several tumor cell lines as well as human cells transformed with Simian Virus (Lee et al., 1971; Wu et al., 2006). Several studies have proposed that the anti-tumor activity of sesquiterpene lactones might occur at the DNA replication as well as other intracellular targets (Ross et al., 1999; Wiedhopf et al., 1973; Woynarowski and Konopa, 1981; Zhang et al., 2004).

A sizeable body of written work indicates that exponential progress has been made concerning the knowledge of bioactive components in plant foods and their relation to obesity (Rayalam et al., 2008). Because adipogenesis is directly related to adipocyte differentiation and maturation, the induction of apoptosis as well as the inhibition of adipogenesis at various stages of the adipocyte life cycle may be target pathways for treating obesity.

As described above, in cancer cells, phytochemicals have a propensity to increase the curative effect by either blocking one or more molecular targets of the signal transduction pathway of high proliferative cancer cells. However, dietary natural products have shown interesting effects on adipose tissue such as inducing apoptosis and decreasing lipid content (Nelson-Dooley et al., 2005), affecting a number of complex interconnected cell signaling pathways involved in regulating adipogenesis. Thus, natural compounds may act at single or multiple 
target sites in the adipocyte or cancer cells life cycle associated with key physiological processes.

About 25 percent of commonly used drugs to treat diseases such as diabetes, obesity and cancer come from plant extracts (Balandrin et al., 1985). Treatments to fight diseases such as obesity, and others illness related to it, focus on either to inhibit the formation or to promote apoptosis of adipose tissue. Plant extracts work on these two aspects with different mechanisms: to prevent the disease or to treat it. Some plants extracts containing caffeine, are metabolic stimulants by inhibiting the degradation of intracellular cAMP that causes an increase in energy expenditure and decreases energy intake by reducing food intake (Dulloo, 1993; Racotta et al., 1994). Extract of Hoodia gordoni works as an appetite suppressant in rats, just as caffeine, by increasing ATP concentration in hypothalamic neurons that regulate food intake (MacLean and Luo, 2004).

Studies showed the role of Siraitia grosvenori and Stachytarpheta cayennensis, among others, in insulin sensitivity and blood glucose control (Adebajo et al., 2007; Suzuki et al., 2007), even though the mechanism of regulation is not yet understood. Plants such as Cissus quadrangularis, Aralia mandshurica, Kochujang and psyllium showed a reduction in triglycerides and cholesterol levels in serum (Abidov et al., 2006; Ahn et al., 2006; Moreno et al., 2003; Oben et al., 2007).

Regulation of these signaling pathways, which can modulate adipogenesis at different developmental stages, is essential for several cellular processes. Several plant extracts have an effect on the first phase of differentiation. 
Flavonoids (Hsu and Yen, 2006) and CLAs (Hsu and Yen, 2006) have been shown to inhibit 3T3-L1 preadipocyte proliferation and to induce apoptosis. In the presence of genestein, mitotic clonal expansion of 3T3-L1 preadipocytes is inhibited (Harmon and Harp, 2001) and apoptosis of mature preadipocytes is enhanced in the presence of esculetin (Yang et al., 2006). Extracts such as EGCG, genistein and capsaicin were shown to activate AMPK, inhibiting phase two of adipogenic differentiation (Hwang et al., 2005).

Natural products or their derivatives compose 67 percent of the anticancer drug treatments (Balunas and Kinghorn, 2005; Ghantous et al., 2010). Plant metabolites containing sesquiterpene lactones have been studied as possible treatments for several human diseases, including inflammation, infections, headaches and cancer (Ghantous et al., 2010). Early work showed the importance of the biological activity of the a-methylene-y-lactone structure in sesquiterpene lactones known to be cytotoxic to tumors (Hartwell and Abbott, 1969). One of the benefits of the plant extract-based treatments in clinical trials is their ability to target tumor cells and cancer stem cells, without affecting normal healthy cells (Jordan, 2006; Kawasaki et al., 2009; Zhou and Zhang, 2008). The following are some examples of ongoing clinical trails based on plant extracts (Artemsia annua, Thapsia and Tanacetum parthenum, among others): laryngeal carcinomas, uveal melanomas, pituitary macrodenomas, lupus nephritis and breast, colorectal and nonsmall cell lung cancers (Berger et al., 2005; Lu, 2002; Singh and Panwar, 2006; Zhang et al., 2008). Even though the mechanism of action is still not fully understood, it seems that these plant extracts target the 
sarco/ER calcium ATPase pump, proteases secreted by cancer cells, NF-kB signaling, p53 and transferrin receptor activity (Christensen et al., 2009; Denmeade and Isaacs, 2005; Efferth, 2006; Gopal et al., 2009; Hehner et al., 1998; Nakase et al., 2009; Pajak et al., 2008).

\section{Hypothesis and Specific Aims}

As discussed above, receptor-mediated endocytosis initiates a series of protein-protein interactions responsible for essential cellular processes including cell proliferation, differentiation, and apoptosis through the regulation of selective and specific genes. Tyrosine kinase regulation changes gene modulation, which in turn affects whole-body metabolism involved in the pathogenesis of a variety of metabolic diseases, including Type 2 diabetes, cardiovascular disease, hypertension, stroke and some forms of cancer.

The actual knowledge on receptor tyrosine kinases and small GTPases interaction is limited and holds high interest among cellular and molecular biologists. Specifically, how activation of receptor tyrosine kinases leads to upregulation of small GTPases, which orchestrate and regulate several signal transduction pathways, remains elusive and far from clear. Thus, the rationale for the dissertation is that the interaction between receptor tyrosine kinases, small molecules and regulators of small GTPases (these factors orchestrate and regulate intracellular membrane traffic, via intermediate multifunctional proteins) are most likely to be essential for modulation of several cellular events in normal and diseased cells. 
The first part of this study addresses whether membrane targeting of Rin1 by receptor tyrosine kinases plays a key role on the spatial and temporal regulation of Rab5 and Ras activities. Furthermore, it will examine how regulation of these small GTPases is connected to selective specific signaling pathways. Therefore, this part of the study will:

1. Determine the mechanism of Rin1-RTKs interaction and its downstream effect in receptor internalization and activation of signaling cascades.

2. Elucidate the role of Rin 1 in different signaling pathways involved in cell differentiation.

The second part of the dissertation focuses on anti-differentiation properties of a natural compound Dehydroleucodine (DhL) on in vitro adipogenesis using 3T3-L1 preadipocytes. As people become obese, their adipocytes enlarge and cause molecular and cellular alterations such as an increase in lipid accumulation and the deregulation of several signaling pathways involved in the pathogenesis of a variety of metabolic diseases. Hence, understanding the origin and development of adipocytes may be critical to the analysis and treatment of many chronic diseases. Therefore, this part of the study aims to:

1. Determine the effect of $\mathrm{DhL}$ as a potent and selective inhibitor for adipogenesis.

2. Elucidate the potential(s) mechanism(s) of action of $\mathrm{DhL}$ on adipogenesis. 
This thesis is divided into five chapters:

Chapter 1 is the introduction and literature review, which describes the importance of 1) RTK-membrane trafficking and signaling in normal and diseased cells and 2) natural products in biological processes.

Chapter 2 examines the mechanism of interaction between Rin1 and RTKs and its regulation toward the activity on Rab5 and Ras in RTK internalization and signal transduction pathways, respectively.

Chapter 3 focuses on the role of Rin1 (and Rin1-like molecules) in different signaling pathways involved in cell differentiation.

Chapter 4 examines the effect of the small molecule Dehydroleucodine in differentiation of adipose cells.

Chapter $\mathbf{5}$ summarizes the findings and significance of this research with future possibilities resulting from this study. 


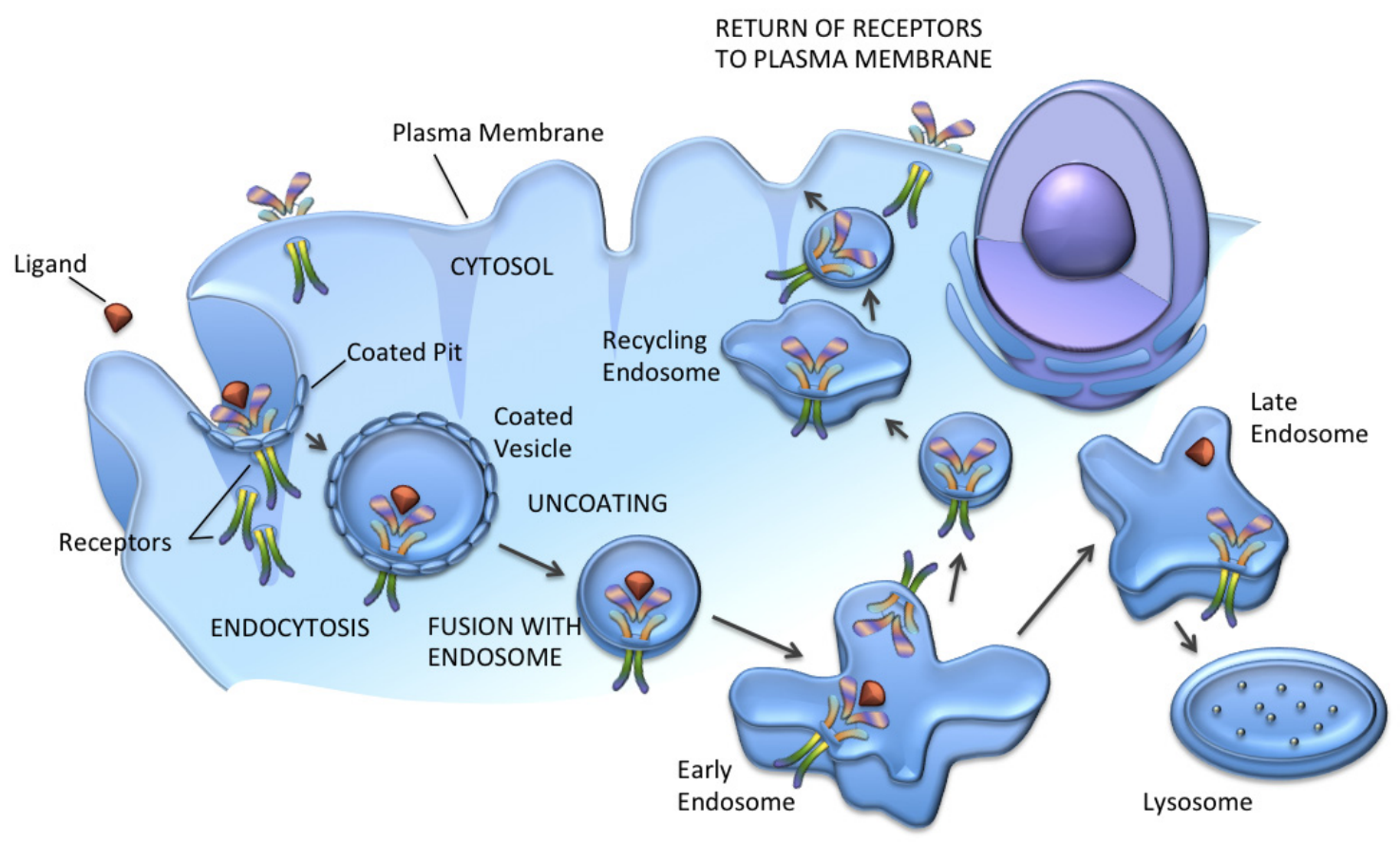

Figure 1.1. Receptor mediated endocytosis.

Receptor mediated endocytosis is initiated when the ligand binds to the receptor at the plasma membrane originating a series of intracellular events, which will allow the formation of coated vesicles. The ligand-receptor complex is internalized in endocytic vesicles (early and late endosomes) that ultimately separate the complex degrading the ligand in the lysosomal compartment and recycling the receptor (in some cases) back to the cell surface. 


\section{EGFR Structure}

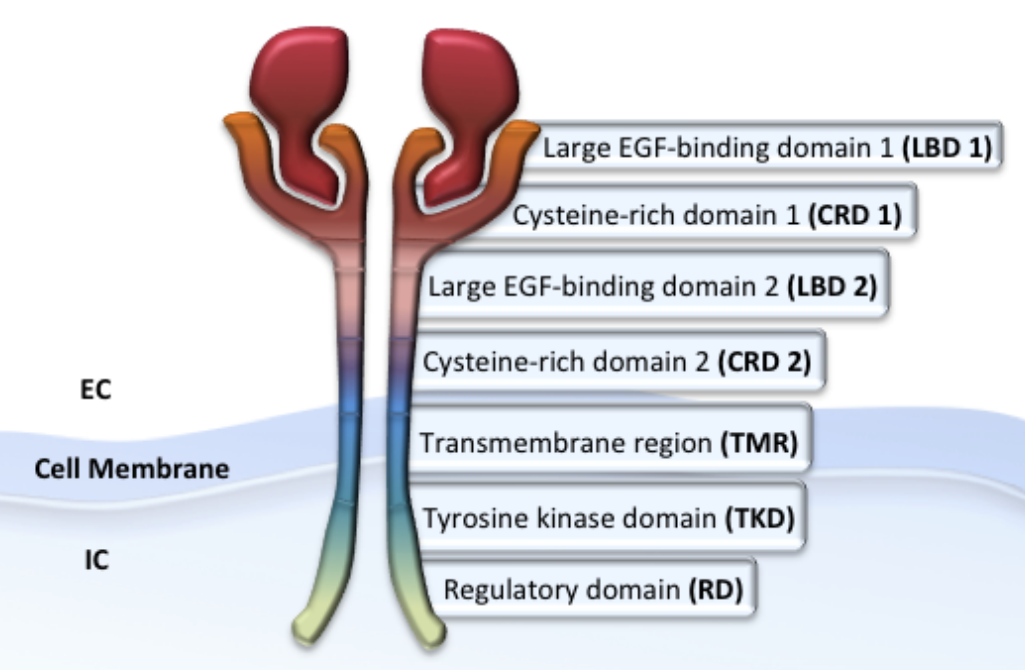

Figure 1.2. EGFR structure.

EGFR is composed in the extracellular (EC) region of two ligand-binding domains (LBD) and two cysteine-rich domains (CRD). The cytoplasmic tail, located inside the cell (IC), is composed of a tyrosine kinase domain (TKD) and a regulatory domain (RD). The extracellular and the cytoplasmic regions are divided by a transmembrane region (TMR). 


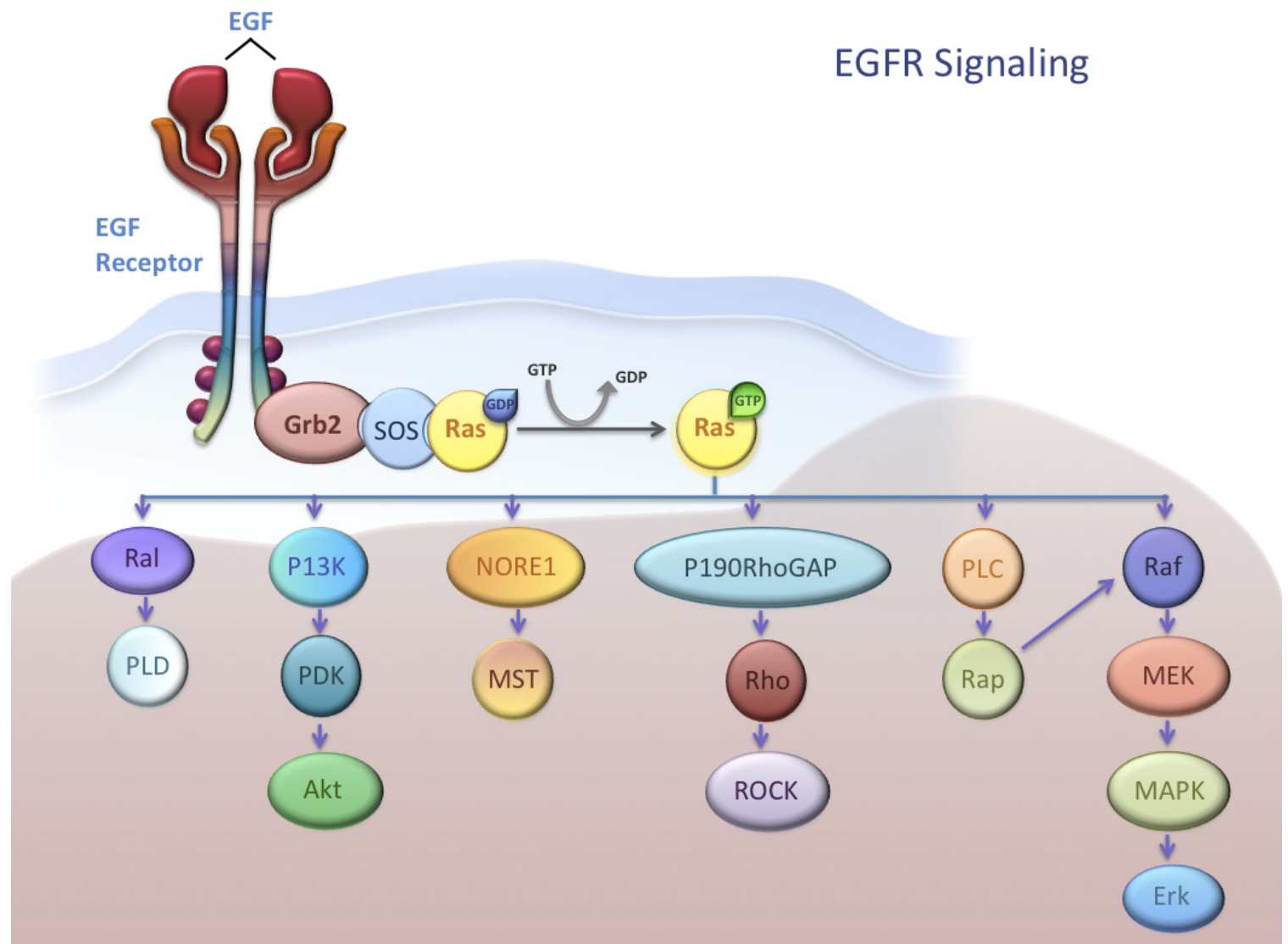

Figure 1.3. EGFR signaling.

Mayor signaling cascades activated by EGFR. Once EGF binds to the receptor, Ras gets activated through the Grb2/SOS complex promoting the activation several signaling cascades including the Ral (Ras related protein)/PLD (phospholipase D), PI3K/ Akt, NORE1 (novel Ras effector 1)/MST (mammalian Sterile20-like), P190RhoGAP/ROCK (Rho-associated, coiled-coil containing protein kinase), PLC/Rap and Raf/Erk. 


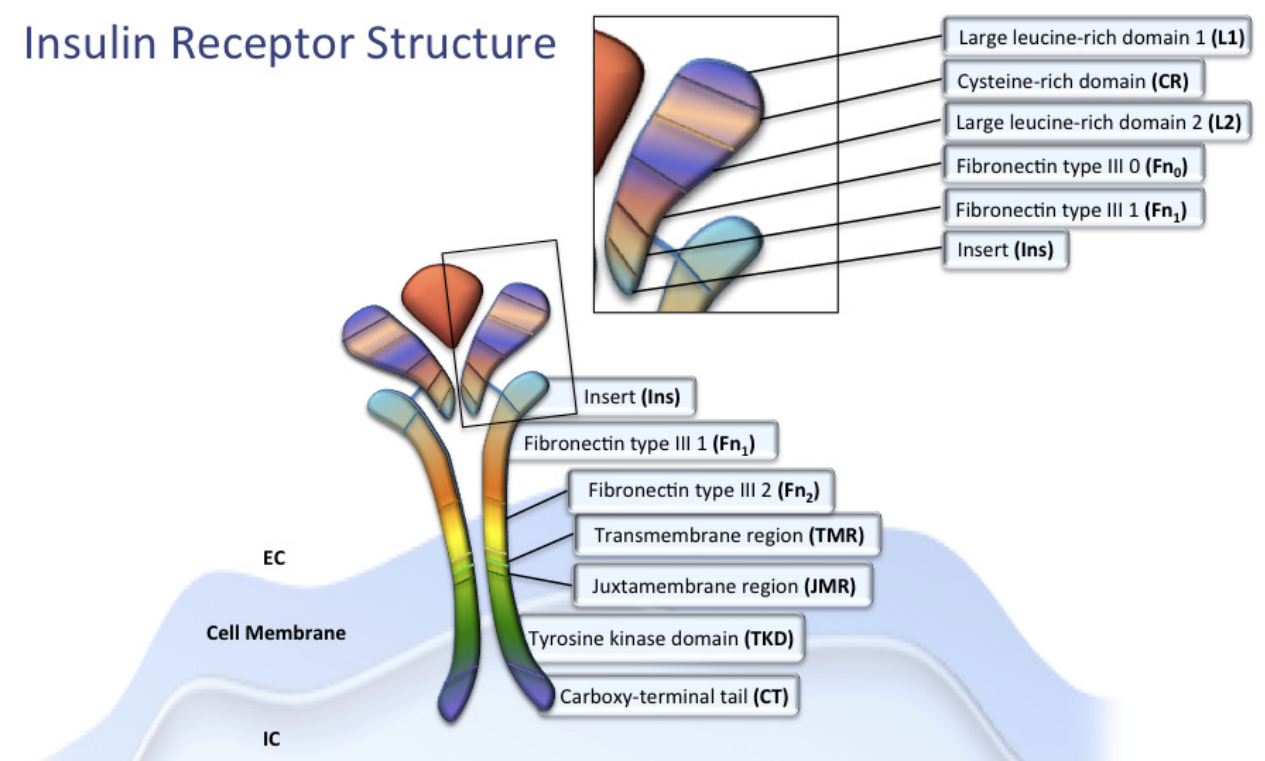

Figure 1.4. Insulin receptor structure.

$I R$ is composed of a ligand-binding domain in the extracellular region $(E C)$ made up of two large leucine-rich domains (L1 and L2), a cysteine-rich domain (CR) and two fibronectin type domains (Fn0 and Fn1). The cytoplasmic tail is composed of a tyrosine kinase domain (TKD) and the carboxy-terminal tail (CT) located inside the cell (IC). The extracellular and the cytoplasmic regions are divided by a transmembrane region (TMR). 


\section{Insulin Receptor Signaling}

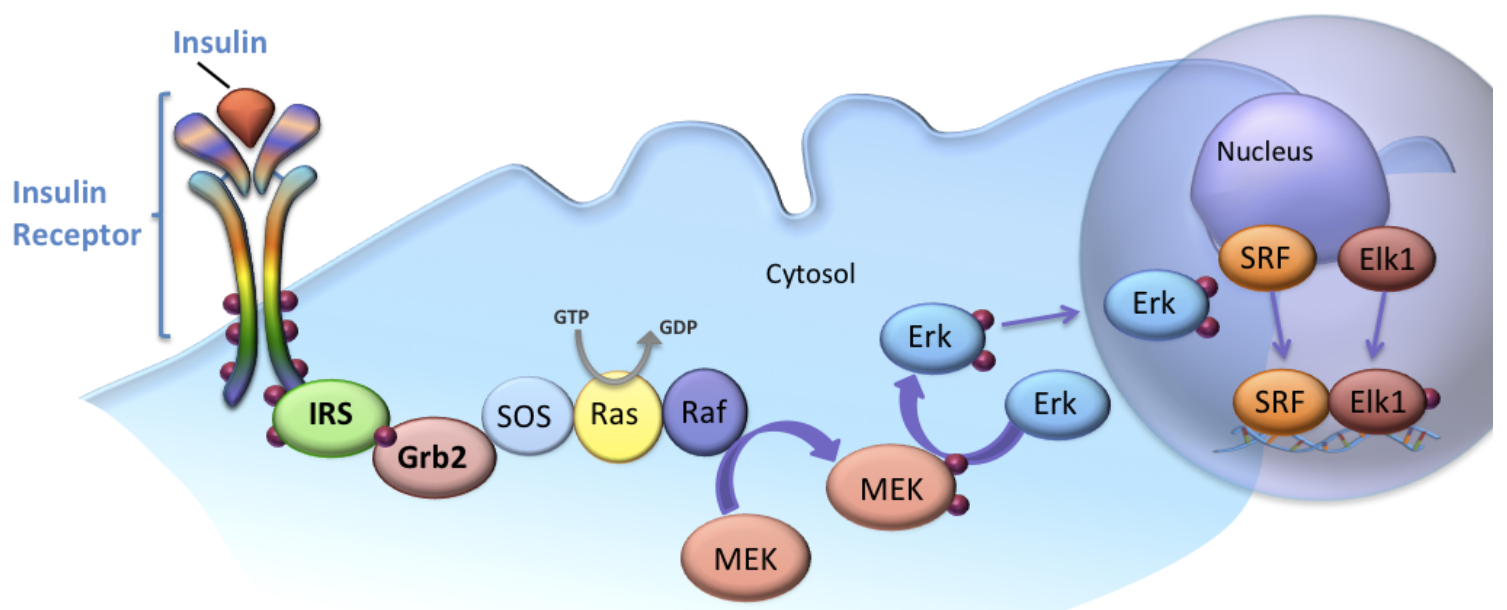

Figure 1.5. Insulin receptor signaling.

Mayor signaling cascades activated by IR. Once insulin binds to the receptor, Ras gets activated through the Grb2/SOS complex promoting the activation several signaling cascades such as the phosphorylation of Erk. 


\section{TrkA (Neurotrophic tyrosine kinase receptor type 1) Structure}

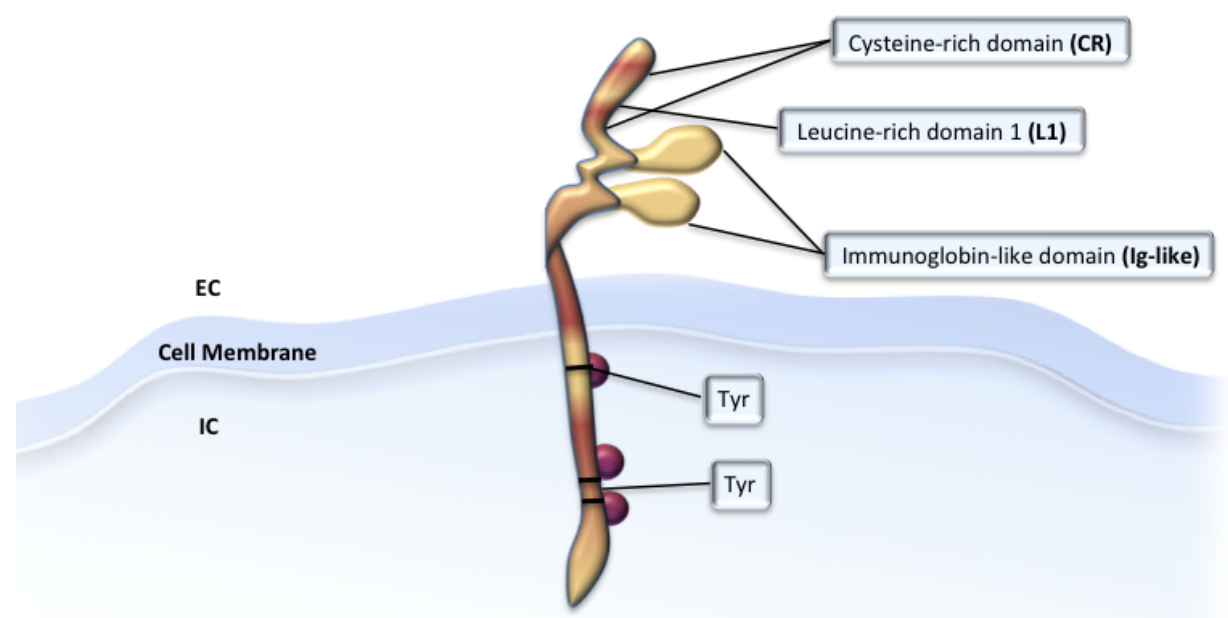

Figure 1.6. TrkA structure.

TrkA is composed of a cysteine-rich (CR), a leucine-rich (L1) and a immunoglobin-like (Ig-like) domain in the extracellular region (EC). The cytoplasmic tail is composed of the tyrosine kinase domain (tyr 490, 674 and 675 ) and the carboxy-terminal tail inside the cell (IC). The extracellular and the cytoplasmic regions are divided by a transmembrane region. 


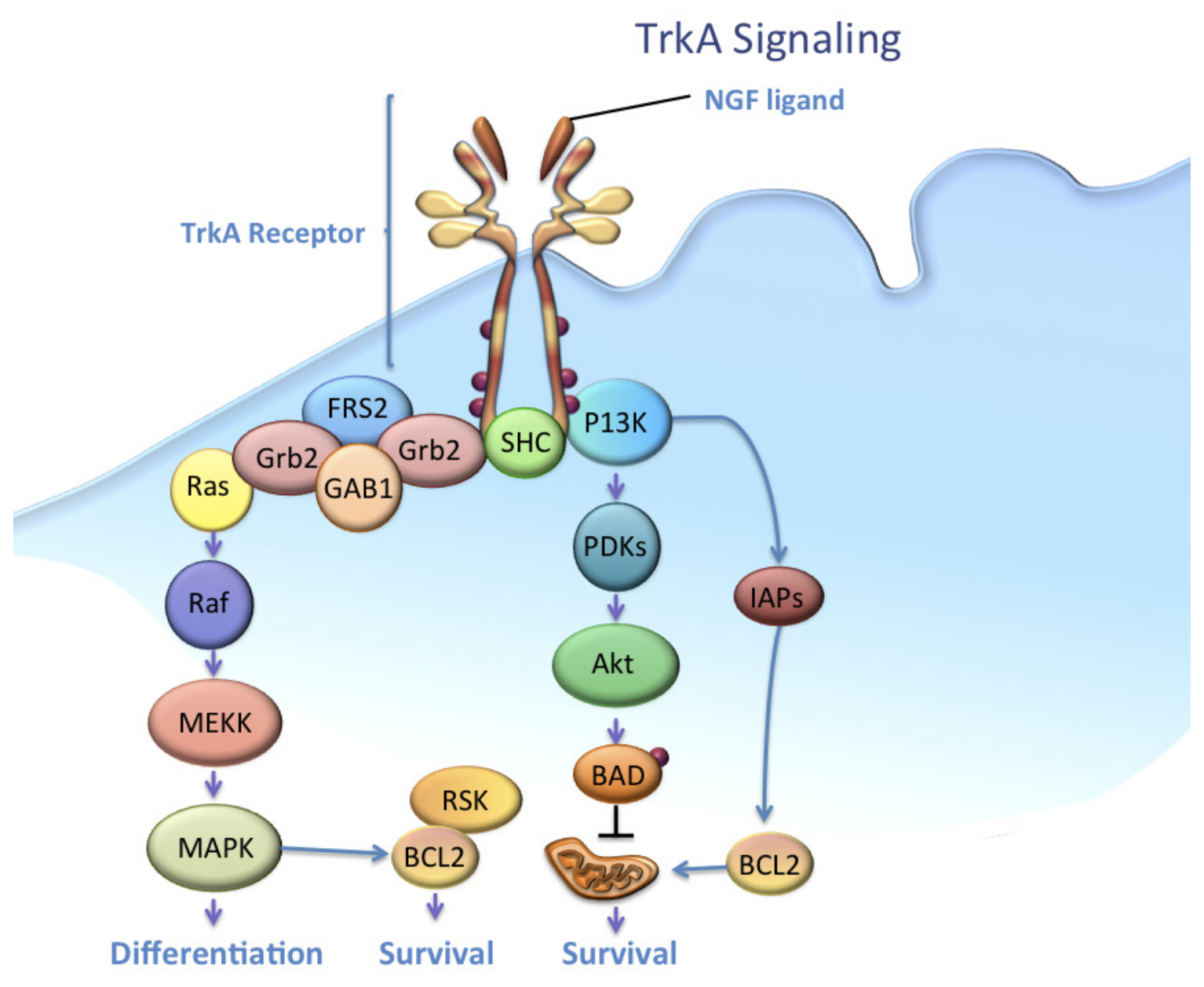

Figure 1.7. TrkA signaling.

Mayor signaling cascades activated by TrkA. Once NGF binds to the receptor, two main pathways get activated: PI3K/Akt/BAD and Ras, promoting the activation several signaling cascades such as Mapk and BCL2. 


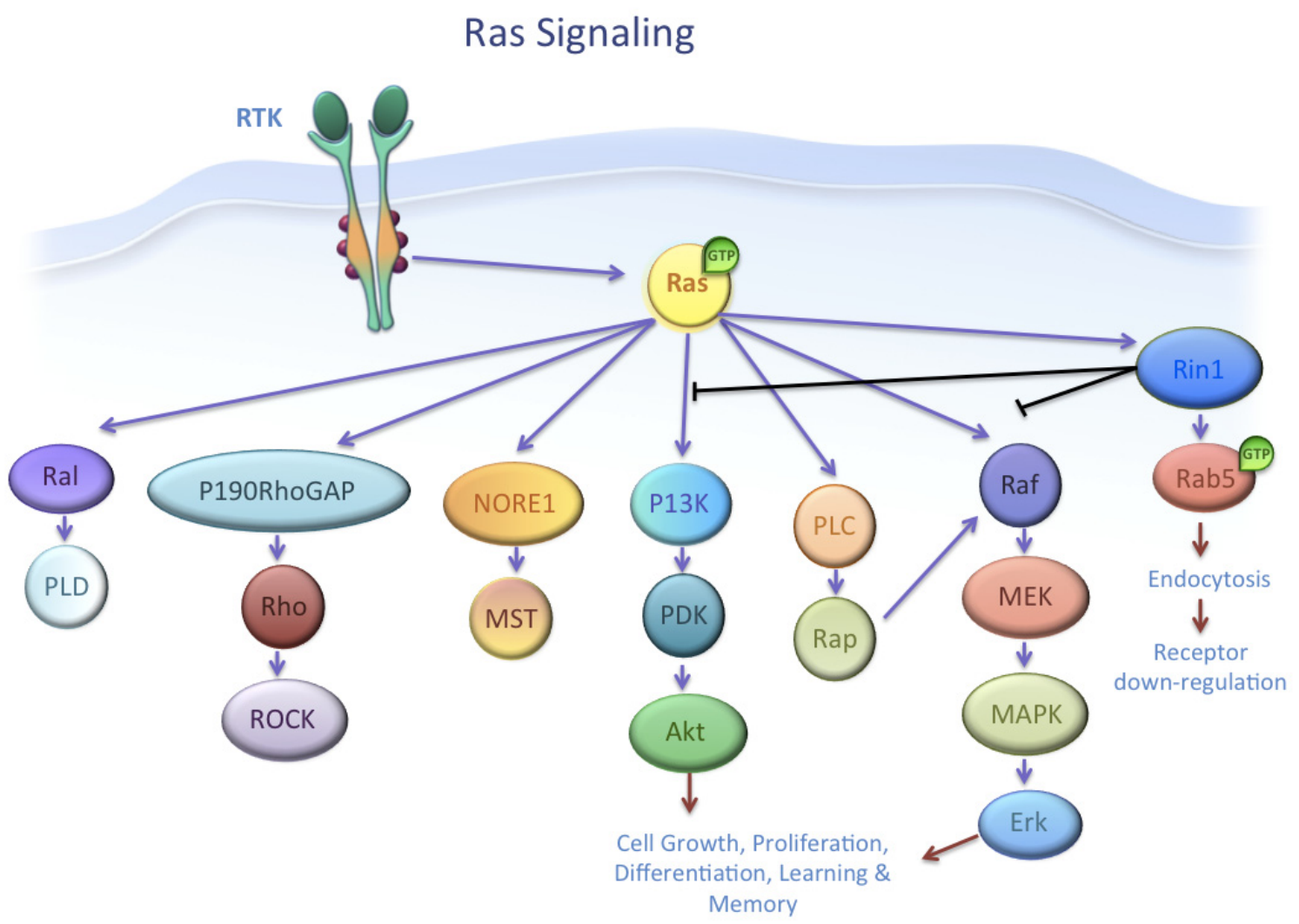

Figure 1.8. Ras signaling.

Mayor signaling cascades activated by Ras. Once the ligand binds to the receptor, Ras gets activated through the Grb2/SOS complex promoting the activation several signaling cascades including the Ral (Ras related protein)/PLD (phospholipase D), PI3K/ Akt, NORE1 (novel Ras effector 1)/MST (mammalian Sterile20-like), P190RhoGAP/ROCK (Rho-associated, coiled-coil containing protein kinase), PLC/Rap and Raf/Erk. Some Ras-GTP effectors compete for binding, such as Rin1 with PI3K and Raf. 


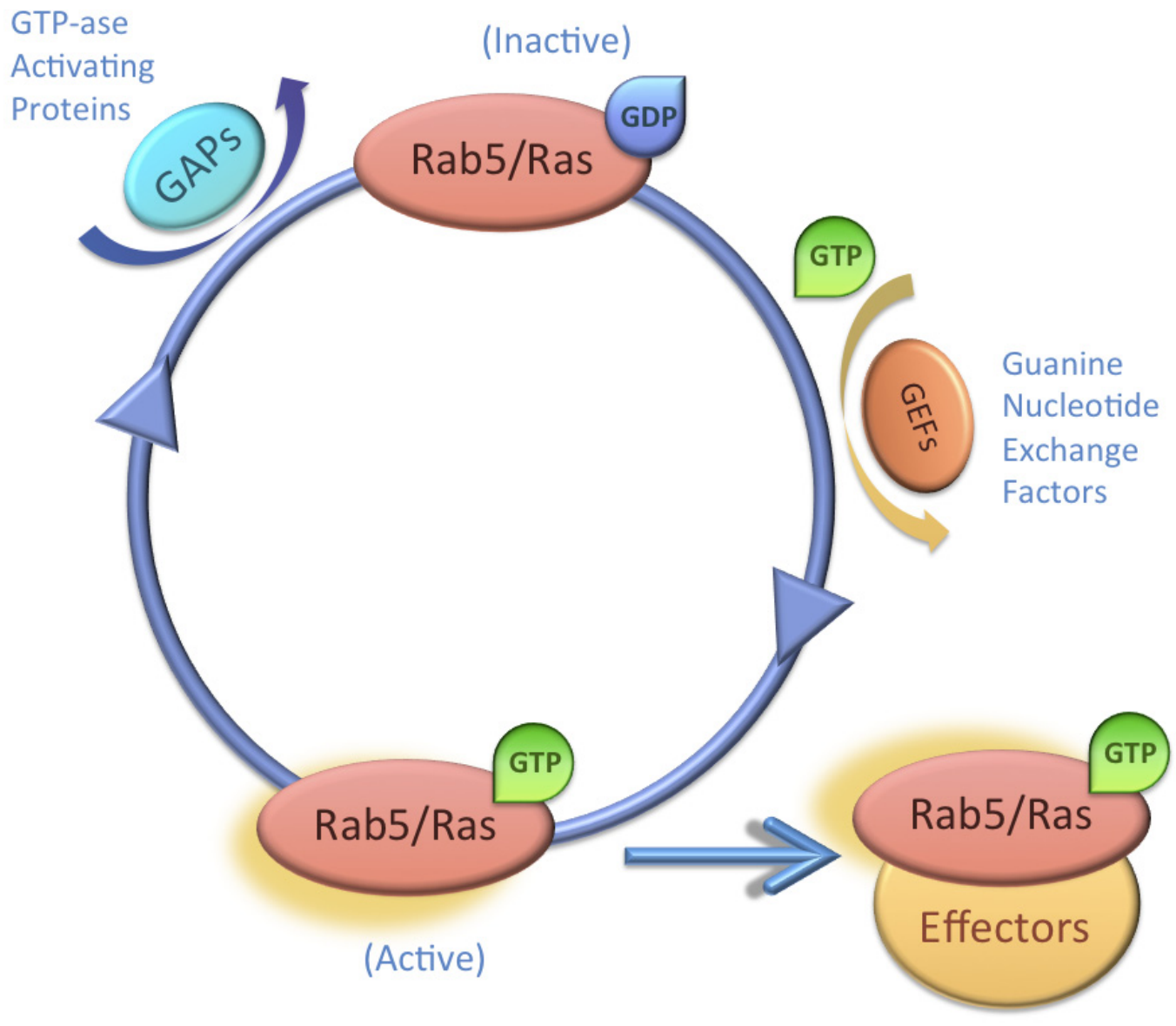

Figure 1.9. Rab5/ Ras cycle.

Rab5 and Ras GTPases cycle between its inactive form (bound to GDP) and its active form (bound to GTP). Guanine nucleotide exchange factors (GEFs) promote the GDP-GTP exchange, while GTPase activating proteins (GAPs) promote GTP hydrolysis. 


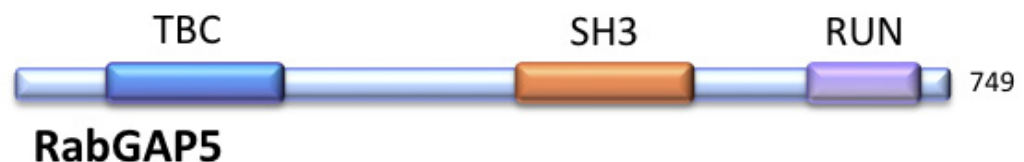

TBC

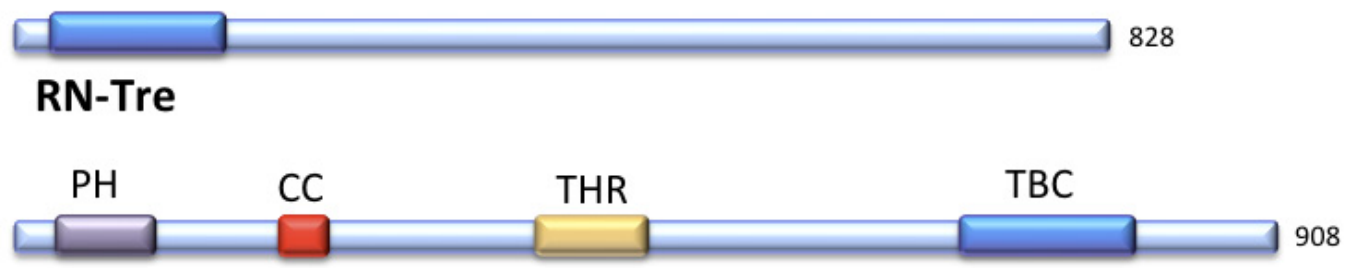

TBC-2

Figure 1.10. Rab5 GAPs proteins.

Proteins that promote GTP hydrolysis, inactivating Rab5. All of them share a TBC (Tre-2, Bub2 and Cdc16) domain responsible of the GTPase activity. RabGAP5 is composed of a TBC, SH3 (Src Homology 3) and RUN domains. TBC-2 is composed of PH (pleckstrin homology), CC (coiled coil), THR and TBC domains. 

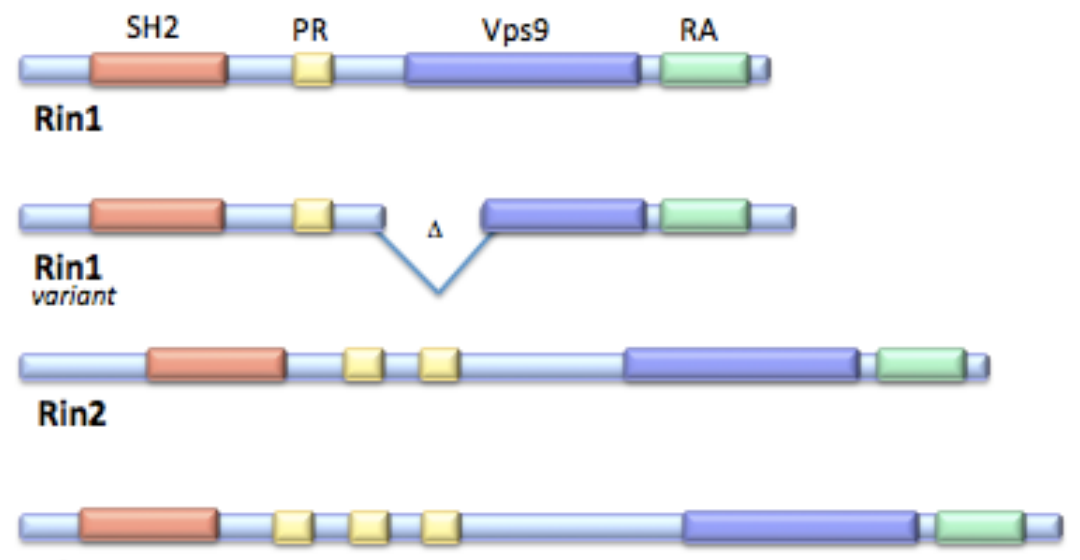

Rin3

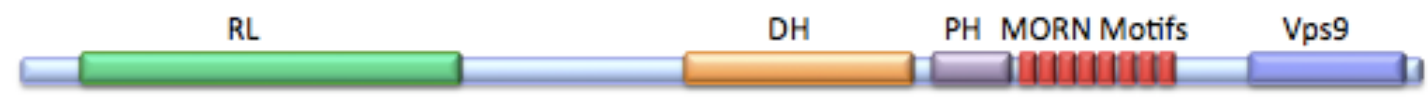

Alsin

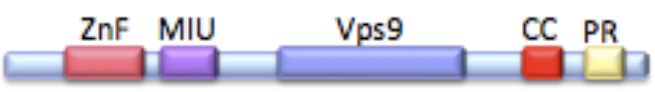

Rabex-5

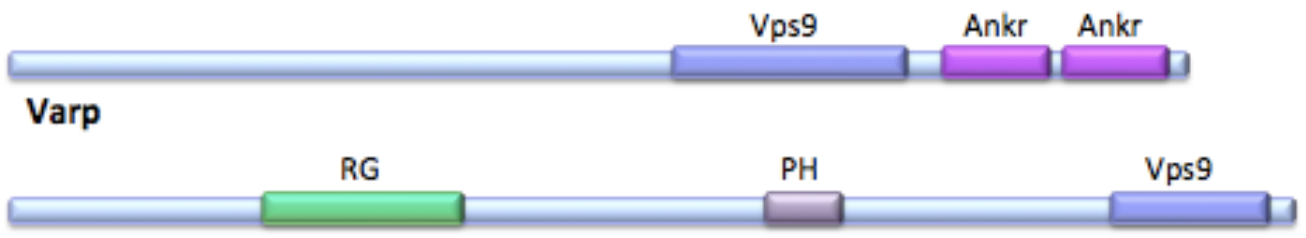

Rap6

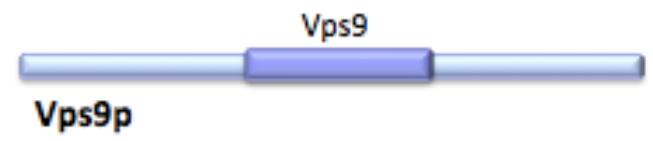

Figure 1.11. Rab5 GEFs proteins.

Proteins that promote GDP-GTP exchange, activating Rab5. All of them share a Vps9 domain responsible for the Rab5 activation. Rin1 is composed of four domains. The N-terminus contains the SH2 (Src Homology 2) and PR (proline rich) domains. The Vps9 (vacuolar protein sorting 9) and the RA (Ras association) domains are located at the C-terminus. Rin1 variant lacks some amino acids on the Vps9 domain. Rin2 and Rin3 are composed of the same domains as Rin1, but they differ in the number of repeats of the PR domain. Alsin is composed of RL (RCC1-like domains), $\mathrm{DH}, \mathrm{PH}$ (pleckstrin homology), MORN motifs and Vps9 domains. Rabex-5 is composed of ZnF (Zinc finger), MIU (motif interacting with Ubiquitin), CC (coiled coil) and PR domains. Varp contains the Vps9a and two ankyrin domains. Rap6 is composed of Ras GAP, $\mathrm{PH}$ and $\mathrm{Vps} 9$ domains. 


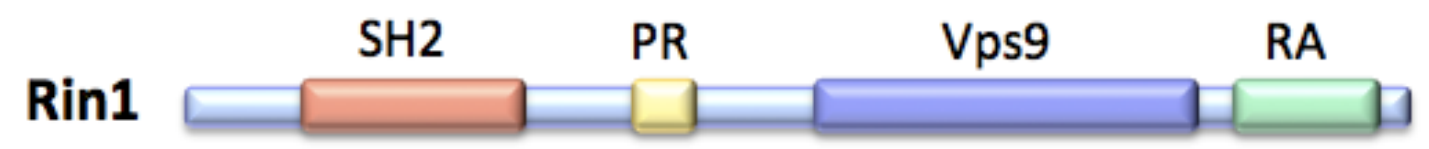

Figure 1.12. Rin1 domains.

Rin1 is composed of four domains. The N-terminus contains the $\mathrm{SH} 2$ and PR domains. The Vps9 and the RA domains are located at the C-terminus. 


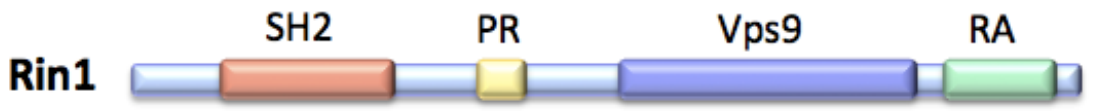

Rin2

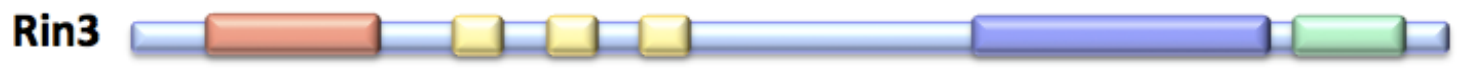

Figure 1.13. Rin protein family.

This protein family is composed of three members named Rin1, Rin2 and Rin3. All members are composed of the same domains: $\mathrm{SH} 2$, proline-rich (PR), Vps9 and a RA domain. They differ in the number of repeats of the PR domain. 


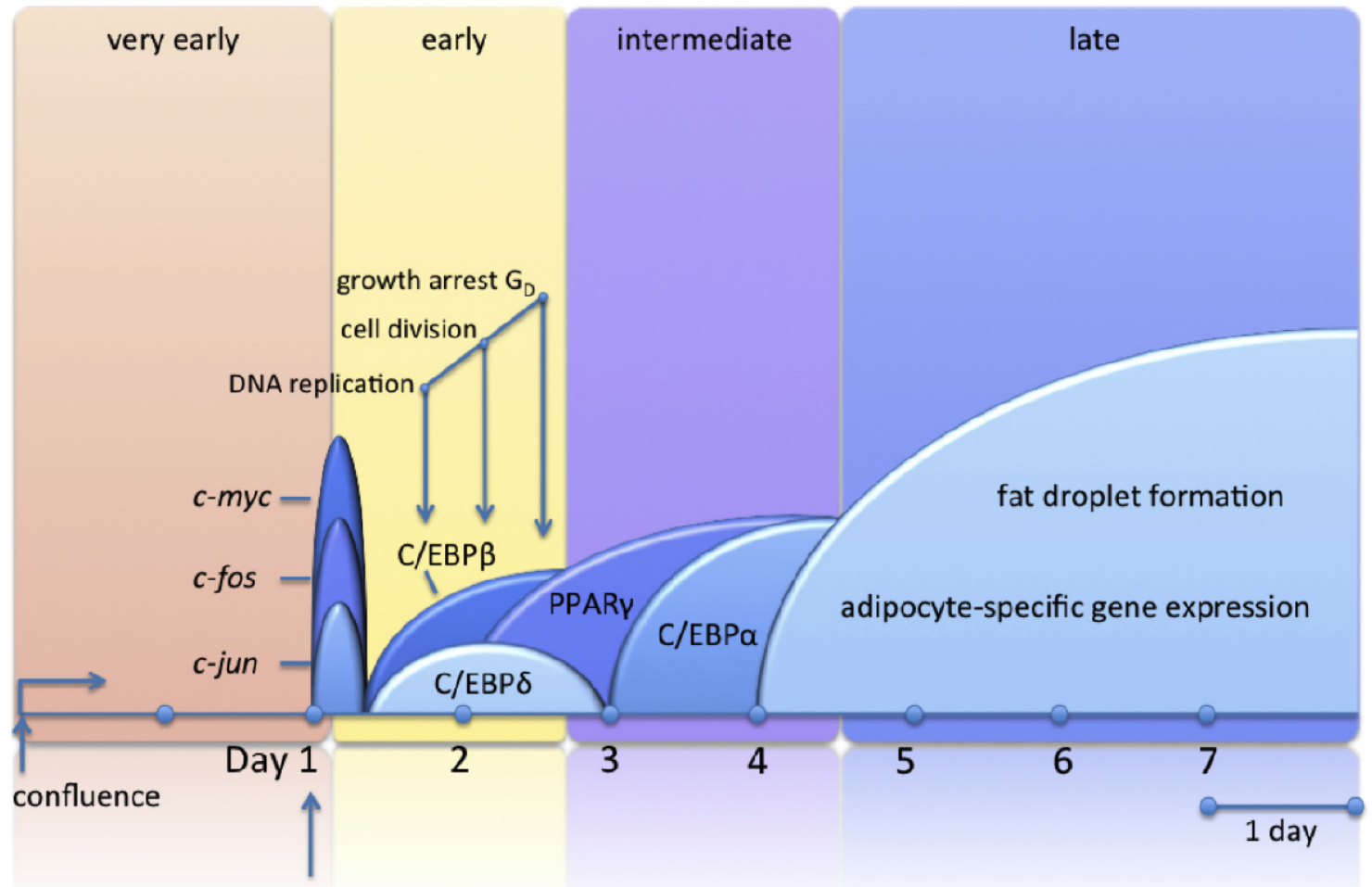

Figure 1.14. Adipogenesis signaling.

Selective activation of key proteins on the different days of adipocyte differentiation. Adipogenesis is the result of specific activation of early (days 1 and 2), intermediate (days 3 and 4 ) and late genes (days 5-9) as showed above. 


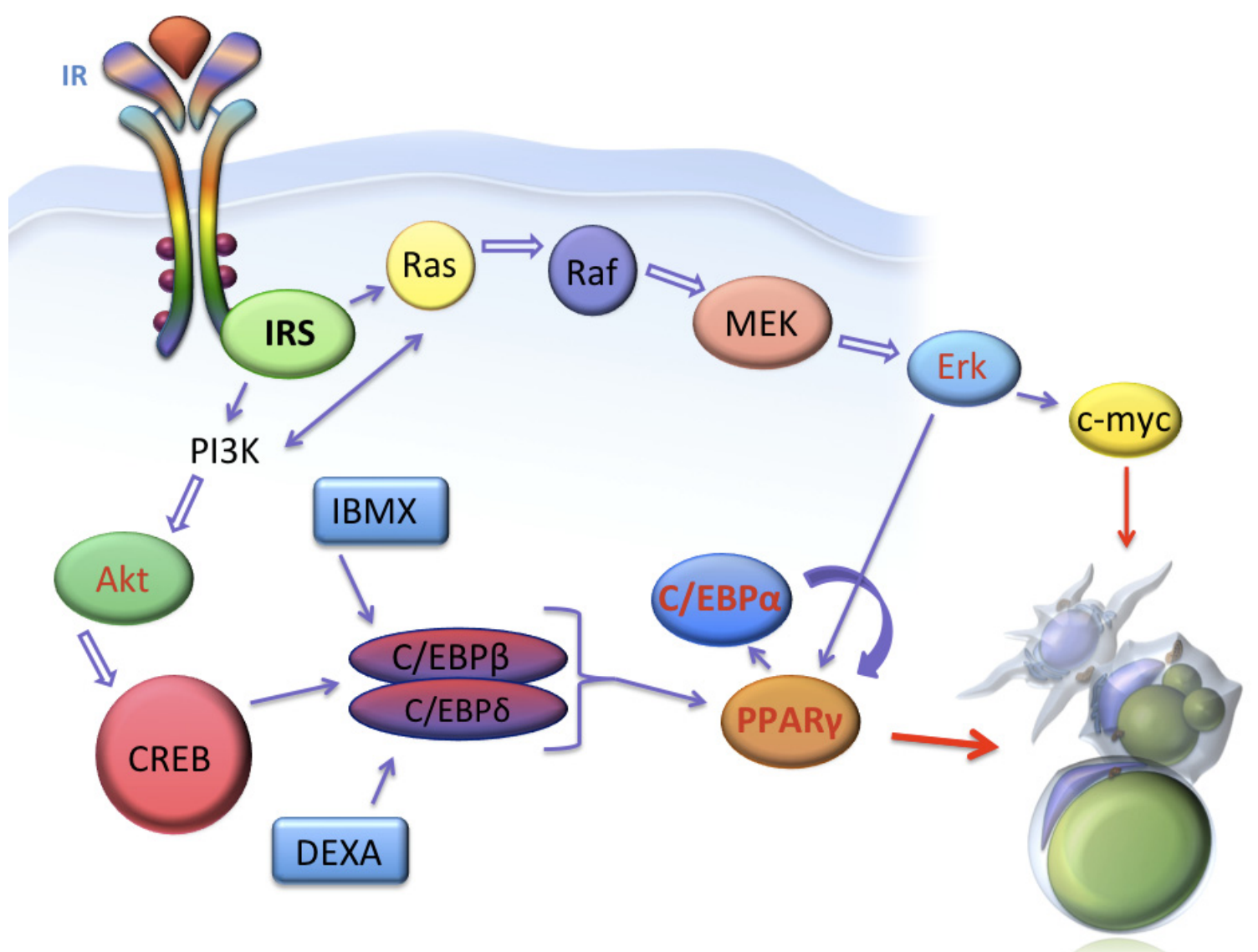

Figure 1.15. Transcription factors involved in adipogenesis.

Signaling cascades involved in fat cell formation. Insulin activate the IR and the Ras and PI3K signaling cascades. 1-Methyl-3-Isobutylxanthine (IBMX) activates $\mathrm{C} / \mathrm{EBP} \beta$ and dexamethasone (DEXA) is responsible for the activation of C/EBPD. All together activate $\mathrm{C} / \mathrm{EBP} \alpha$ and PPARY, the key adipogenic markers of adipogenesis. 


\section{MECHANISM OF INTERACTION BETWEEN RIN1 AND RTKS AND ITS}

\section{EFFECTS TOWARD THE ACTIVITY OF RAB5 AND RAS.}

Tyrosine kinase receptors are membrane-bound receptors that get internalized through receptor-mediated endocytosis. These receptors share a common structure: an extracellular region responsible for the ligand interaction, a hydrophobic region that transverses the lipid bilayer, and a cytoplasmic tail that interacts with molecules inside the cell. Through the extracellular region, the receptor gets activated upon ligand binding. The ligand binding leads to autophosphorylation of the cytoplasmic tail of specific tyrosine residues, which then serve as docking sites for proteins containing an $\mathrm{SH} 2$ domain. The interaction between receptor cytoplasmic tail and $\mathrm{SH}$-containing proteins may represent one of the several mechanisms of the signal transduction regulation. Thus, the aim of this chapter is to determine key residues of Rin1 required for the interaction with tyrosine kinase receptors such as NGFR, EGFR, and IR and how this interaction affects several downstream signaling pathways.

\section{Interaction between Rin proteins and RTKs.}

Ras interference 1 interacts with activated EGFR through its $\mathrm{SH} 2$ domain (Barbieri et al., 2003). Key amino acids in this domain interact with the phosphorylated tyrosine residues in the cytoplasmic tail of the activated receptor.

To study the interaction of Rin1 and EGFR two approaches were carried out: 1- immunoprecipitation and 2- GST-pulldown. Each one of these assays is described in the Material and Methods section. 
First, an immunoprecipitation assay was carried out by utilizing several Rin1 constructs: Rin1:WT as well as individual Rin1 domains named Rin1:R2 (which contains SH2 and proline rich domains) and Rin1:R3 (which contains Vps9 and RA domains) (Figure 3.3).

Second, a GST-pulldown was carried out by preparing cell lysates from stimulated (+EGF) and non-stimulated (-EGF) NR6 fibroblasts overexpressing EGFR, and the following GST-labeled purified proteins: Rin1 (SH2:WT), Rin1 (SH2:H120L) and Rin1 (SH2:Y121F). Glutathione S-transferase (GST) alone was used as negative control in these experiments. Figure 2.1 shows a specific interaction of EGFR with Rin1:WT and Rin1:R2 (Figure 2.1A,B), but not Rin1:R3 (Figure $2.1 \mathrm{C}$ ). These results suggest that the $\mathrm{SH} 2$ domain of Rin1 recognizes phosphorylated tyrosine residues on the receptor cytoplasmic tail, which is present both in the Rin1:WT and Rin1:R2 constructs, but not in Rin1:R3.

Previous studies showed the important role of arginine 94 (Rin1:R94A) of Rin1 in the interaction with EGFR (Hu et al., 2008). Figure 2.2 shows the interaction of EGFR and the GST-tagged Rin1:SH2 domain (WT and mutants). This time, two other point mutations were studied: Rin1:H120L and Rin1:Y121F. It can be observed that none of these mutants affected the Rin1/EGFR.

To study the interaction of Rin1 and IR different techniques were utilized as described in the Material and Methods section. The same as with EGFR, an immunoprecipitation assay was used to study the Rin1-IR interaction. Figure 2.3 shows that there is a specific interaction with the phosphorylated receptor (+insulin) with Rin1:WT (Figure 2.3A) and Rin1:R2 (Figure 2.3B) (which contains 
the $\mathrm{SH} 2$ domain). Surprisingly, there is also a strong interaction with the Rin1:R3 construct (Figure 2.3C). To further confirm this interaction, the yeast two hybrid method was used. Figure 2.4 shows the interaction between the IR tail and Rin1:R3. It also showed that Rin1:WT, as well as Rin1:R2, interact with the tail of the receptor as expected.

Finally, a GST-pulldown assay was carried out using lysates from stimulated (+insulin) and non-stimulated (-insulin) NIH3T3 fibroblasts overexpressing IR, and the following GST-tagged purified proteins: Rin1 (SH2), Rin1 (SH2:W69E), Rin1 (SH2:A76E), Rin1 (SH2:R94A), (SH2:H120L), (SH2:Y121F) and Rin1 (SH2:Y148F). Mutations in the SH2 domain of Rin1 were made on key amino acids that may play an important role in the interaction with RTKs. Figure $2.5 \mathrm{~A}$ shows the Western blot and quantification of Rin1:WT, Rin1:W69A, and Rin1:A76E. Figure 2.5B shows the IR interaction with all mutants of the $\mathrm{SH} 2$ domain of Rin1. From the six mutants two of them have the most inhibitory effect (Rin1:A76E, Rin1:Y121F), while mutant Rin1:Y148F showed less inhibitory effect when compared to SH2:WT. Mutants W69E, R94A and Rin1:H120L have no effect at all in the interaction with the active IR.

The Rin1-NGFR interaction was analyzed by doing a GST-pulldown assay (as described in the Material and Methods section) using cell lysates from stimulated (+NGF) and non-stimulated (-NGF) PC12 cells, which overexpress the TrkA receptor. Figure 2.6 shows a clear interaction of the receptor with Rin1 upon NGF stimulation. 
In summary, these results confirm that all three receptors interact with Rin1 upon stimulation through the $\mathrm{SH} 2$ domain, which recognizes and binds to the phosphorylated tyrosines in the cytoplasmic tail of the activated receptor. Mutations on this domain have been related to different types of diseases such as leukemia (Cazzaniga et al., 1999), autoinflammatory disease (Zhou et al., 2012), diabetes (Marion et al., 2002), and cancer (Friedman et al., 1993). Surprisingly, just the IR, and neither EGFR nor NGFR, interacts with the Vps9 domain of Rin1. The Vps9 domain is responsible for the binding and further activation of Rab5 by promoting GDP to GTP exchange.

\section{Signaling regulation by Rin proteins.}

The next section describes 1 - how these interactions affect the activity of key endocytic and signaling proteins such as Rab5 and Ras, respectively, and 2how they affects major biological processes such as cell differentiation.

Upon activation, RTKs initiate a cascade of protein-protein interactions that modulate the receptor internalization and signaling through the activation of the key GTPases Rab5 and Ras, respectively. Rab5 is responsible for the clathrincoated vesicle transportation from plasma membrane to early endosomes and its further homotypic early endosome docking and fusion (Barbieri et al., 1994; Bucci et al., 1992; Gorvel et al., 1991; Li et al., 1994; Zerial and McBride, 2001). Receptor activation promotes recruitment and activation of Rab5, as was demonstrated for EGFR (Barbieri et al., 2000). Rab5 is inactivated by the interaction with GAPs proteins, such as RabGap5 (Haas et al., 2005), RN-tre (Albert et al., 1999), and TBC-2 (Chotard et al., 2010), by promoting the 
hydrolization of GTP into GDP. GEF proteins, such as Rabex5, Alsin2, Vps9p and Rin1, promote the exchange of GDP into GTP activating Rab5. All these proteins share a Vps9 domain, which is the one responsible for the activation (Carney et al., 2006).

Figure 2.7 shows Rab5 activation in EGF-stimulated cells overexpressing Rin proteins. Ras interference 1 and Rin3 promote Rab5 activation compared with control, while Rin2 barely promoted any Rab5 activation (Figure 2.7). Interestingly, it was observed that all Rin family members also stimulated Rab5 activity in non-stimulated cells (Figure 2.7).

In the case of IR, Rab5 activation shows a similar tendency as in EGFstimulated cells. (Figure 2.8) shows an increase in Rab5-GTP in Rin1 overexpressing cells, and to a lesser extent, in cells overexpressing Rin2 and Rin3. Also observed was that overexpression of all Rin proteins stimulates Rab5 activity in non-stimulated cells (Figure 2.8).

Ras is a major signaling protein responsible of amplifying RTK signaling. Active Ras is important in cell differentiation and proliferation, and when it is overactive, it has been related to numerous types of cancer (Fernandez-Medarde and Santos, 2011). GTPase activating proteins (GAPs) and GEF proteins regulate Ras activity in the same way as Rab5, or any other GTPase protein. Ras activation is initiated by the activation of the receptor. Once the receptor is activated, an adaptor protein (GRB2) will bind through its $\mathrm{SH} 2$ domain to a phosphorylated tyrosine residue in the cytoplasmic tail of the receptor. GRB2 also contains an SH3 domain, which will bind and activate SOS, a GEF, and 
promote the GDP-GTP exchange activating Ras (Olivier et al., 1993). But Ras signaling regulation is much more complex than that. Proteins containing RA domain, such as Rin1, serve as Ras effectors (Ponting and Benjamin, 1996). These effectors directly interact with the active form of Ras, without having any effect on the rate of GTP hydrolysis. Even though Ras effectors do not inactivate Ras, they can have an impact in signaling cascades by competing with other effectors. This aim studied the effect of the Rin proteins in Ras and its signaling cascades activation.

Figure 2.9 shows that there is no effect in Ras activity upon EGF stimulation if Rin1 is overexpressed when compared to control cells. As mentioned above, Rin proteins have a domain (RA) that interacts with the active form of Ras (Barbieri et al., 2003). This interaction may have an effect in one or more signaling pathways activated by Ras.

To study the effect of Rin overexpression in Ras-activated signal transduction several signaling proteins were examined. Figure 2.10 shows the effect of Rin1 overexpression in NR6 cells stimulated with EGF. As expected, the absence of EGF did not stimulate any of the activities analyzed (Figure 2.10A-E). A small inhibition of the tyrosine phosphorylation of EGFR was observed in cells expressing Rin1 (Figure 2.10E). Akt, Erk, and Junk activities were dramatically blocked in cells expressing Rin1 as compared with control-stimulated cells (Figure 2.10A,B and D). In contrast, p38 activity was not affected (Figure 2.10C). Rin2 overexpression in EGF-stimulated NR6 cells generated slightly different results. Figure 2.11 shows a significant inhibition of phosphorylated Akt (Figure 
2.11B), while Erk (Figure 2.11A) activation seems to be enhanced. The activation of p38 (Figure 2.11C), similar to Rin1 overexpression, is not affected by the overexpression of Rin2. In the case of Rin3 overexpression, there is an inhibition in phosphorylated Erk (Figure 2.12A) and Akt (Figure 2.12B). Once again, there is no effect on p38 phosphorylation (Figure 2.12C), just as in the case of Rin1 and Rin2 overexpression (Figure 2.12) upon EGF-stimulation.

The effect of Rin proteins overexpression was also studied in NIH3T3 fibroblast overexpressing IR. Figure 2.13 shows the effect of Rin1 overexpression in the Ras-activated signaling cascades. As in the EGFR overexpressed cells, Rin1 inhibits Erk (Figure 2.13A) and Akt (Figure 2.13B) phosphorylation upon insulin stimulation. In this case, opposite to what is observed upon EGF stimulation, Rin1 did not block p38 (Figure 2.13C) and IR (Figure 2.13D) phosphorylation upon stimulation. A similar tendency was observed when Rin2 is overexpressed. Figure 2.14 shows an inhibitory effect on Erk (Figure 2.14A) and Akt (Figure 2.14B) activation, while it promotes p38 (Figure 2.14C) phosphorylation upon insulin stimulation. In the case of Rin3 overexpression, Figure 2.15 shows a similar inhibitory effect on Erk (Figure 2.15A) observed for Rin1 and Rin2, but this time there is no significant effect on Akt (Figure 2.15B) or p38 (Figure 2.15C) activation.

To obtain a better understanding of the effect of Rin1 in IR signaling, several residues of each domain of Rin1 were mutated and their effects in insulin driven signaling pathways were studied. The following residues were mutated: Rin1:R94A (SH2 domain), Rin1:Y561F (Vps9 domain), Rin1:T580A (Vps9 
domain) and Rin1:R629A (RA domain). Interestingly, arginine 94 is important in the interaction of Rin1 with activated EGFR (Hu et al., 2008). Figure 2.16 shows that Rin1:R94A mutant has no effect on IR phosphorylation (Figure 2.16A), it reverses the inhibitory effect of Rin1:WT (Figure 2.16B), and more importantly, it has a greater inhibitory role than the wild type protein in Akt activation (Figure 2.16C). It has been shown that tyrosine 561 is necessary for the proper activation of Rab5, and it is involved in the interaction with active Ras (Galvis et al., 2009). Figure 2.17 shows that Rin1:Y561F mutant has no effect in IR phosphorylation (Figure 2.17A), but it reverses the inhibitory effect caused by Rin1:WT in both Erk (Figure 2.17B) and Akt (Figure 2.17C) activity. Figure 2.18 shows that Rin1:T580A mutant, which blocks Rab5 activation but not Ras binding (Galvis et al., 2009), enhances the phosphorylation of the receptor (Figure 2.18A) and reverses the inhibitory effect in both Erk (Figure 2.18B) and Akt (Figure 2.18C) phosphorylation. Lastly, Rin1:R629A mutant, which affects the interaction with Ras, enhances the phosphorylation of IR (Figure 2.19A) and Akt (Figure 2.19C) compared to Rin1:WT, while it has a greater inhibitory effect on Erk (Figure 2.19B) activity. Interestingly, all mutants promote the activation of p38 in nonsimulated cells; in some cases this activation is greater than the one observed in insulin stimulated cells (Figures 2.16-2.19D). 

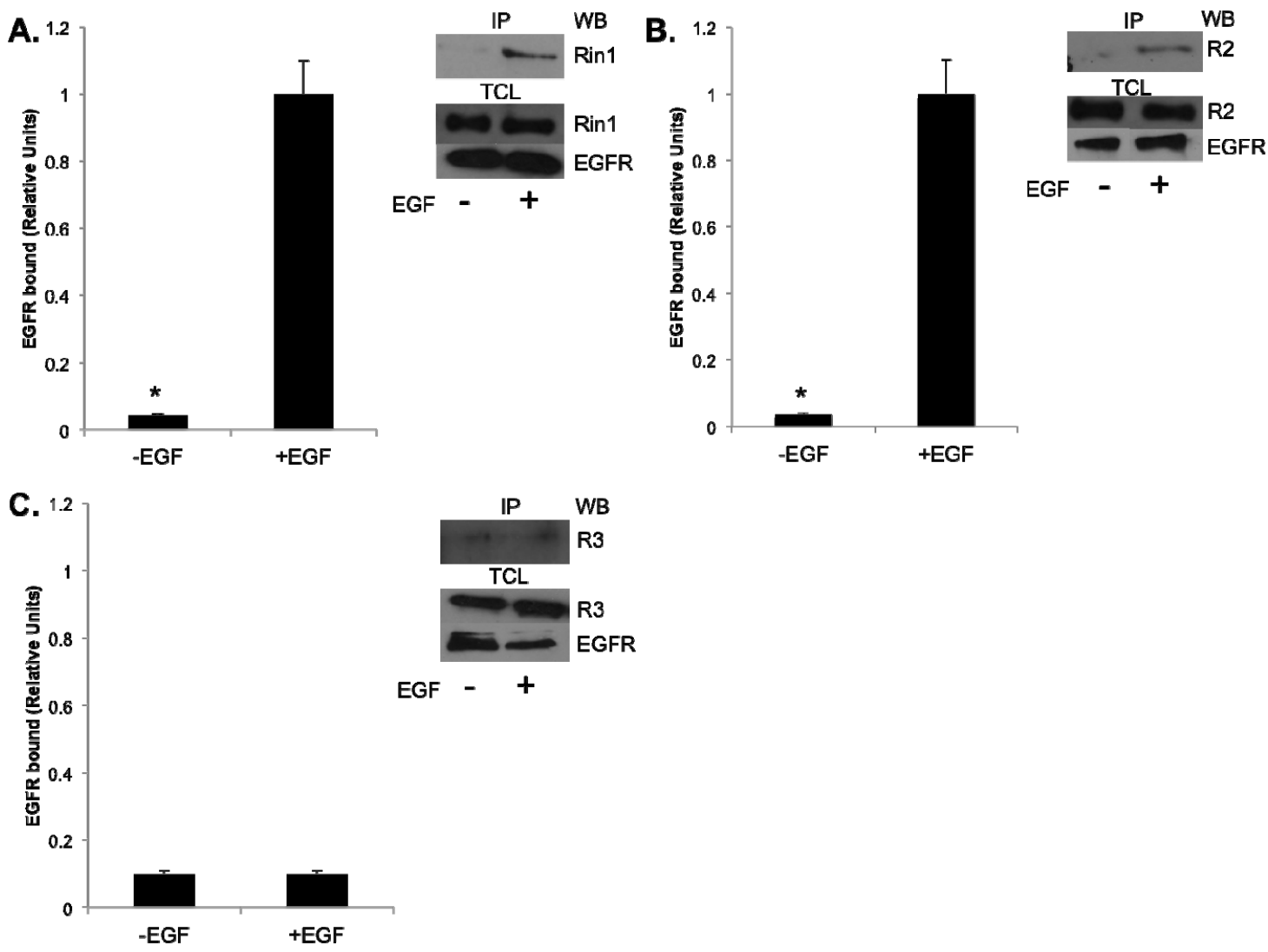

Figure 2.1. Immunoprecipitation assay between Rin1 (WT and domains) and the EGF receptor.

NR6 fibroblasts overexpressing EGFR, in the presence (+EGF) or absence (EGF) of 100ng/ul EGF, were lysed and immunoprecipitated as explained in Material and Methods. Stimulated and non-stimulated cell lysates were immunoprecipitated with a anti-EGFR antibody, and the presence of Rin1 (A), R2 (B) or R3 (C) bound to the receptor was visualized using anti-Rin1 antibody. Rin1 and EGFR present in the total cell lysate (TCL) shows the total amount of protein added to the assay. Rin1 present in the IP sample represents the amount of protein bound to the receptor. Relative levels of proteins were determined by densitometry as described in Material and Methods. Data represent the mean \pm S.E.M. of three independent experiments. ${ }^{*} P<0.05$ by Student's t-test compared to EGF-stimulated cells. 


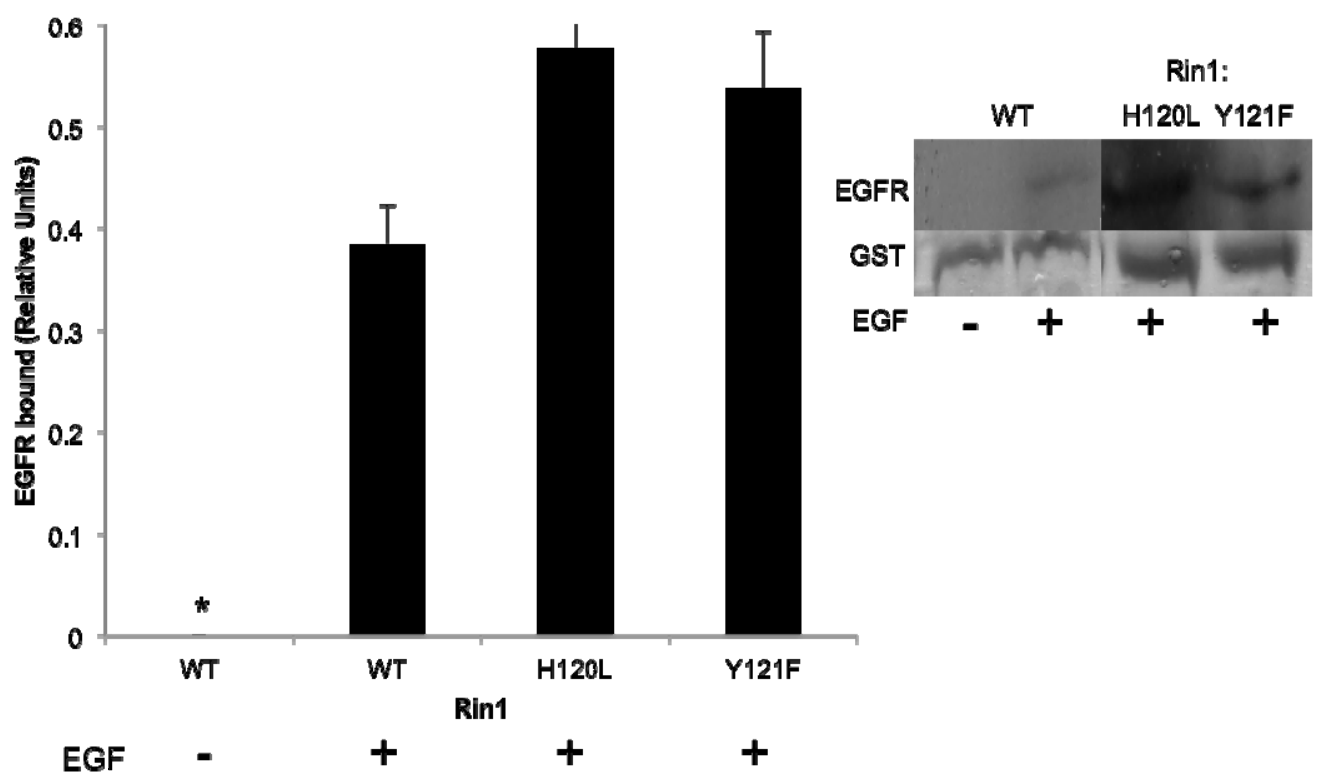

Figure 2.2. GST-pulldown assay between EGF receptor and Rin1 mutants. NR6 cells overexpressing EGFR, in the presence (+EGF) or absence (-EGF) of $100 \mathrm{ng} / \mathrm{ul}$ EGF, were lysed and incubated with GST-fused lysates of the different Rin1 constructs, as explained in Material and Methods. In the presence of EGF, cell lysates were incubated with Rin1:H120L and Rin1:Y121F mutants, and the amount of Rin1 protein bound to the receptor was visualized using anti-EGFR antibody. Relative levels of proteins were determined by densitometry as described in Material and Methods. Data represent the mean \pm S.E.M. of three independent experiments. ${ }^{*} P<0.05$ by Student's t-test compared to EGFstimulated cells. 

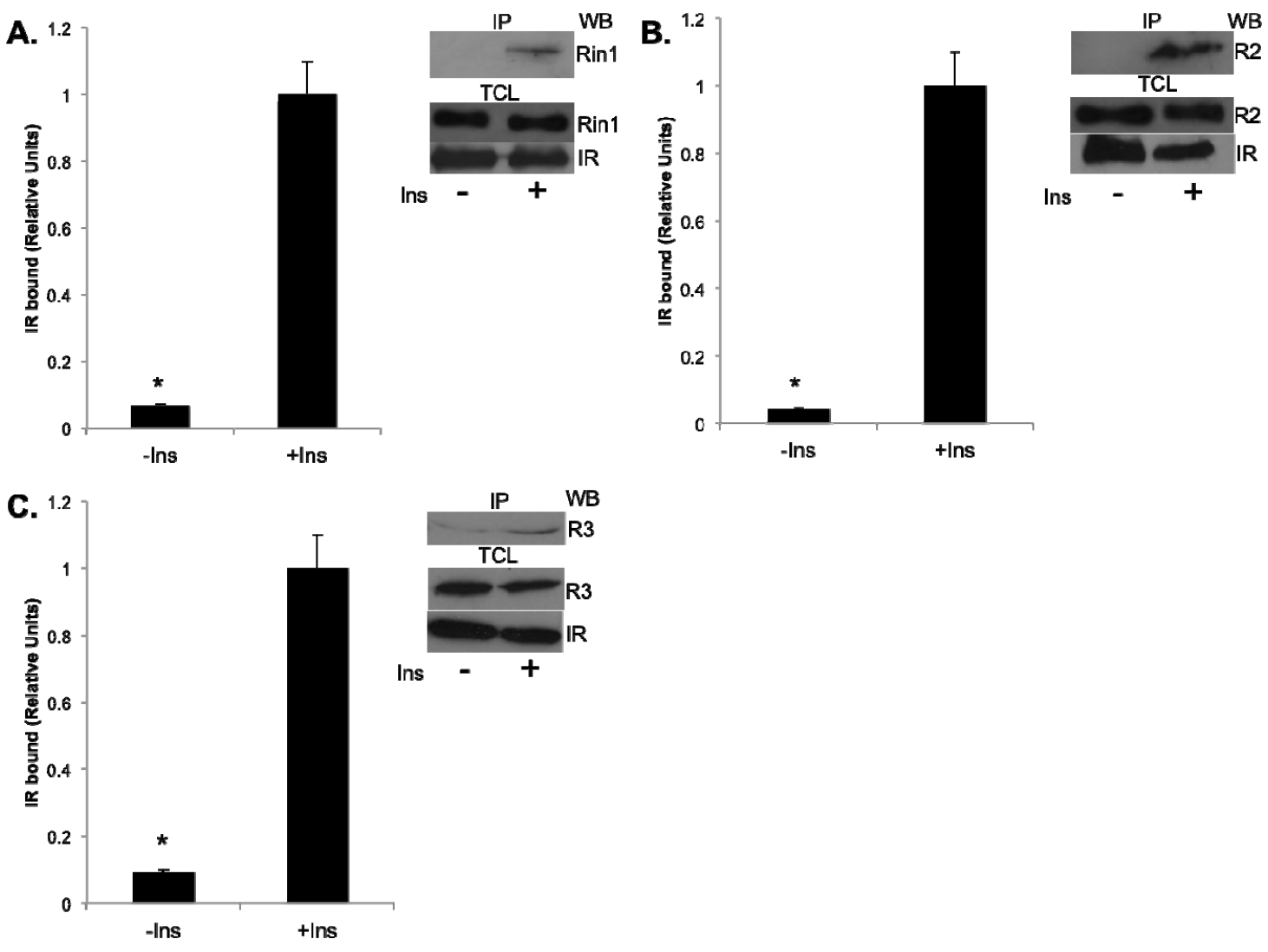

Figure 2.3. Immunoprecipitation assay between Rin1 (WT and domains) and the insulin receptor.

NIH3T3 fibroblasts overexpressing IR, in the presence (+Ins) or absence (-Ins) of $100 \mathrm{nM}$ insulin, were lysed and immunoprecipitated as explained in Material and Methods. Stimulated and non-stimulated cell lysates were immunoprecipitated with anti-IR antibody, and the presence of Rin1 (A), R2 (B) or R3 (C) bound to the receptor was visualized using anti-Rin1 antibody. Rin1 and IR present in the total cell lysate (TCL) shows the total amount of protein added to the assay. Rin1 present in the IP sample represents the amount of protein bound to the receptor. Relative levels of proteins were determined by densitometry as described in Material and Methods. Data represent the mean $\pm S . E . M$. of three independent experiments. ${ }^{*} P<0.05$ by Student's t-test compared to insulin-stimulated cells. 


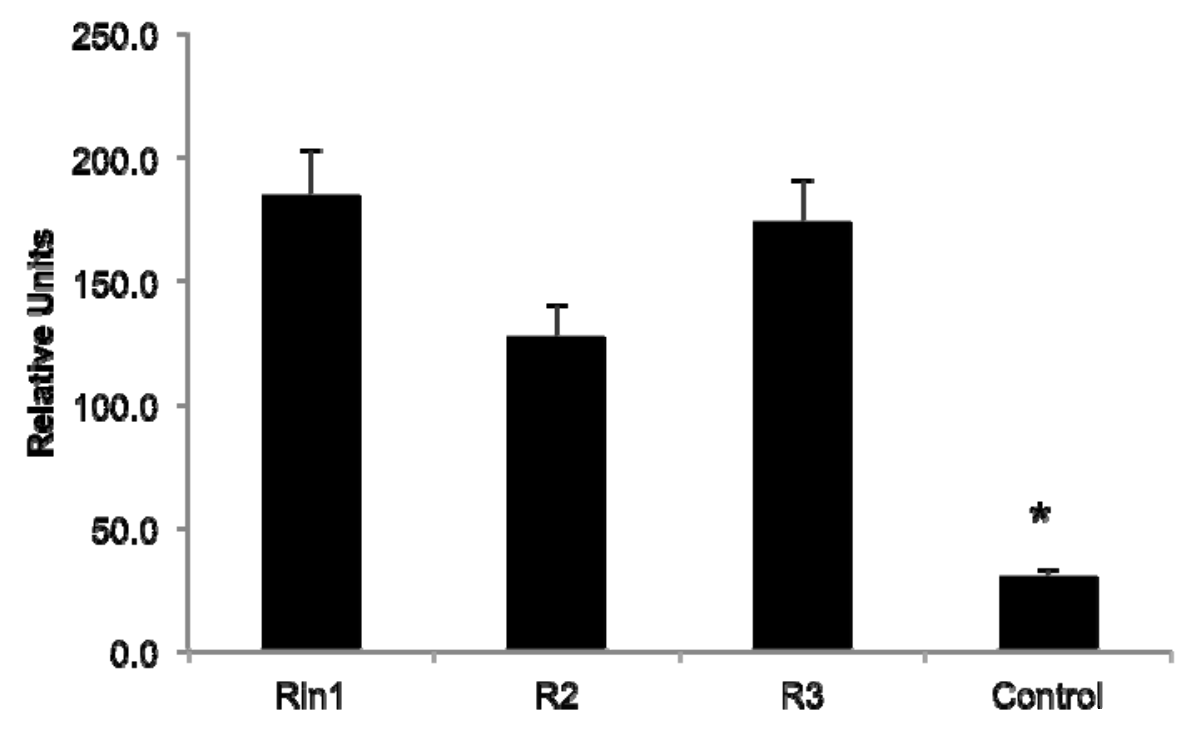

Figure 2.4. Yeast two hybrid system using Rin1 constructs and the insulin receptor cytoplasmic tail.

Rin1, R2 (SH2 and proline rich domains) and R3 (Vps9 and RA domains) were used to do the yeast two hybrid system with the insulin receptor cytoplasmic tail as explained in Materials and Methods. The insulin receptor tail: kinase dead was used as negative control. Data represent the mean $\pm S$.E.M. of three independent experiments. ${ }^{*} P<0.05$ by Student's t-test compared to IR: kinase dead (control). 

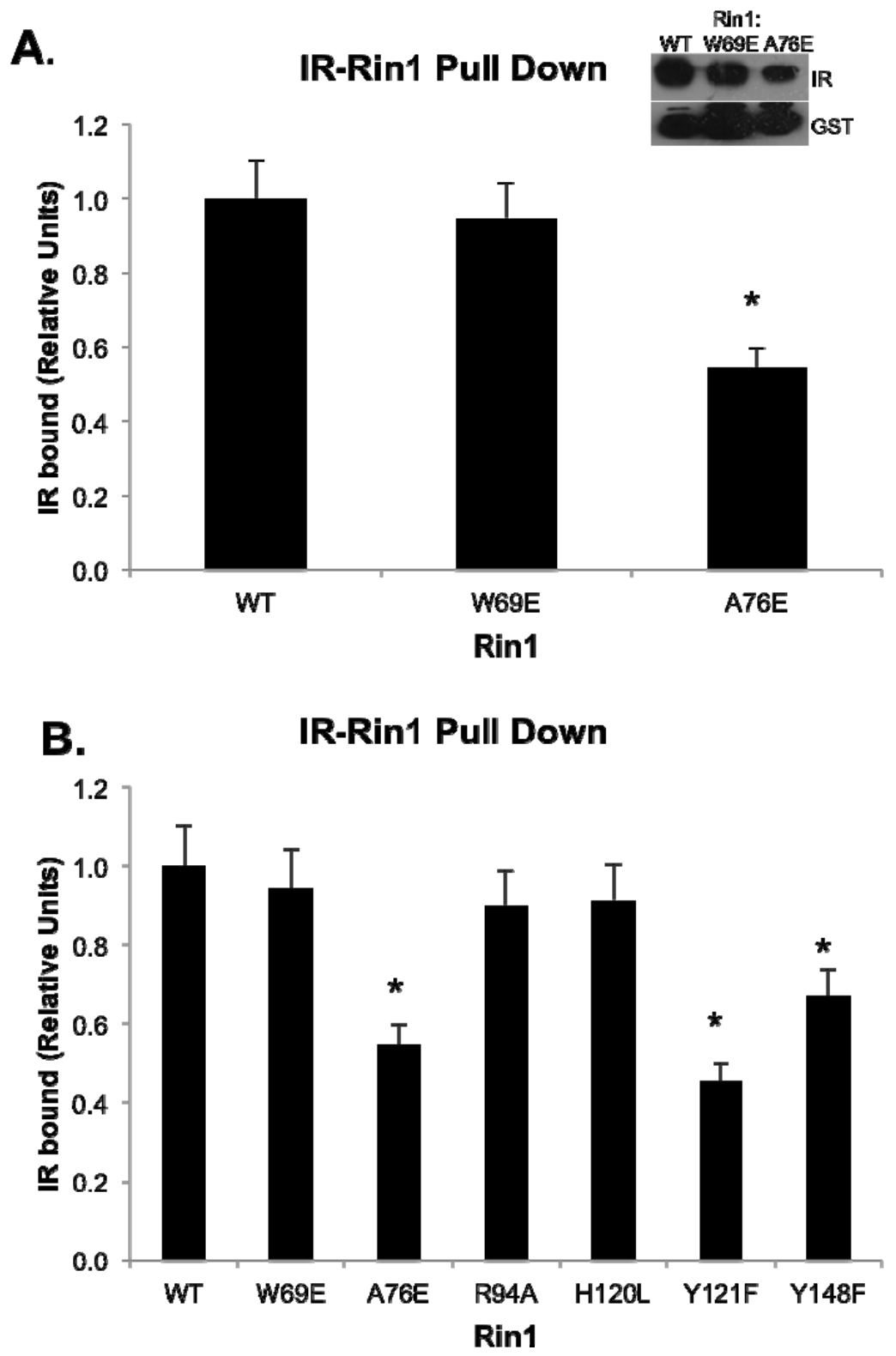

Figure 2.5. GST-pulldown assay between the insulin receptor and Rin1 mutants.

Pure recombinant insulin receptor tail was phosphorylated in the presence of ATP, as explained in the Material and Methods section, prior to the binding to Rin1-SH2 mutants GST-fused lysates. The amount of Rin1 protein bound to the receptor was visualized using anti-IR antibody. (A) Western blot and quantification of the IR interaction with Rin1:SH2 WT, Rin1:W69A and Rin1: A76E. (B) Quantification of the IR interaction with the Rin1: SH2 mutants. Relative levels of proteins were determined by densitometry as described in Material and Methods. Data represent the mean \pm S.E.M. of three independent experiments. ${ }^{*} P<0.05$ by Student's t-test compared to Rin $1: W T$. 


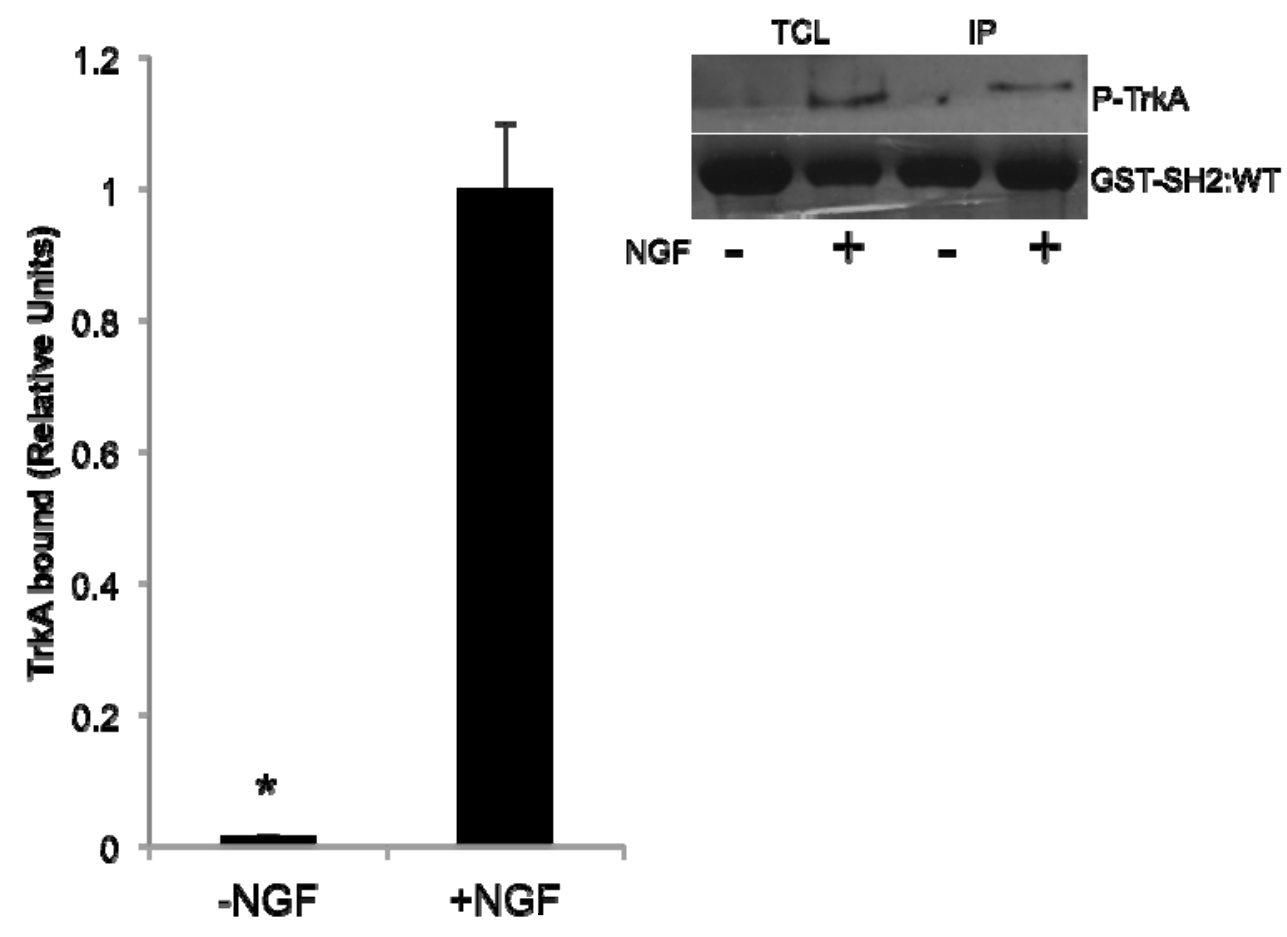

Figure 2.6. GST-pulldown assay between the NGF receptor and Rin1 mutants.

PC12 cells overexpressing TrkA, in the presence (+NGF) or absence (-NGF) of 100nM NGF, were lysed and incubated with GST-tagged lysates of Rin1:SH2 domain, as explained in Material and Methods. The amount of Rin1 protein bound to the receptor was visualized using anti-NGFR antibody. Relative levels of proteins were determined by densitometry as described in Material and Methods. Data represent the mean $\pm S . E . M$. of three independent experiments. ${ }^{*} P<0.05$ by Student's t-test compared to NGF-stimulated cells. 


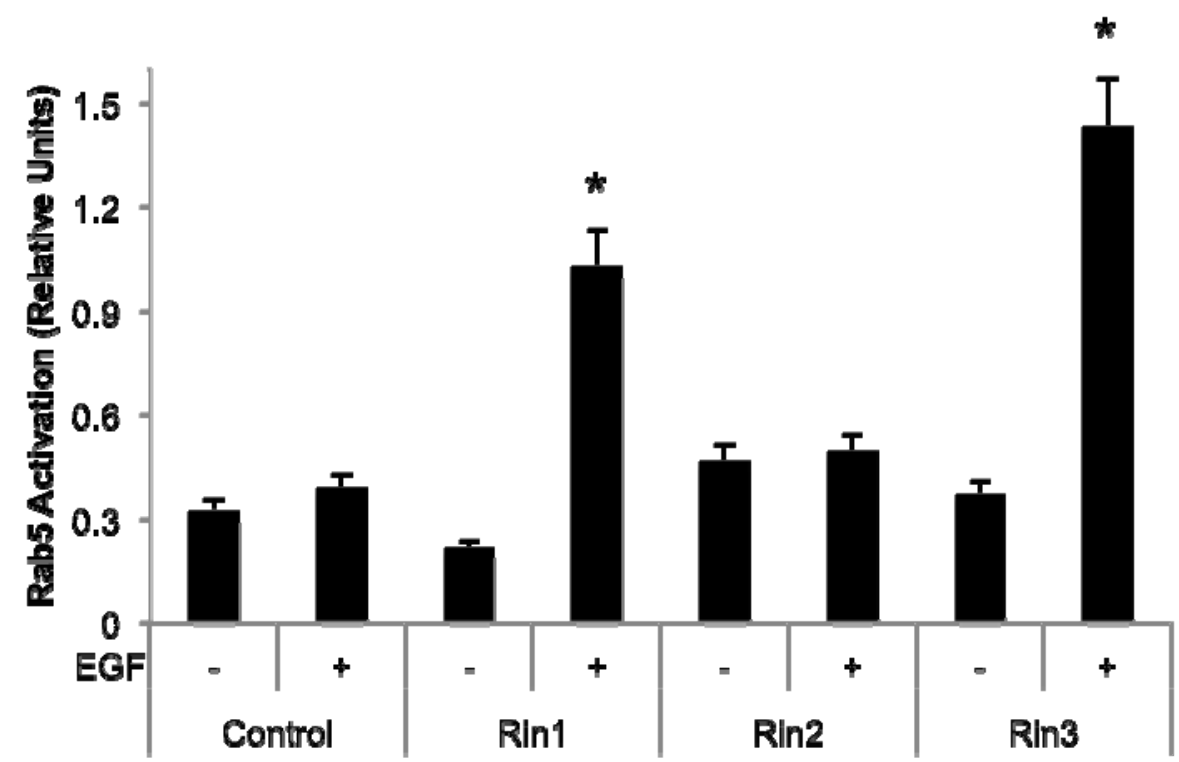

Figure 2.7. Rab5 activation in NR6 cells overexpressing EGFR and Rin proteins.

Rab5 activation was measured as described in Materials and Methods in NR6 control fibroblasts and cells overexpressing Rin1, Rin2 and Rin3 in the presence (+EGF) or absence (-EGF) of 100ng/ul EGF. Relative levels of proteins were determined by densitometry as described in Material and Methods. Data represent the mean \pm S.E.M. of three independent experiments. ${ }^{*} P<0.05$ by Student's t-test compared to EGF-stimulated cells. 


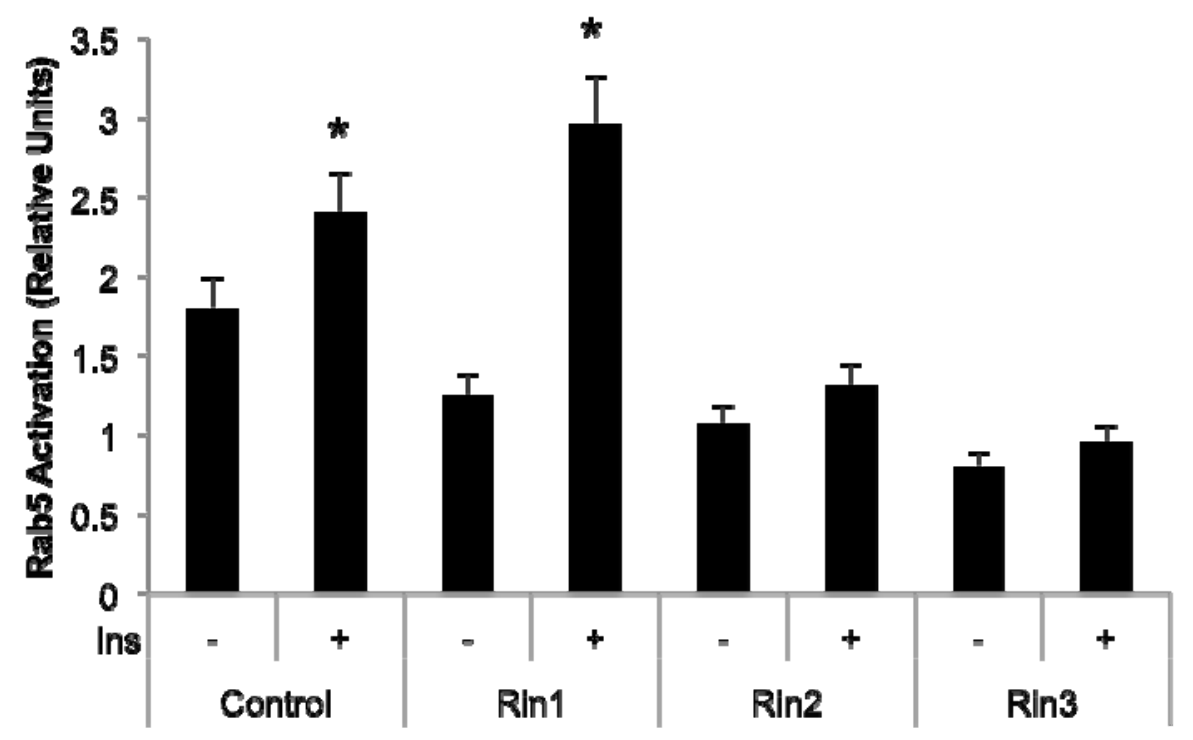

Figure 2.8. Rab5 activation in NIH3T3 cells overexpressing Rin1.

Rab5 activation was measured as described in Materials and Methods in NIH3T3 control fibroblasts and cells overexpressing Rin1, Rin2 and Rin3 in the presence $(+\operatorname{lns})$ or absence (-Ins) of $100 \mathrm{nM}$ insulin. Relative levels of proteins were determined by densitometry as described in Material and Methods. Data represent the mean \pm S.E.M. of three independent experiments. ${ }^{*} P<0.05$ by Student's t-test compared to insulin-stimulated cells. 


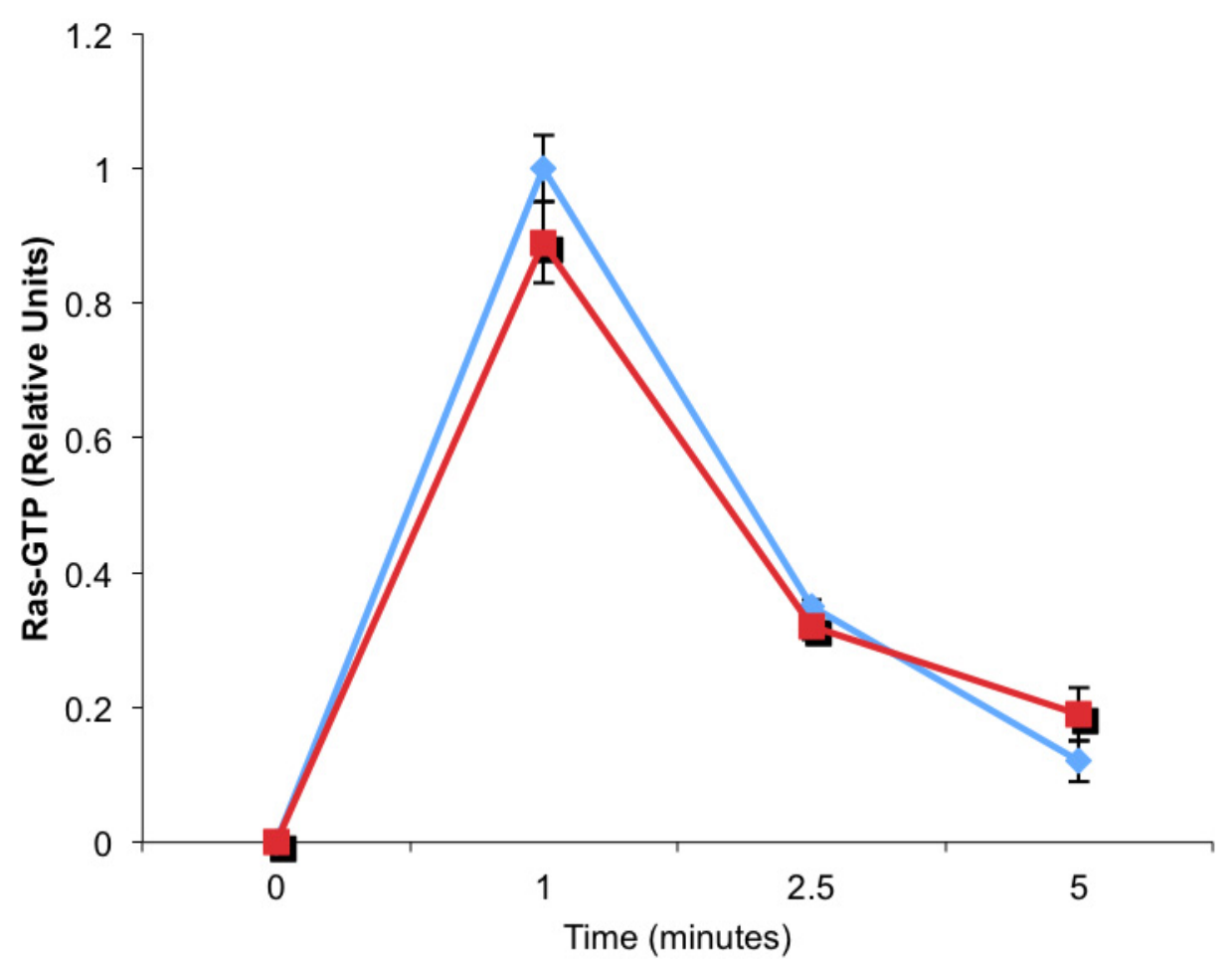

Figure 2.9. Ras activation in NR6 cells overexpressing Rin1.

NR6 cells expressing GFP (circle-blue) and Rin1:WT (square-red) were lysed and incubated with the GST-fused Ras binding domain of Raf . The pull-downs were subjected to SDS-PAGE and analyzed by Western blotting using an antipan Ras antibody. Relative Units (\% of maximum) of proteins were determined by densitometry using the ratio of active Ras to total-Ras. Data represent the mean \pm S.E.M. of three independent experiments. 

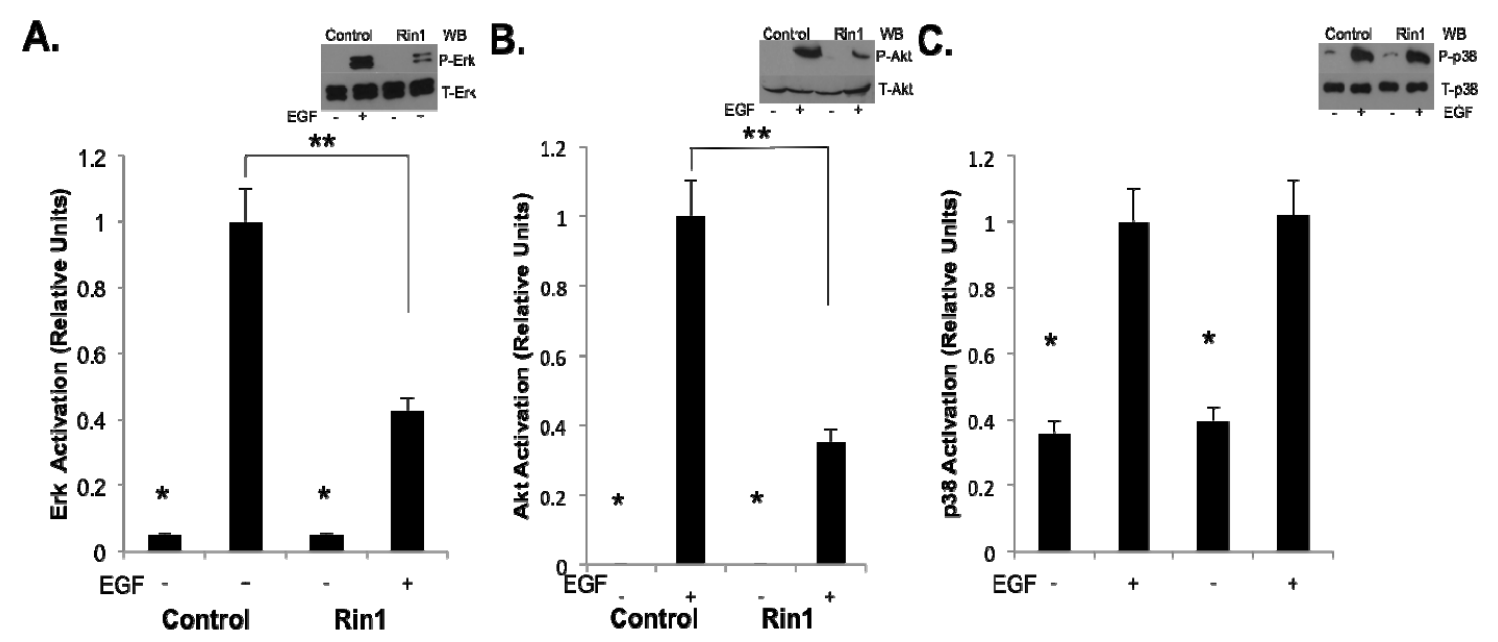

D.

E.
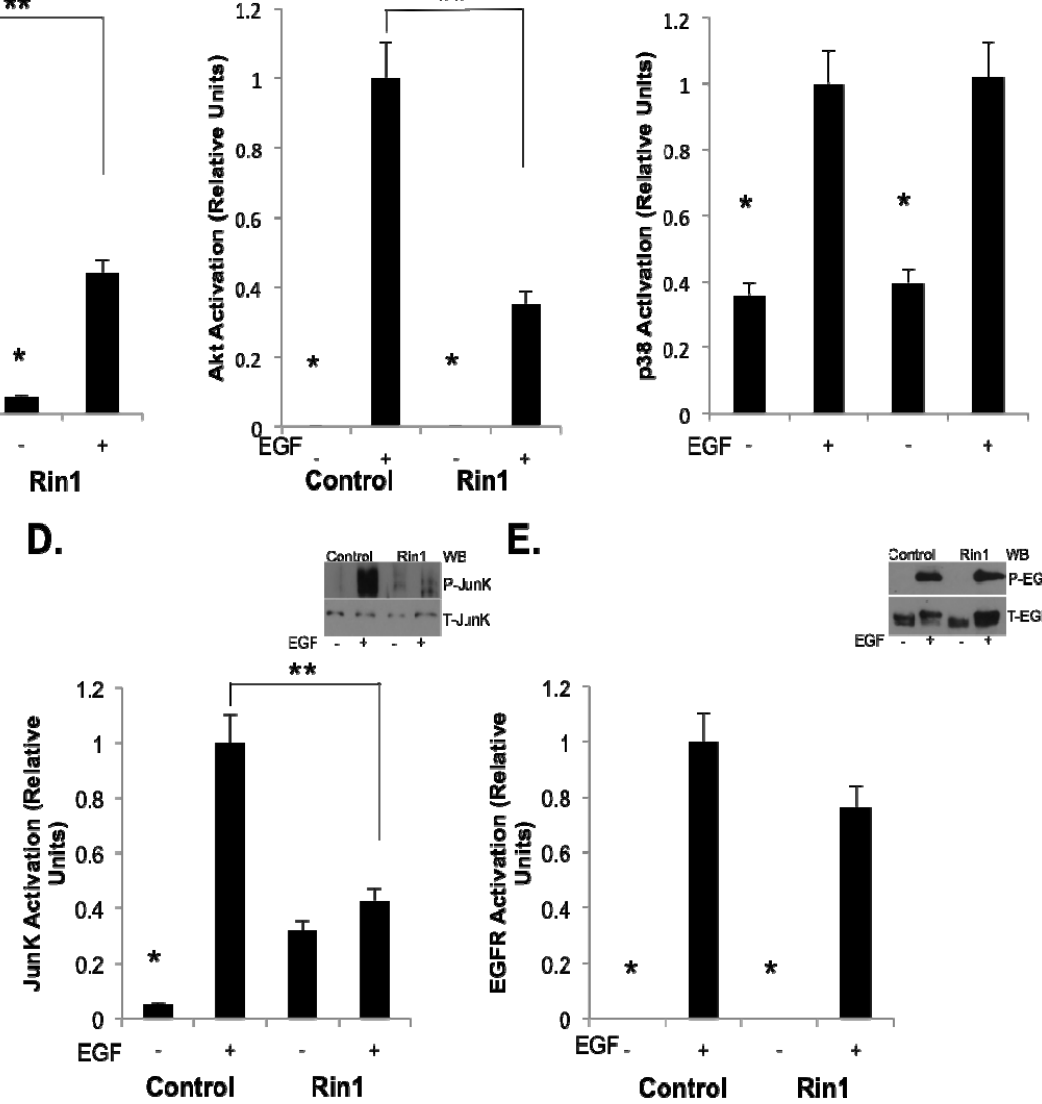

Figure 2.10. EGFR signaling in NR6 cells overexpressing Rin1.

NR6 fibroblasts control and cells overexpressing Rin1 were stimulated in the presence (+EGF) or absence (-EGF) of 100ng/ $\mu \mathrm{l} E G F$ and the effect on phosphorylation of Erk (A), Akt (B), p38 (C), Junk (D), and EGFR (E) was measured on total cell lysates using the appropriate antibodies. Relative levels of proteins were determined by densitometry as described in Material and Methods. Data represent the mean \pm S.E.M. of three independent experiments. ${ }^{*} P<0.05$ by Student's t-test compared to EGF-stimulated cells. ${ }^{* *} P<0.05$ by Student's t-test compared to Rin1 overexpressing/ EGF-stimulated cells. 
A.
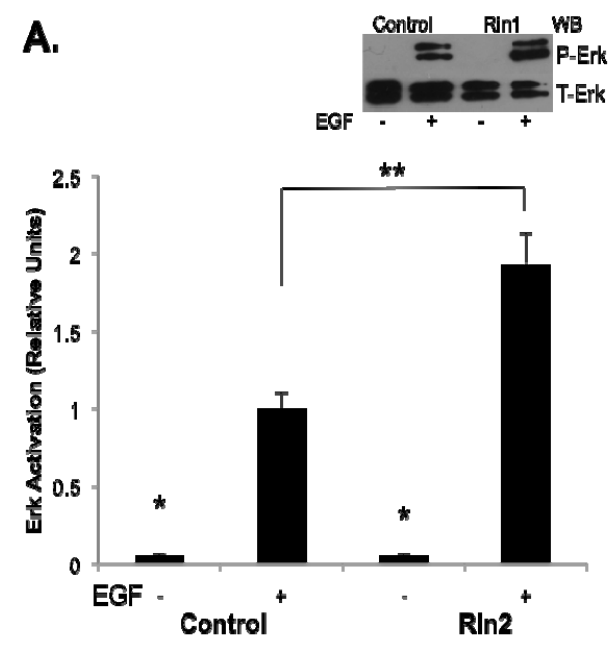

C.

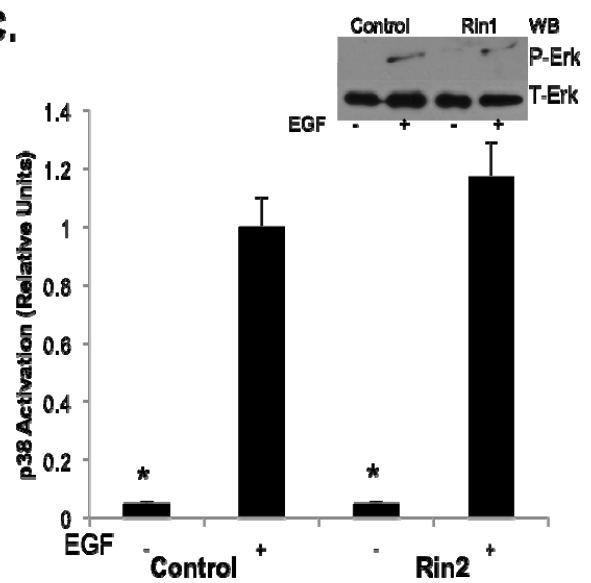

B.
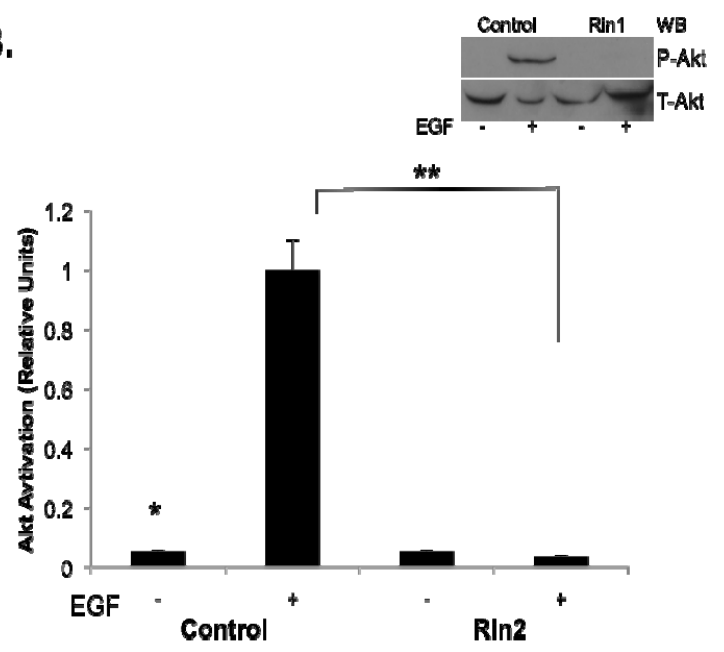

Figure 2.11. EGFR signaling in NR6 cells overexpressing Rin2.

NR6 fibroblasts control and cells overexpressing Rin2 were stimulated in the presence (+EGF) or absence (-EGF) of 100ng/ $/ \mathrm{l}$ EGF and the effect on phosphorylation of Erk (A), Akt (B) and p38 (C), was measured on total cell lysates using the appropriate antibodies. Relative levels of proteins were determined by densitometry as described in Material and Methods. Data represent the mean \pm S.E.M. of three independent experiments. ${ }^{*} P<0.05$ by Student's t-test compared to EGF-stimulated cells. ${ }^{* *} P<0.05$ by Student's t-test compared to Rin2 overexpressing/ EGF-stimulated cells. 


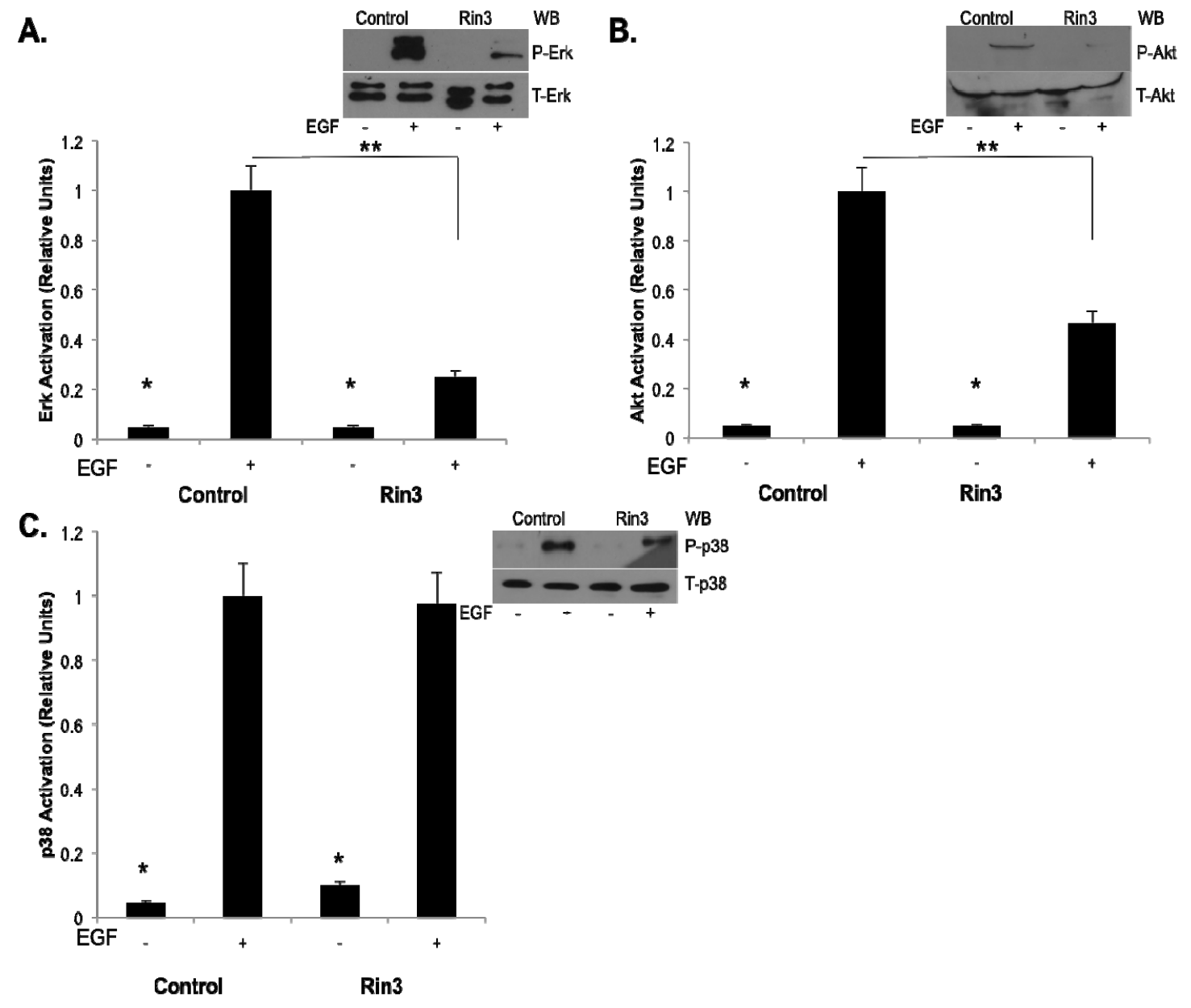

Figure 2.12. EGFR signaling in NR6 cells overexpressing Rin3.

NR6 fibroblasts control and cells overexpressing Rin3 were in the presence (+EGF) or absence (-EGF) of 100ng/ $\mu$ l EGF and the effect on phosphorylation of Erk (A), Akt (B) and p38 (C), was measured on total cell lysates using the appropriate antibodies. Relative levels of proteins were determined by densitometry as described in Material and Methods. Data represent the mean \pm S.E.M. of three independent experiments. ${ }^{*} P<0.05$ by Student's t-test compared to EGF-stimulated cells. ${ }^{* *} P<0.05$ by Student's t-test compared to Rin3 overexpressing/ EGF-stimulated cells. 
A.
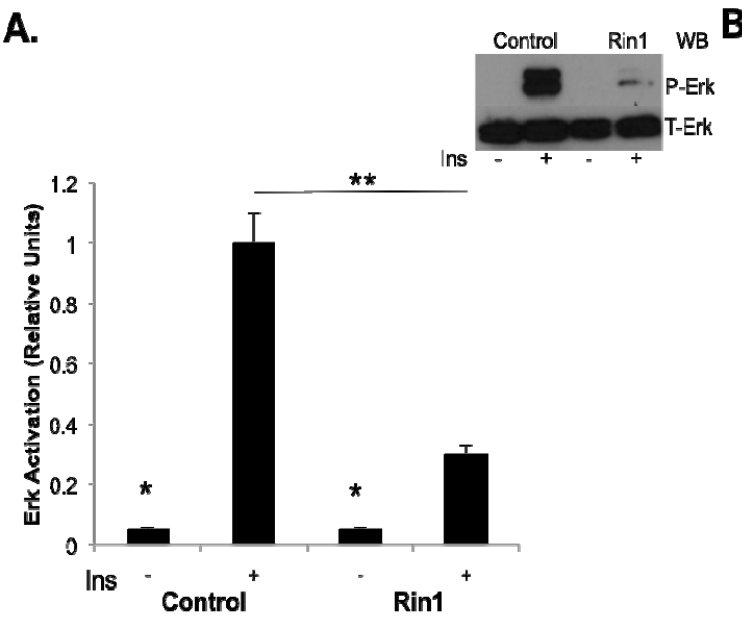

C.
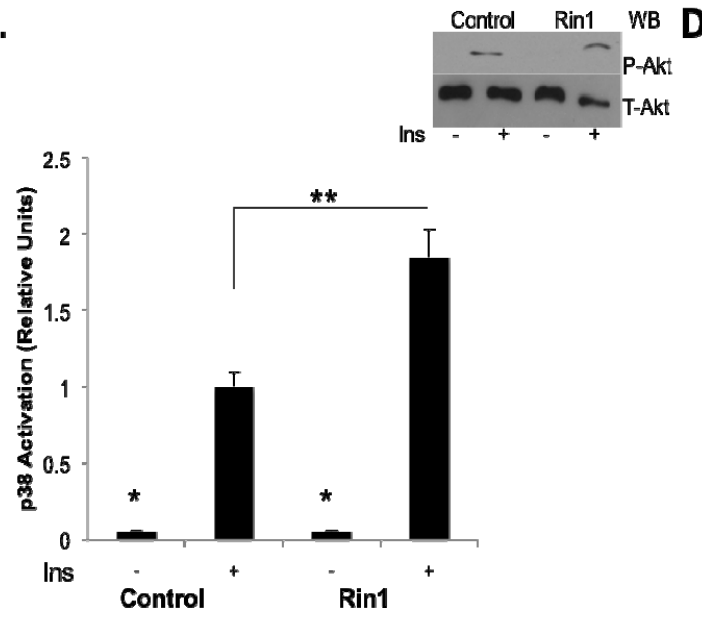

B.
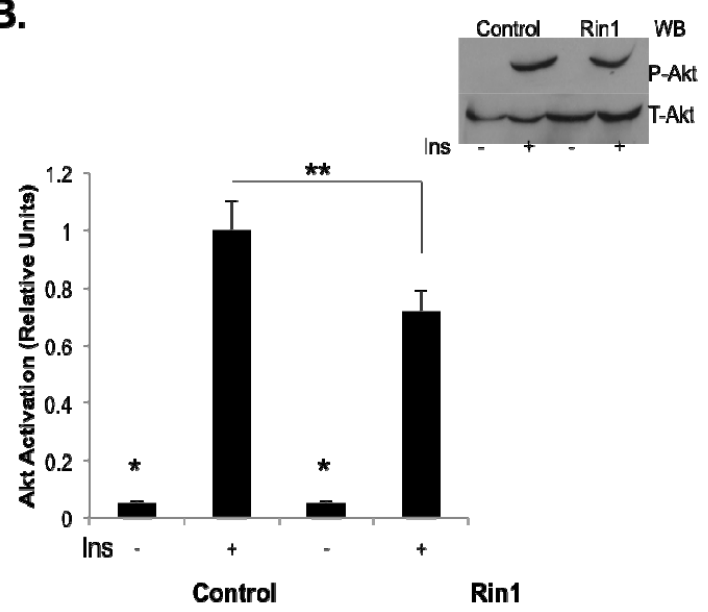

D.
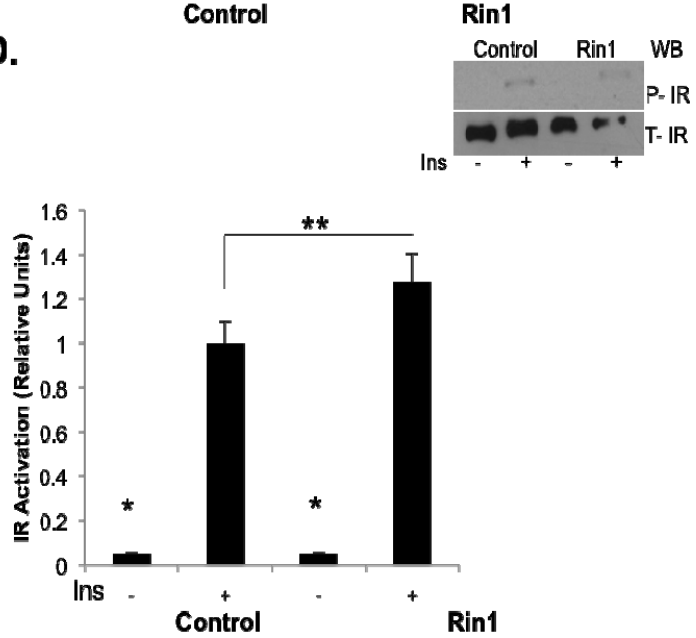

Figure 2.13. IR signaling in NIH3T3 cells overexpressing Rin1.

NIH3T3 fibroblasts control and cells overexpressing Rin1 were stimulated in the presence (+Ins) or absence (-Ins) of $100 \mathrm{nM}$ insulin and the effect on phosphorylation of Erk (A), Akt (B), p38 (C), and IR (D) was measured on total cell lysates using the appropriate antibodies. Relative levels of proteins were determined by densitometry as described in Material and Methods. Data represent the mean \pm S.E.M. of three independent experiments. ${ }^{*} P<0.05$ by Student's t-test compared to insulin-stimulated cells. ${ }^{* *} P<0.05$ by Student's t-test compared to Rin1 overexpressing/ EGF-stimulated cells. 
A.

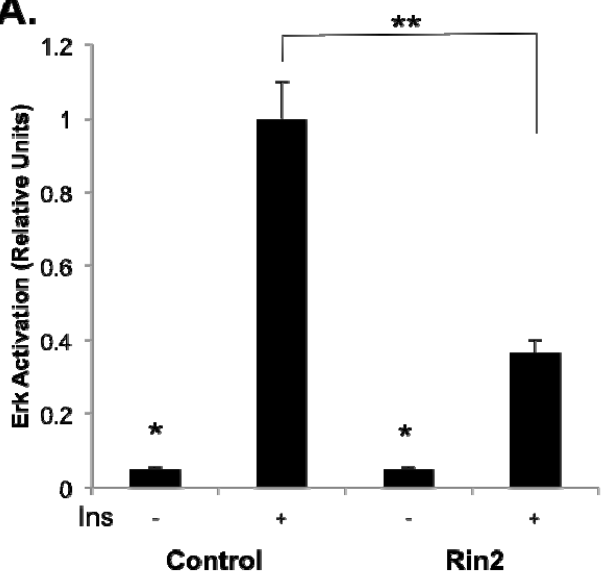

C.

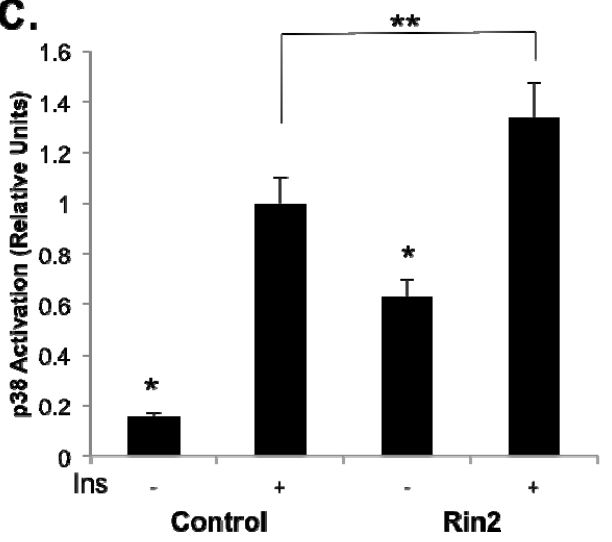

B.

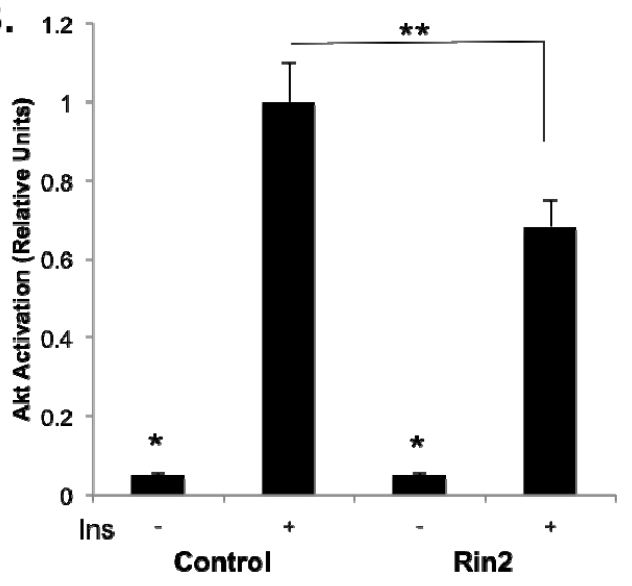

Figure 2.14. IR signaling in NIH3T3 cells overexpressing Rin2.

NIH3T3 fibroblasts control and cells overexpressing Rin2 were stimulated in the presence $(+\operatorname{lns})$ or absence (-Ins) of $100 \mathrm{nM}$ insulin and the effect on phosphorylation of Erk (A), Akt (B), and p38 (C) was measured on total cell lysates using the appropriate antibodies. Relative levels of proteins were determined by densitometry as described in Material and Methods. Data represent the mean \pm S.E.M. of three independent experiments. ${ }^{*} P<0.05$ by Student's t-test compared to insulin-stimulated cells. ${ }^{* *} P<0.05$ by Student's t-test compared to Rin2 overexpressing/ EGF-stimulated cells. 

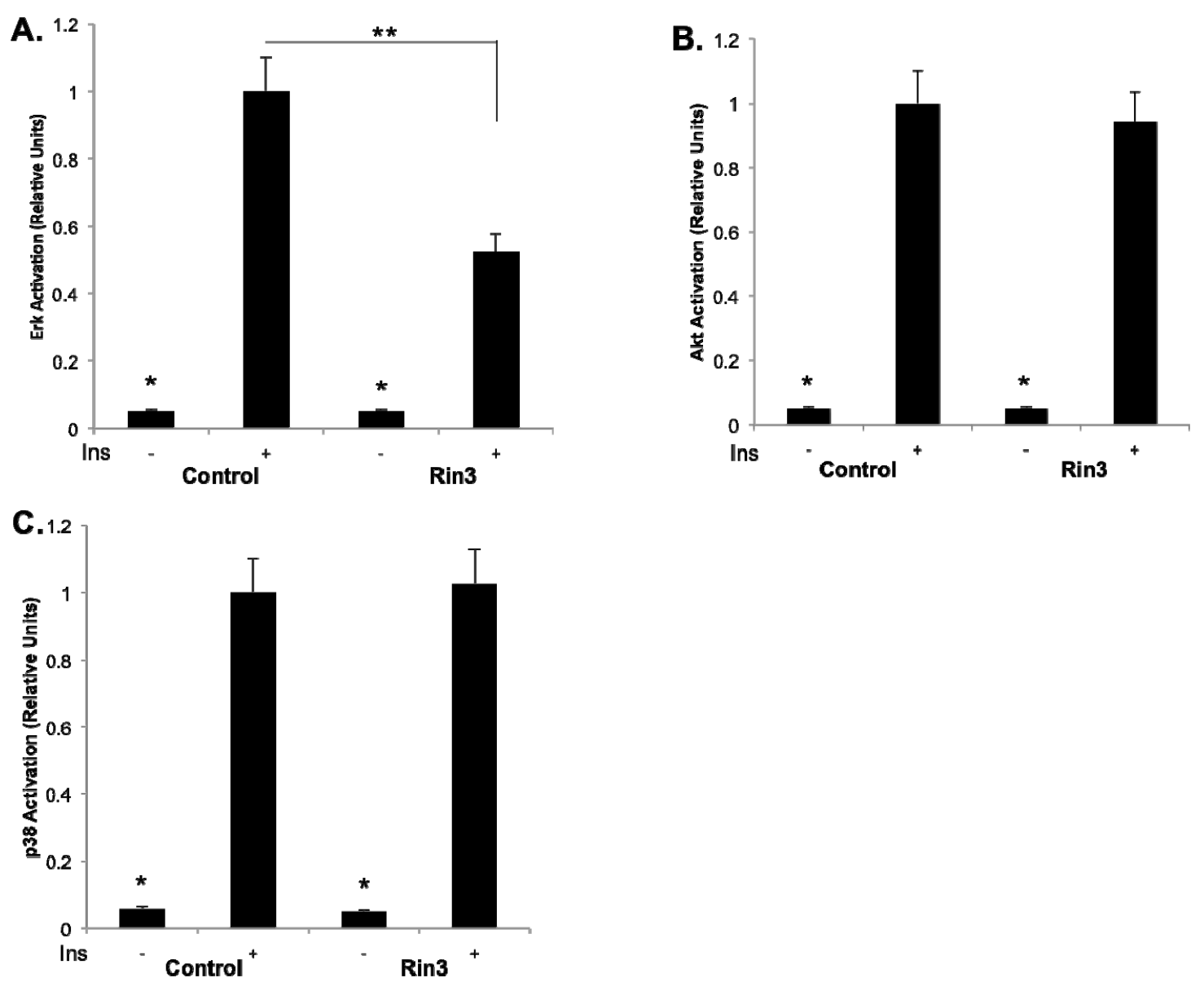

Figure 2.15. IR signaling in NIH3T3 cells overexpressing Rin3.

$\mathrm{NIH} 3 \mathrm{~T} 3$ fibroblasts control and cells overexpressing Rin3 were stimulated in the presence (+Ins) or absence (-Ins) of $100 \mathrm{nM}$ insulin and the effect on phosphorylation of Erk (A), Akt (B), and p38 (C) was measured on total cell lysates using the appropriate antibodies. Relative levels of proteins were determined by densitometry as described in Material and Methods. Data represent the mean \pm S.E.M. of three independent experiments. ${ }^{*} P<0.05$ by Student's t-test compared to insulin-stimulated cells. ${ }^{* *} P<0.05$ by Student's t-test compared to Rin3 overexpressing/ EGF-stimulated cells. 

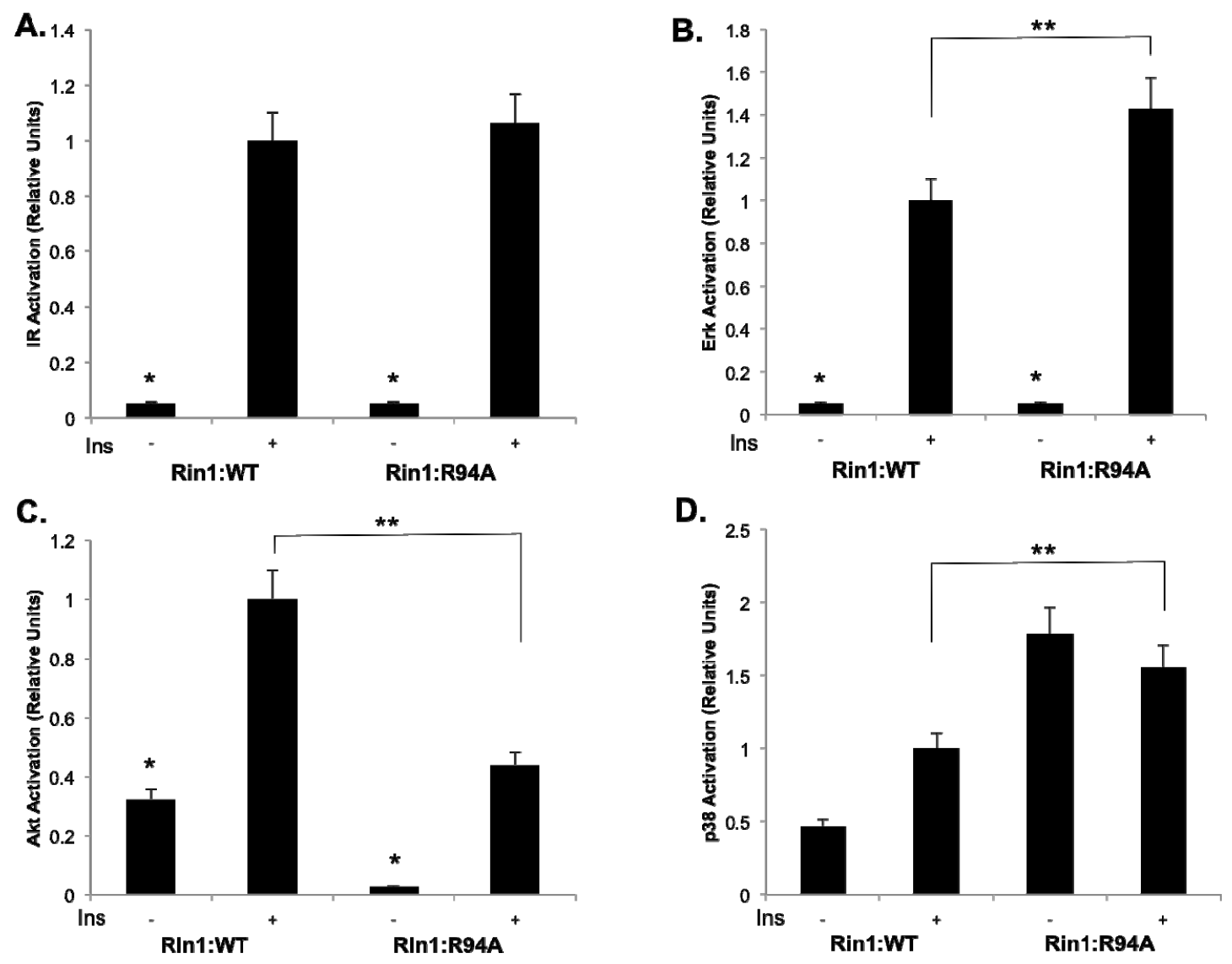

Figure 2.16. IR signaling in NIH3T3 cells overexpressing Rin1:R94A mutant. NIH3T3 fibroblasts overexpressing Rin1:WT (used as control) and Rin1:R94A were stimulated in the presence (+Ins) or absence (-Ins) of 100nM insulin and the effect on phosphorylation of IR (A) Erk (B), Akt (C), and p38 (D) was measured on total cell lysates using the appropriate antibodies. Relative levels of proteins were determined by densitometry as described in Material and Methods. Data represent the mean \pm S.E.M. of three independent experiments. ${ }^{*} P<0.05$ by Student's t-test compared to insulin-stimulated cells. ${ }^{* *} P<0.05$ by Student's t-test compared to Rin1:WT overexpressing/ EGF-stimulated cells. 

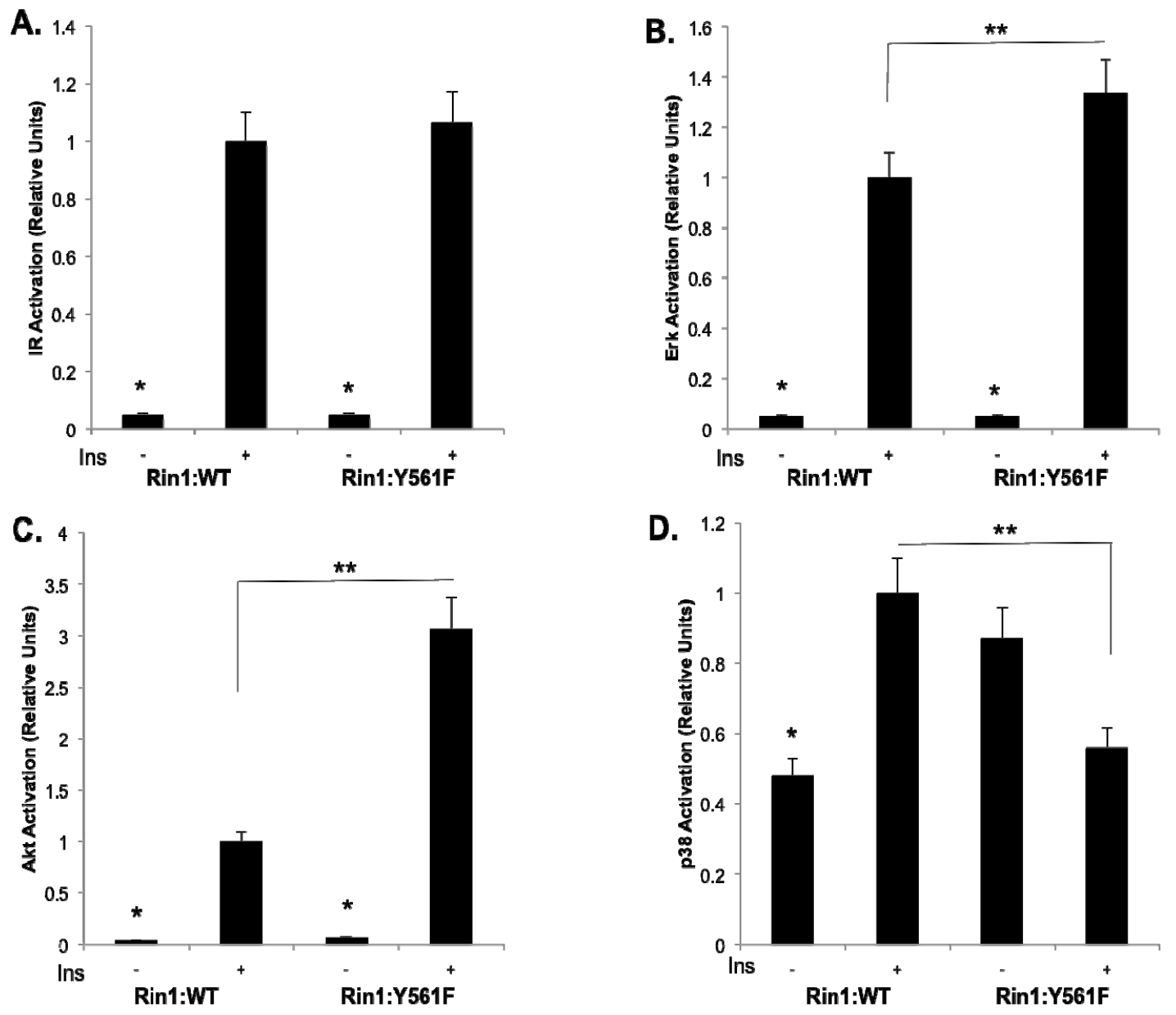

Figure 2.17. IR signaling in NIH3T3 cells overexpressing Rin1: Y561F mutant.

NIH3T3 fibroblasts overexpressing Rin1:WT (used as control) and Rin1:Y561F were stimulated in the presence (+Ins) or absence (-Ins) of $100 \mathrm{nM}$ insulin and the effect on phosphorylation of IR (A) Erk (B), Akt (C), and p38 (D) was measured on total cell lysates using the appropriate antibodies. Relative levels of proteins were determined by densitometry as described in Material and Methods. Data represent the mean \pm S.E.M. of three independent experiments. ${ }^{*} P<0.05$ by Student's t-test compared to insulin-stimulated cells. ${ }^{* *} P<0.05$ by Student's t-test compared to Rin:WT overexpressing/ EGF-stimulated cells. 

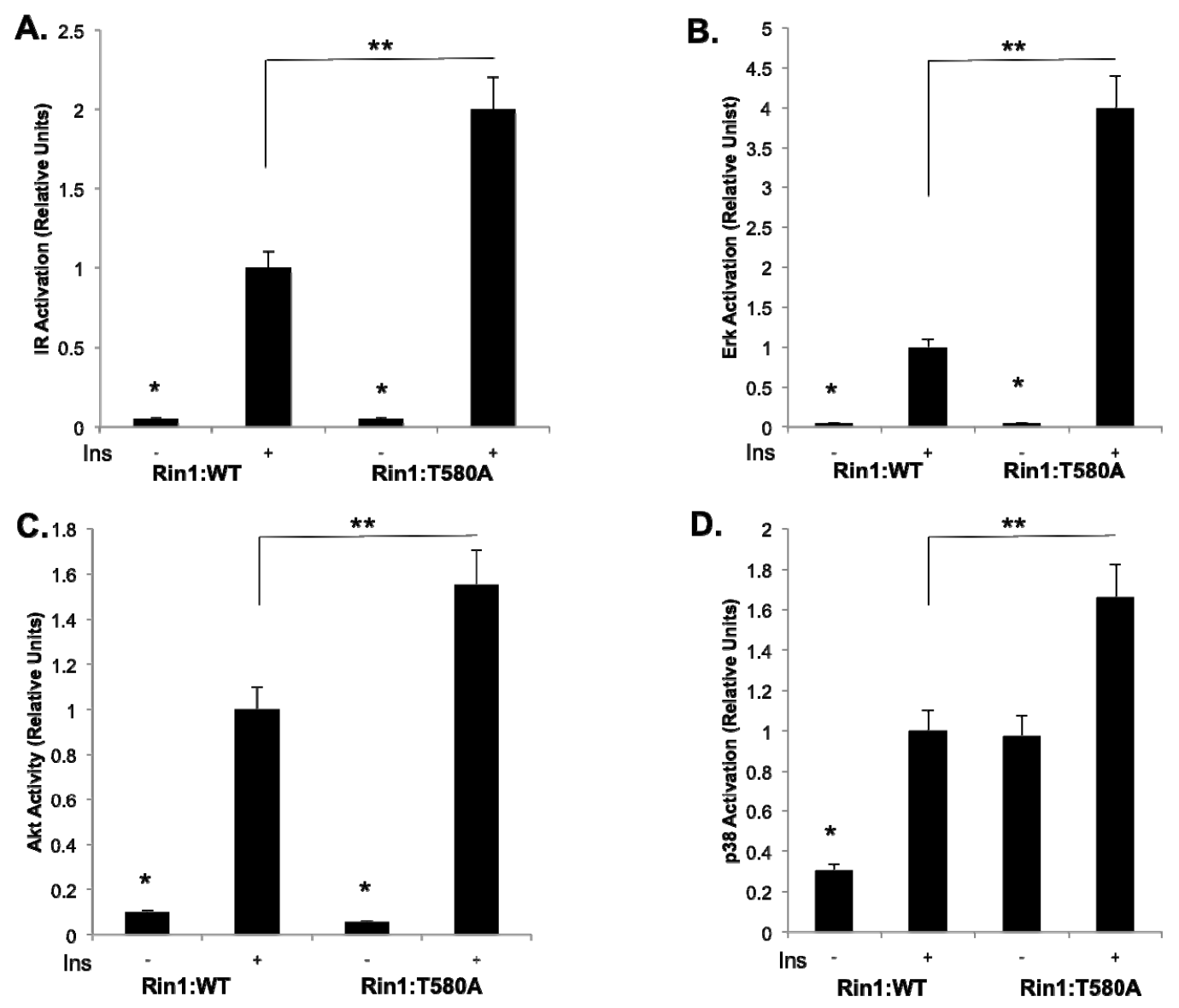

Figure 2.18. IR signaling in NIH3T3 cells overexpressing Rin1: T580A mutant.

NIH3T3 fibroblasts overexpressing Rin1:WT (used as control) and Rin1:T580A were stimulated in the presence $(+\operatorname{lns})$ or absence $(-\operatorname{lns})$ of $100 \mathrm{nM}$ insulin and the effect on phosphorylation of IR (A) Erk (B), Akt (C), and p38 (D) was measured on total cell lysates using the appropriate antibodies. Relative levels of proteins were determined by densitometry as described in Material and Methods. Data represent the mean \pm S.E.M. of three independent experiments. ${ }^{*} P<0.05$ by Student's t-test compared to insulin-stimulated cells. ${ }^{* *} P<0.05$ by Student's t-test compared to Rin1:WT overexpressing/ EGF-stimulated cells. 

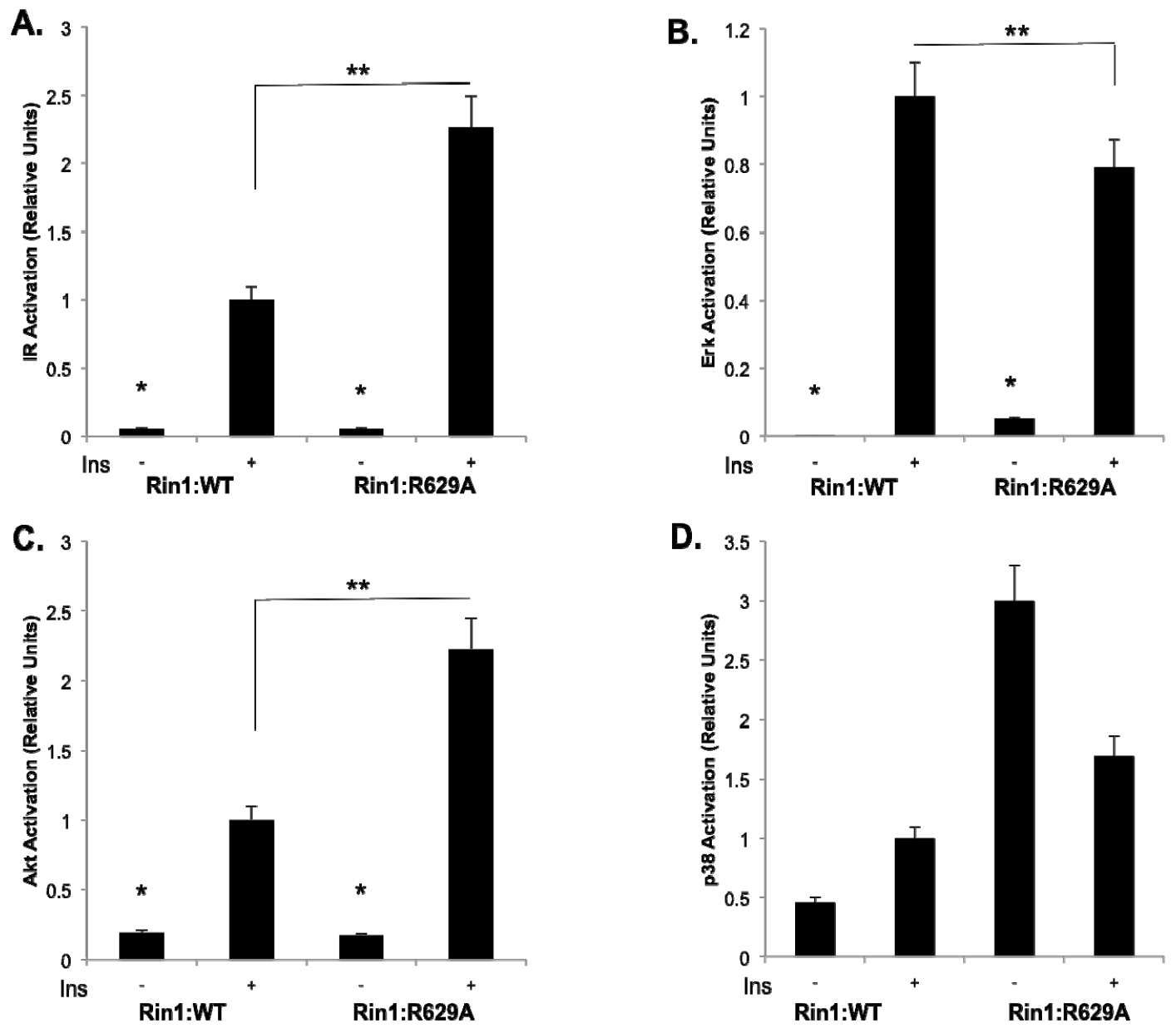

Figure 2.19. IR signaling in NIH3T3 cells overexpressing Rin1:R629A mutant.

NIH3T3 fibroblasts overexpressing Rin1:WT (used as control) and Rin1:R629A were stimulated in the presence (+Ins) or absence (-Ins) of $100 \mathrm{nM}$ insulin and the effect on phosphorylation of IR (A) Erk (B), Akt (C), and p38 (D) was measured on total cell lysates using the appropriate antibodies. Relative levels of proteins were determined by densitometry as described in Material and Methods. Data represent the mean \pm S.E.M. of three independent experiments. ${ }^{*} P<0.05$ by Student's t-test compared to insulin-stimulated cells. ${ }^{* *} P<0.05$ by Student's t-test compared to Rin1:WT overexpressing/ EGF-stimulated cells. 


\section{THE ROLE OF RIN1 (AND RIN1-LIKE MOLECULES) IN SIGNALING}

\section{TRANSDUCTION PATHWAYS INVOLVED IN CELL DIFFERENTIATION.}

Cell proliferation, differentiation, and apoptosis are exceptionally similar processes in both normal and diseased cells. However, they show unique traits. Cell proliferation is a complex molecular mechanism that involves the regulation of genes. These genes are required for cell division cycle, which is an orderly and unidirectional transition from one cell cycle phase to the next. Cell differentiation is a process in which a cell develops into certain type upon specific stimulation. Cell differentiation changes a cell's size, shape, intracellular metabolism, and more important it is sensitive to external signals. These changes are largely the result of highly controlled and regulated gene expression upon stimulation. Several in vitro differentiation systems have been described. Here, two in vitro differentiation systems, 3T3L1 preadipocytes and PC12 cells, are studied.

Adipogenesis is the formation of adipocytes (fat cells) from preadipocytes. Different types of hormones and signaling cascades, including insulin, regulate this process. To study adipogenesis in vitro, preadipocytes cells are exposed to an induction cocktail composed of insulin, dexamethasone (dexa) and 1-Methyl3-Isobutylxanthine (IBMX). The induction cocktail actives adipogenic factors C/EPB $\beta$ and $\delta$, which are responsible for the activation of C/EBPa and PPARY. The last ones are key regulators of adipogenesis; they are responsible for the morphological and transcriptional changes in adipocytes. Ras interference 1, as explained above, is a multifunctional protein involved both in the internalization 
and signal transduction of IR. In the present study 3T3-L1 preadipocytes cells were used to determine the effects of Rin1 (its domains and Rin1-like molecules) during the differentiation process. Several Rin1 point mutations as well as Rin1 deletion mutants were created on key amino acids that affect the function of each domain in order to analyze their effects on preadipocyte differentiation in vitro.

Ras interference 1 is part of a protein family composed of two other members: Rin2 and Rin3. The three of them share a highly conserved Vps9 domain that activates Rab5. Figure 3.1 shows the endogenous expression levels of Rab5 and Rin1 in days 1, 3, 5 and 10 of differentiation. The expression of Rab5 increases until day 5, and then there is a decrease up to day 10 (Figure 3.1A). In the case of Rin1, it highly expressed in fibroblasts, and upon stimulation, there is a constant decrease (Figure 3.1B). To study the effect of Rin proteins in 3T3-L1 differentiation, stable cell lines were done, differentiated for ten days and the lipid droplet formation quantified as explained in Materials and Methods. Figure 3.2A shows that individual overexpression of Rin proteins inhibited adipocyte differentiation. Ras interference 1 showed the greater inhibitory effect. In contrast, when Rin1 is depleted by RNAi, the inhibitory effect was not observed (Figure 3.2B).

To determine which specific domain of Rin1 is responsible for the inhibitory effect on adipocyte differentiation, the $\mathrm{N}$ - (Rin1:R2), C-terminus (Rin1:R3) and each individual domain were cloned and overexpressed in 3T3-L1 cells (Figure 3.3). Following the protocol described in Material and Methods section, the lipid droplet formation was quantified at day 10 of differentiation and 
is showed in Figure 3.2C. As expected, the C-terminus (Rin1:R3) and the Vps9 domain alone (Rin1:R4) were enough to produce the inhibitory effect. Surprisingly, the same was observed for each individual domain ( $\mathrm{SH} 2$ and $\mathrm{RA}$ ) and for the N-terminus. All of them had a similar inhibitory effect as Rin1:WT.

To confirm the morphological effects and lipid quantification, expression of key adipogenic markers (C/EBPa and PPARY) and signaling proteins (Erk and Akt) were studied on day 10 of differentiation of all cell lines overexpressing Rin1 and its domains. Figure 3.4 shows that the expression of both C/EBPa (Figure 3.4A) and PPARy (Figure 3.4B) is inhibited compared to control cells, supporting the morphological and lipid quantification data. The expression of PPARY is dramatically inhibited, which explains why the cells overexpressing Rin1 resemble a fibroblast-like shape instead of an adipocyte one. PPARY is known to be the master regulator of adipocyte differentiation; its expression in the cell is absolutely necessary in order for adipogenesis to occur. On the other hand, activation of important signaling proteins such as Erk (Figure 3.4C) and Akt (Figure 3.4D), does not seem to be affected by the overexpression of Rin1. These observations may suggest that the mechanism used by Rin 1 to inhibit adipogenesis is independent from the Erk and PI3K signaling pathways. Figure 3.5 shows that the different Rin 1 domains have the same inhibitory tendency on the adipogenic markers as Rin1:WT. Again, PPARy (Figure 3.5B) is the one inhibited the most, even though the higher inhibition is observed by the expression of Rin1:WT, but not by the expression of any specific Rin1 domain. 
In an effort to elucidate which Rin1 domain(s) is/are required in the inhibition of differentiation, the following key amino acids (for the proper functioning) of the $\mathrm{SH} 2, \mathrm{Vps} 9$ and RA domains were mutated and overexpressed as described in Material and Methods section: Rin1:R94A, Rin1:Y561F, Rin1:R94A+Y561F, Rin1:T580A and Rin1:R629A. Each mutant is able to reverse the inhibitory effect shown by its domain, as it is shown in Figure 3.6. The same is observed in the expression of the key adipogenic markers: the Rin1 mutants are almost able to restore the normal expression levels for C/EBPa and PPARY (Figure 3.7A and B, respectively). The effect of the Rin1 mutants supports previous morphological and biochemical data that show that all the domains play an important role in the inhibitory effect that Rin1 has in adipocyte differentiation (Figure 3.3).

In order to understand the molecular mechanism by which Rin1 inhibits in vitro differentiation of 3T3-L1 cells, controls as well as Rin1-overexpressing cells were differentiated and the activation of CREB was analyzed at days 1, 3, 5 and 10 of treatment. Figure 3.8 shows that activation of CREB increases during differentiation of control cells, opposite to what is seen in Rin1-overexpressing cells: a decrease during the differentiation treatment. Even though these data is complex to explain, it is the only difference in signaling that has been found so far when Rin1 is overexpressed, so it may help elucidate the exact mechanism by which Rin1 inhibit 3T3-L1 preadipocyte differentiation.

To investigate whether Rin1 has a similar inhibitory effect in other cell differentiation systems, a second differentiation system was studied. PC12 cells 
overexpress the TrkA receptor and respond to NGF differentiating into neuronlike cells with neurite projections. PC12 cells overexpressing Rin1, Rin2 and Rin3 were exposed to NGF for ten days and the neurite projections were measured.

Cells overexpressing the Rin proteins were NGF stimulated and the neurite growth quantified 10 days later as described in Materials and Methods. Figure 3.9 shows that any of the Rin proteins have a major effect on PC12 differentiation (percentage of differentiated cells: Control $57.23 \%$, Rin1: $47.62 \%$, Rin2 $56.5 \%$ and $\operatorname{Rin} 350.5 \%$ ). Overexpression of Rin1, Rin2 or Rin3 has no effect on the amount of cells that actually commit to differentiation, or in the length of the neurite projections. The fact that there seems to be no major effect by Rin1 in PC12 differentiation compared to its regulatory role in 3T3-L1 differentiation, may suggest a receptor and cell specific role of Rin1. 
A.

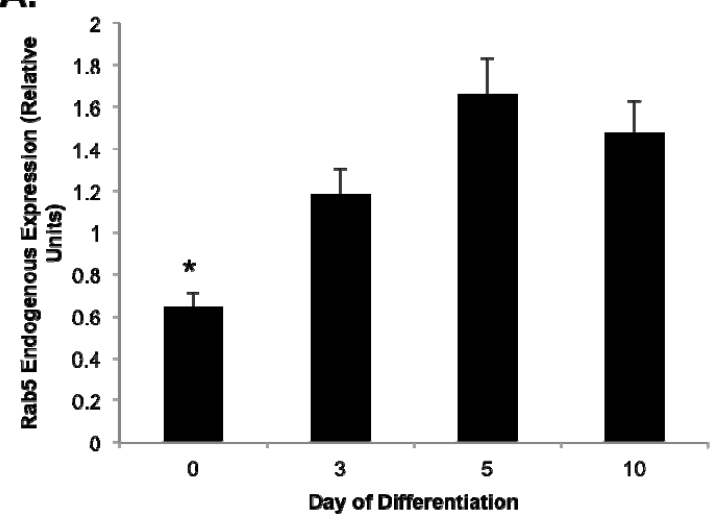

B.

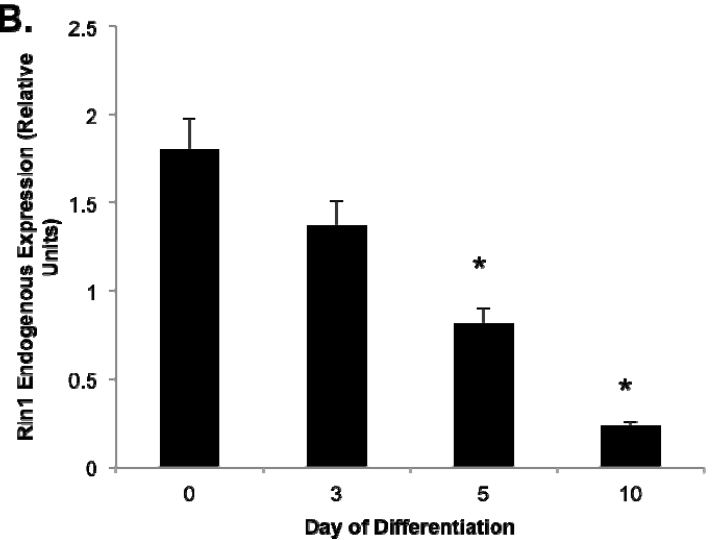

Figure 3.1. Rab5/ Rin1 endogenous expression during 3T3-L1 differentiation.

3T3-L1 preadipocytes were induced to differentiate by induction media into adipocytes as explained in Material and Methods. Total protein extracts were prepared at day $0,3,5$, and 10 . The proteins were subset to $12 \%$ SDS PAGE electrophoresis, blotted to a nitrocellulose membrane, and probed with antibodies specific to Rab5 (A) and Rin1 (B). Relative levels of proteins were determined by densitometry as described in Material and Methods. Data represent the mean \pm S.E.M. of three independent experiments. ${ }^{*} P<0.05$ by Student's t-test. 

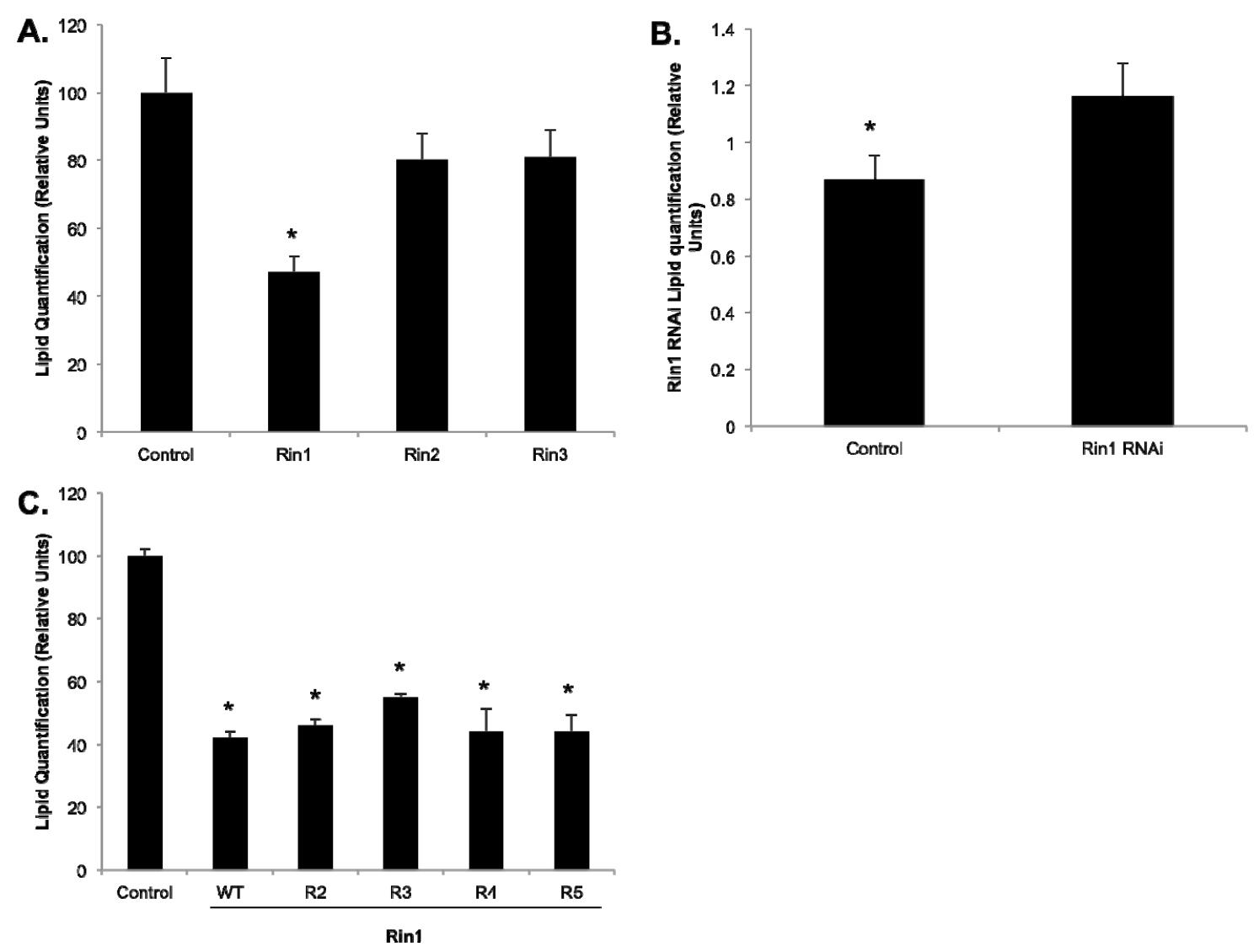

Figure 3.2. Lipid droplet quantification in cells overexpressing Rin proteins and Rin1 domains.

(A) 3T3-L1 preadipocytes overexpressing Rin1, Rin2 and Rin3 proteins were differentiated for 10 days as described in Material and Methods. Lipid quantification was done and compared to control cells. Results were represented as Relative Units (relative lipid contents). The data represent the mean $+/$ - SEM of 3 independent experiments. (B) 3T3-L1 preadipocytes were transfected with Rin1 RNAi for different period of times during the differentiation process as described in Material and Methods. Lipid quantification was done on day 10 and compared to control cells. Results were represented as Relative Units (relative lipid contents). The data represent the mean +/- SEM of 3 independent experiments. (C) 3T3-L1 preadipocytes overexpressing Rin1 domains were differentiated as explained above. Lipid quantification is compared to control and cells overexpressing Rin1. Results were represented as Relative Units (relative lipid contents). The data represent the mean +/- SEM of 3 independent experiments. ${ }^{*} P<0.05$ by Student's t-test compared to control cells. 


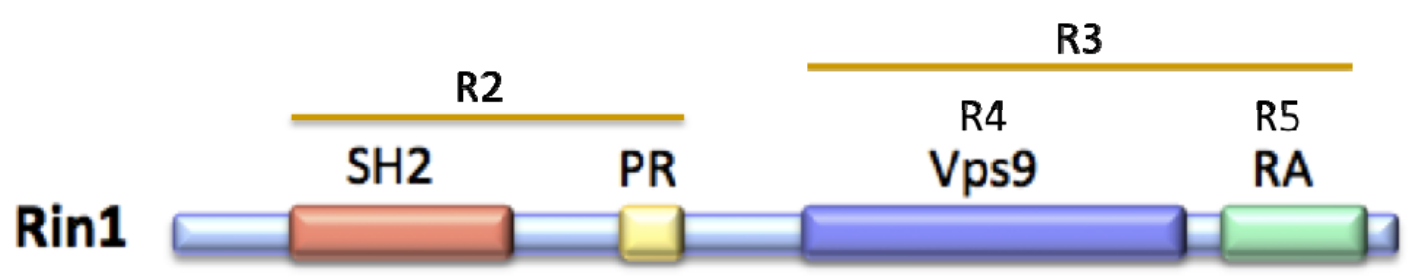

Figure 3.3. Different constructs of the domains of Rin1.

$\mathrm{R} 2$ represents the $\mathrm{N}$-terminus of the protein containing the $\mathrm{SH} 2$ and $\mathrm{PR}$ domains. $\mathrm{R} 3$ represents the $\mathrm{C}$-terminus of Rin1 containing the Vps9 and RA domains. R4 represents the Vps9 domain, and R5 the RA domain. 


\section{A. C/EBPa}
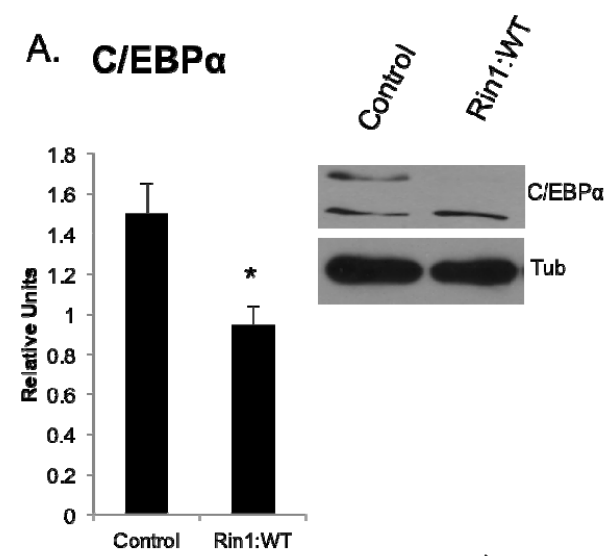

C. P-Erk

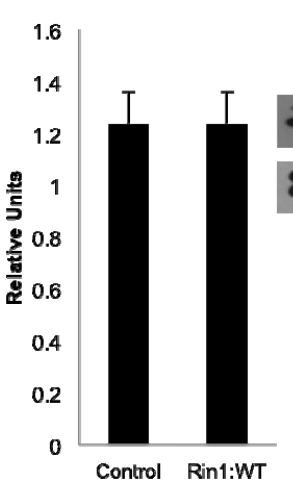

B. PPARY
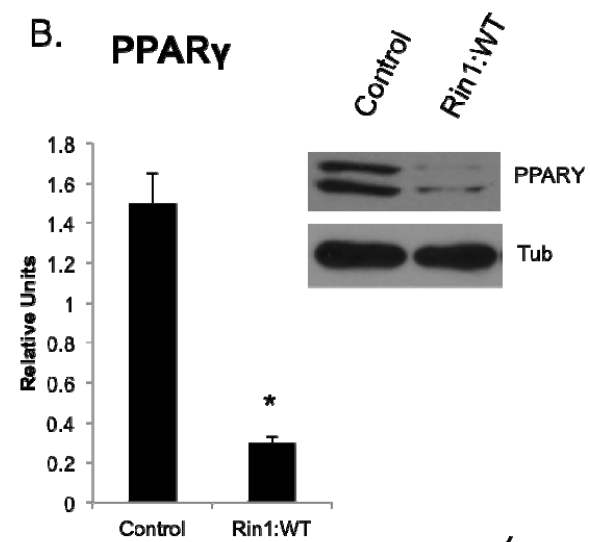

D.
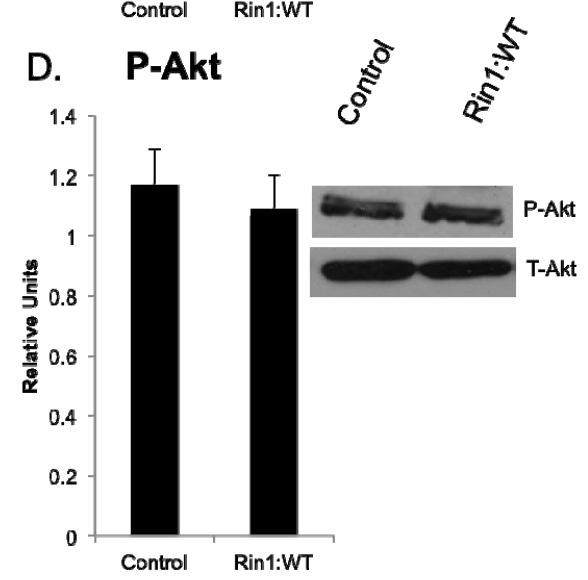

Figure 3.4. Adipogenic markers expression in cells overexpressing Rin1.

3T3-L1 preadipocytes overexpressing Rin1:WT were differentiated for 10 days and total protein extracts were prepared as described in Material and Methods. Total protein extracts were subset to $10 \%$ SDS-PAGE electrophoresis, blotted to a nitrocellulose membrane and probed against the following antibodies: (A) C/EBPo, (B) PPARy, (C) P-Erk and T-Erk, (D) P-Akt and T-Akt. Results were represented as Relative Units (relative lipid contents). Relative levels of proteins were determined by densitometry as described in Material and Methods. Data represent the mean \pm S.E.M. of three independent experiments. ${ }^{*} P<0.05$ by Student's t-test compared to control cells. 
A.

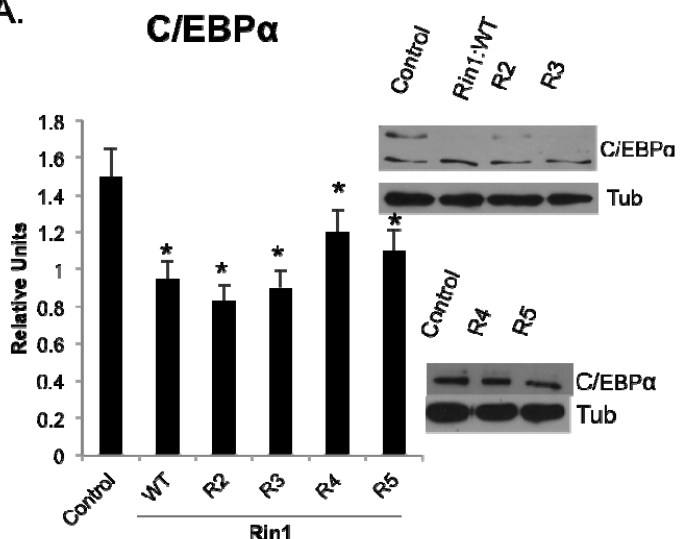

C.
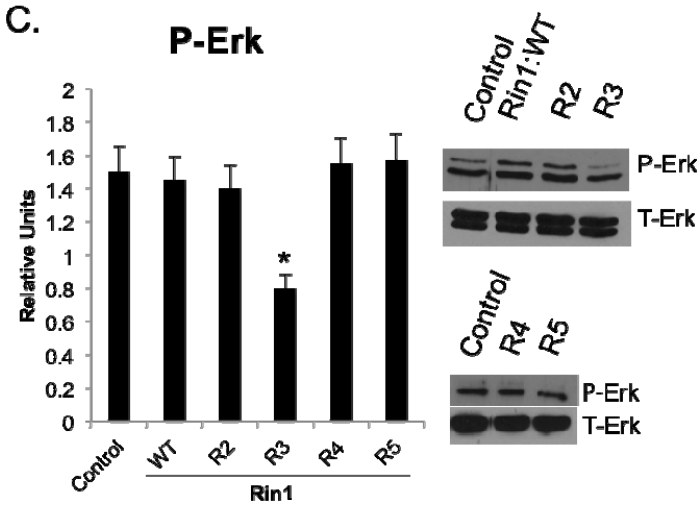

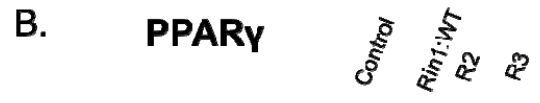

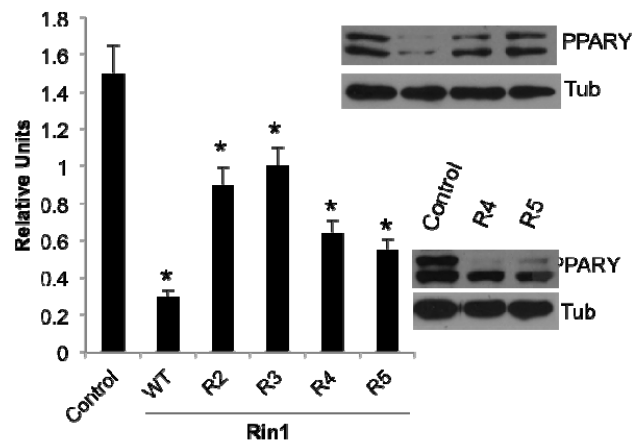

Figure 3.5. Adipogenic markers expression in cells overexpressing the different Rin1 domains.

3T3-L1 preadipocytes overexpressing Rin1 and the different domains were differentiated and total protein extracts were obtained as explained above. The nitrocellulose membrane was probed against (A) C/EBP $\alpha$, (B) PPARy and (C) PErk. Results were represented as Relative Units (relative lipid contents). Relative levels of proteins were determined by densitometry as described in Material and Methods. Data represent the mean \pm S.E.M. of three independent experiments. ${ }^{*} P<0.05$ by Student's t-test compared to control cells. 


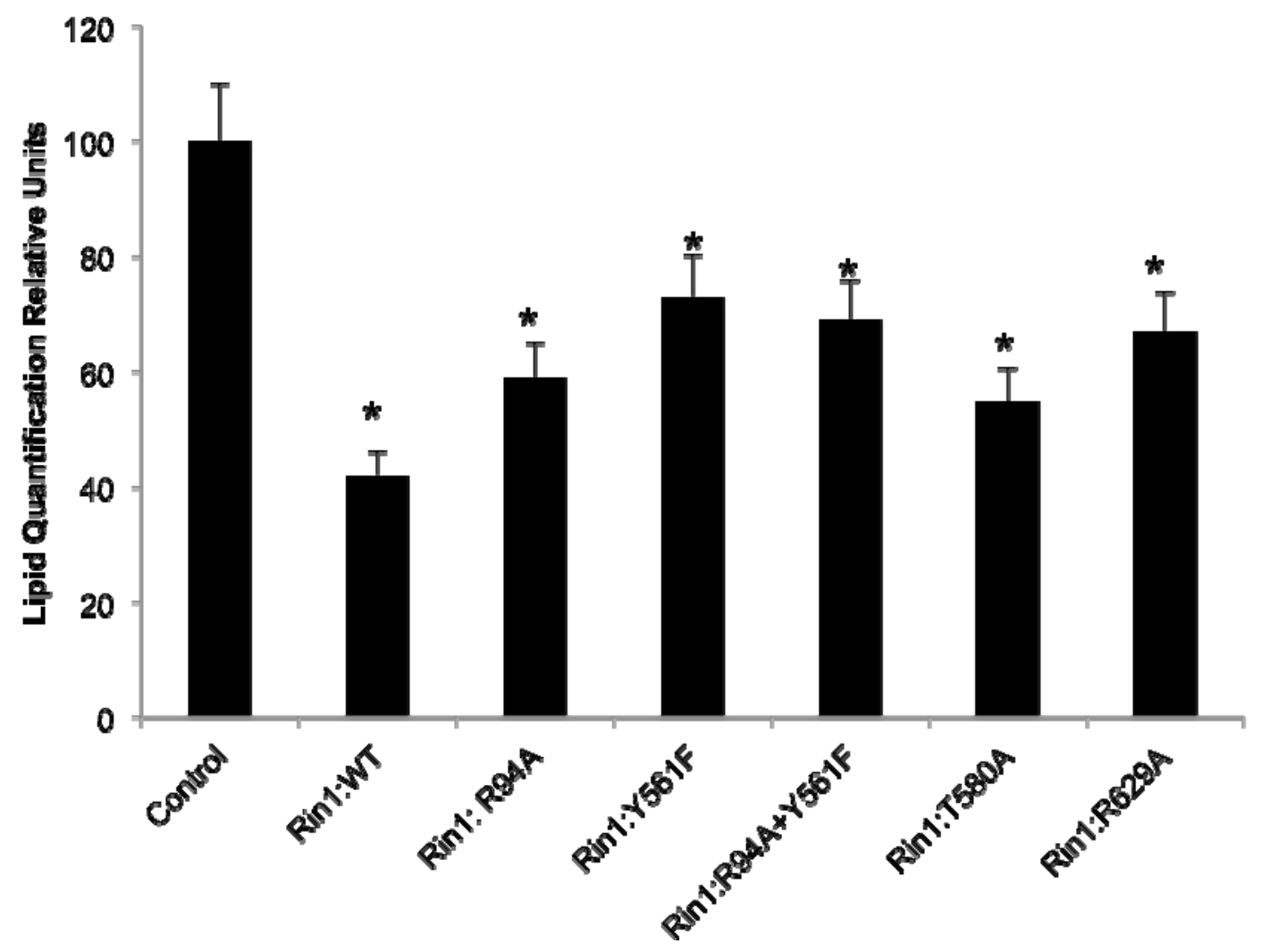

Figure 3.6. Lipid droplet quantification in cells overexpressing Rin1 mutants.

3T3-L1 preadipocytes overexpressing Rin1:WT and the following mutants: R94A, Y561F, R94A+Y561F, T580A and R629A, were differentiated for 10 days as described in Material and Methods. Lipid quantification was done and compared to control cells. Results were represented as Relative Units (relative lipid contents). The data represent the mean +/- SEM of 3 independent experiments. ${ }^{*} P<0.05$ by Student's t-test compared to control cells. 
A. C/EBPa

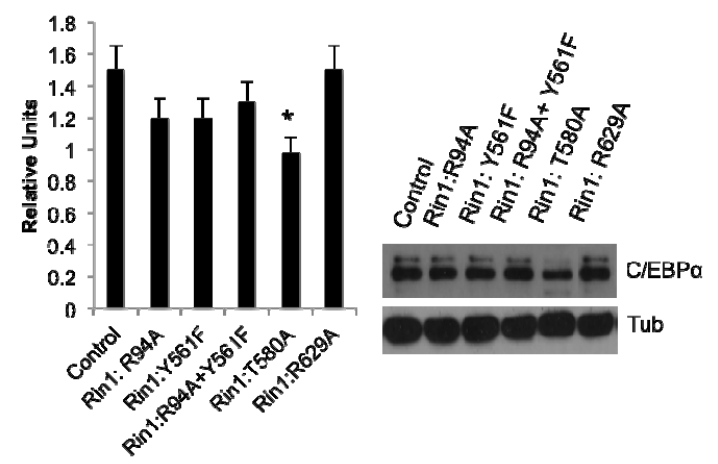

\section{P-Erk}

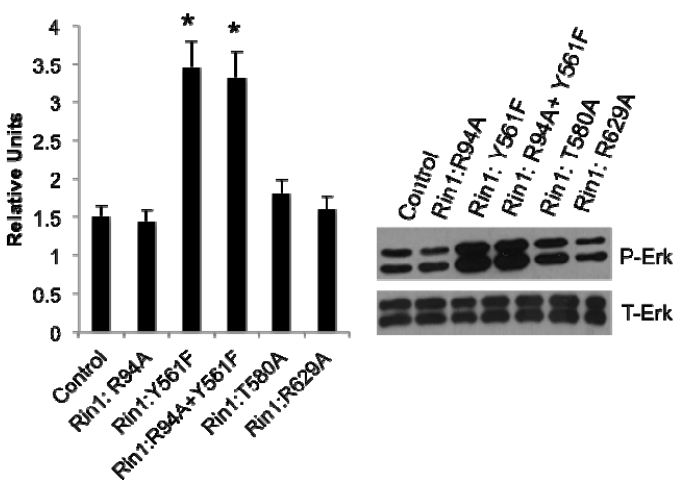

B.

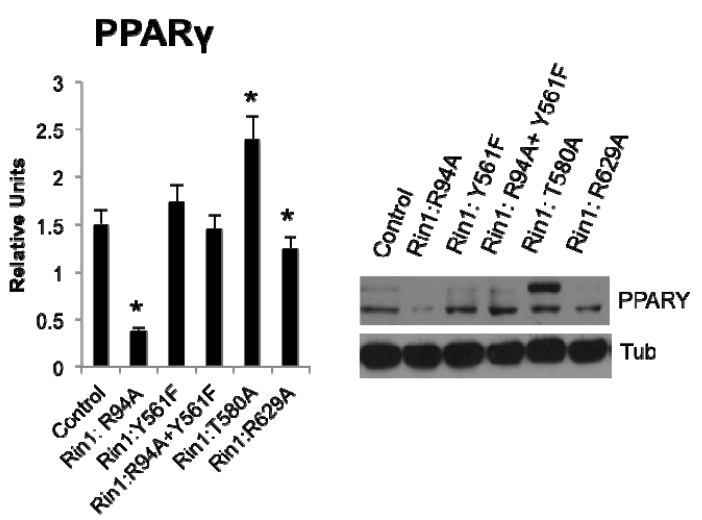

Figure 3.7. Adipogenic markers expression in cells overexpressing the different Rin1 mutants.

3T3-L1 preadipocytes overexpressing the different Rin1 mutants were differentiated for 10 days and total protein extracts were prepared as described in Material and Methods. Total protein extracts were subset to $10 \%$ SDS-PAGE electrophoresis, blotted to a nitrocellulose membrane and probed against the following antibodies: (A) C/EBP $\alpha$, (B) PPARy, (C) P-Erk and T-Erk. Results were represented as Relative Units (relative lipid contents). Relative levels of proteins were determined by densitometry as described in Material and Methods. Data represent the mean \pm S.E.M. of three independent experiments. ${ }^{*} P<0.05$ by Student's t-test compared to control cells. 

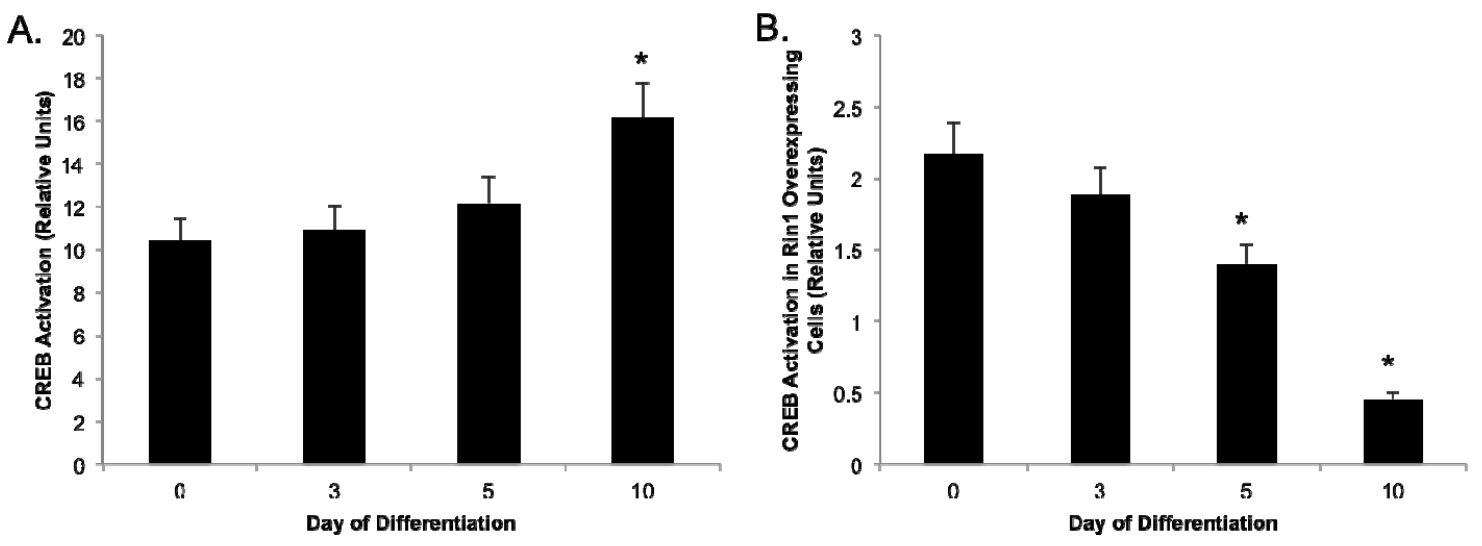

Figure 3.8. CREB activation in cells overexpressing Rin1 and control cells. 3T3-L1 control preadipocytes (A) and cells overexpressing Rin1 (B) were induced to differentiate by induction media into adipocytes as explained in Material and Methods. Total protein extracts were prepared at day 1, 3, 5, and 10. The proteins were subset to $12 \%$ SDS PAGE electrophoresis, blotted to a nitrocellulose membrane, and probed with antibodies specific to T-CREB and PCREB. Results were represented as Relative Units (relative lipid contents). Relative levels of proteins were determined by densitometry as described in Material and Methods. Data represent the mean $\pm S . E . M$. of three independent experiments. ${ }^{*} P<0.05$ by Student's t-test. 

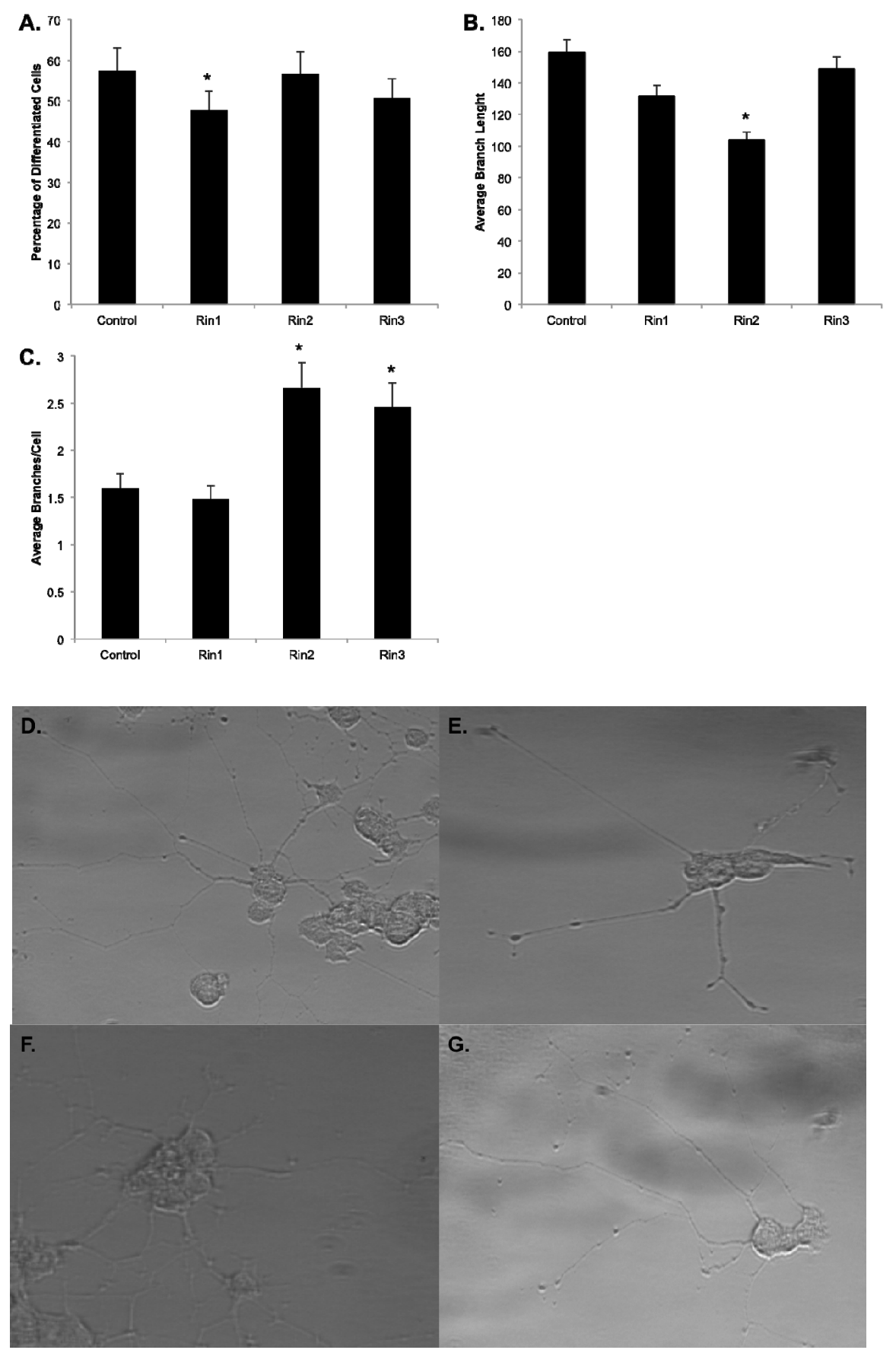

Figure 3.9. Effect of Rin proteins in PC12 differentiation.

PC12 control cells and overexpressing Rin proteins were stimulated with $100 \mathrm{ng} / \mu \mathrm{l} \mathrm{NGF}$ and the neurite growth quantified 10 days later as described in Materials and Methods. (A) Percentage of differentiated cells. (B) Average branch length. (C) Average number of branches per cell. Pictures were taken at day 10 of differentiation for control cells (D), Rin1 (E), Rin2 (F) and Rin3 (G) overexpressing cells. ${ }^{*} P<0.1$ by Student's t-test compared to control cells. 


\section{EXAMINING THE EFFECT OF DEHYDROLEUCODINE IN}

\section{DIFFERENTIATION OF ADIPOSE CELLS.}

Sesquiterpene lactones are a large and structurally diverse group of plant second metabolites (Heinrich et al., 1998) with distinctive biological activities, including gastric cytoprotector effects (Penissi et al., 1998), anti-migraine (Beekman et al., 1997), antiviral and antimicrobial activities (Hayashi et al., 1996; Perry and Foster, 1995), anti-tumor (Robles et al., 1995) and neurotoxic effect (Cheng et al., 1992).

Sesquiterpene lactones are also blockers of smooth muscle contractility (Hay et al., 1994) aromatase activity (Blanco et al., 1997) and NF-kB activation (Hehner et al., 1998; Lyss et al., 1998). Also, it has been found that sesquiterpene lactones inhibit the activation of cyclooxygenase and proinflammatory cytokines in macrophages (Hwang et al., 1996). Within the group of sesquiterpene lactones, helenalin, which occurs in the aerial portion of Arnica Montana L., was also found to block the hormonally induced Sky2 mRNA and Akt phosphorylation during early stages of adipocyte differentiation (Auld et al., 2006). Inhibitory activities have been principally linked to the a-methylene- $\gamma-$ lactone function (Heinrich et al., 1998). However, the reduction of the amethylene-y-lactone limited its cytotoxicity effect without affecting the antiproliferative and anti-aromatase activity (Blanco et al., 1997).

Dehydroleucodine $(\mathrm{DhL})$ is a sesquiterpene lactone of the guaianolide group, which also contains a a-methylene-y-lactone ring in its molecule. It was first isolated from Lidbeckia pectinata (Bohlmann and Zdero, 1972). The aerial 
parts of Artemisia douglasiana Besser are also rich in DhL (Giordano et al., 1990). Chloroform extracts of the air-dried aerial parts of Artemisia douglasiana showed significant gastric cytoprotective activity (Giordano et al., 1992). In addition, DhL inhibited cell proliferation (Polo et al., 2007) and growth of Trypanosome cruzi in culture (Brengio et al., 2000). Recent studies also showed the antiproliferative effects of DhL on B16 mouse melanoma cells, without having an effect on the normal Melan-A mouse melanocytes (Priestap et al., 2012). Furthermore, it has been proved that the exposure of $\mathrm{DhL}$ (either transient or continuous) to cancer cells inhibits proliferation and promotes apoptosis of human cancer cells by the activation of p53 and the DNA damage control mechanism, in a dose dependent manner (Costantino et al., 2013).

To examine the potential role of DhL on the differentiation of preadipocytes, cells were incubated with induction media in the presence of various concentration of $\mathrm{DhL}$. Figure $4.1 \mathrm{~A}$ shows that the addition of $\mathrm{DhL}$ inhibited the lipid content in a dose-dependent manner with an $\mathrm{IC}_{50}$ of $6 \mu \mathrm{M}$. Furthermore, the experimental conditions demonstrate that the addition of DMSO $(0.2 \%)$ exclusively does not hinder 3T3-L1 preadipocytes differentiation.

To examine the effect of DhL on the viability of 3T3-L1 preadipocytes, cells were incubated with induction media in the presence of $8 \mu \mathrm{M}$ DhL for $24 \mathrm{hrs}$ (Day 1) or throughout the entire 9 days of differentiation (Day 9). Cell viability was measured using the MTT colorimetric assay as described in Material and Methods section. Figure $4.1 \mathrm{~A}$ shows that the addition of $\mathrm{DhL}$ blocked the differentiation of 3T3-L1 preadipocytes whereas cell viability was not affected as 
compared with DMSO or untreated cells (Figure 4.1B). However, at higher DhL concentrations $(>10 \mu \mathrm{M}), 3 \mathrm{~T} 3-\mathrm{L} 1$ preadipocytes detached from the plate, which was coupled with a significant reduction in the MTT assay. These results suggest that, up to a maximum concentration of $10 \mu \mathrm{M}$, DhL has a strong inhibitory activity of 3T3-L1 preadipocytes differentiation without significant effect on cell viability.

Adipocyte differentiation can be also monitored by formation of intracellular lipid droplets (Rosen and Spiegelman, 2000). As described above, 3T3-L1 preadipocytes were cultivated and induced to differentiate into adipocytes with induction media in the absence or presence of $8 \mu \mathrm{M}$ DhL. At day 9, Oil Red O staining showed that an abundant number of lipid droplets suggesting a significant lipid accumulation in untreated differentiated cells. However, lipid droplets were not observed in untreated non-differentiated cells (compare Figure 4.2A and B). More importantly, formation of lipid droplets was inhibited by $8 \mu \mathrm{M}$ DhL treatment (Figure 4.2C). These observations were further supported with the quantitative measurement of lipid content by determining the absorbance at 540nm (Figure 4.1A). In addition, DhL treatment significantly inhibited adipogenic morphology (i.e., transition from a fibroblast-like shape to an increasingly rounded-up appearance with an accumulation of cytoplasmic lipid droplets; compare Figure 4.2B and C).

Given that DhL inhibited differentiation to 3T3-L1 preadipocytes, next it was considered whether DhL would inhibit triglyceride accumulation. Cells treated with induction medium in the presence of $8 \mu \mathrm{M}$ of $\mathrm{DhL}$ accumulated 
roughly $31 \pm 5 \%$ of the intracellular triglyceride contained in controls (Figure $4.2 \mathrm{D}$ ). As expected, DMSO-treated cells did not affect the formation of triglyceride accumulation as compared with cells incubated with induction media alone.

Adipogenesis is a highly regulated process requiring coordinated expression and activation of key transcriptional factors and signaling molecules (Rosen and Spiegelman, 2000). To investigate whether DhL affects the expression of PPARy and C/EBP $\alpha, 3 T 3-\mathrm{L} 1$ preadipocytes were incubated with induction media in the absence or presence of $8 \mu \mathrm{M} \mathrm{DhL}$, and then harvested at day 9 for Western blot analysis using anti-PPARy and C/EBP $\alpha$ antibodies. Figure 4.3A shows that the addition of DhL clearly attenuated the expression of PPARY and C-EBP $\alpha$. The effect of DhL on the phosphorylation of Akt1 and Erk1/2 proteins was also examined. Surprisingly, it was found that the addition of DhL did not attenuate phosphorylation of Erk and Akt (Figure 4.3B and C). Furthermore, it was tested whether the addition of DhL affected the phosphorylation of AMPK $\alpha$ during 3T3-L1 preadipocytes differentiation. The data shows that phosphorylation of AMPK $\alpha(\mathrm{P}-\mathrm{AMPK} \alpha)$ was not inhibited by the addition of DhL (Figure 4.3D). In contrast, DhL further enhanced phosphorylation of AMPK $\alpha$ (Figure 4.3D). It was also found that the level of total AMPK $\alpha$ appeared relatively constant in the presence or absence of $\mathrm{DhL}$. Therefore, these results indicated that the level of phosphorylated AMPK $\alpha$ increased in the presence of DhL. Interestingly, both PPARY and C/EBP $\alpha$ are selectively expressed during the differentiation of 3T3-L1 preadipocytes. The levels of 
expression of these transcription factors is undetectable in preadipocytes; however, expression increases two days after induction and they are expressed five days after the induction of differentiation (Rosen and Spiegelman, 2000). Consistent with these observations, it was also observed that the expression of PPARY and C-EBP $\alpha$ was significantly increased with the progression of the differentiation of 3T3-L1 preadipocyte (Figure 4.4A and B). However, DhL treatment at the concentration of $8 \mu \mathrm{M}$ significantly blocked the expression of PPARY and C-EBP $\alpha$ (Figure 4.4A and B). In addition, the differentiation of 3T3L1 preadipocyte progressed with an increase of the phosphorylation status of AMPKo (Figure 4.4C). Treatment with DhL further significantly increased the phospho-status of AMPK $\alpha$, suggesting that $\mathrm{DhL}$ also induced the activation of AMPKo (Figure 4.3C). Furthermore, the addition of $\mathrm{DhL}$ also inhibited, in a concentration dependent manner, the expression of FAS (Fatty acid synthase) (Figure 4.6). Fatty acid synthase is a key protein in the production of lipids, responsible for the synthesis reaction of long-chain fatty acids (Semenkovich, 1997). On the other hand, AMPK stimulates energy production promoting glucose transport and fatty acid oxidation, inhibiting lipogenesis and protein synthesis (Daval et al., 2006). Taken together, these data suggest that DhL selectively blocks the expression of FAS, PPARY and C-EBP $\alpha$ and also increases the phosphorylation of AMPK $\alpha$ during the differentiation of 3T3-L1 preadipocytes. 
It is also possible that the extent of inhibition is dependent on the timing of DhL addition. For this purpose, $8 \mu \mathrm{M}$ DhL was added in discrete periods during differentiation (Figure 4.5A). A significant reduction in the differentiation of 3T3L1 preadipocytes was observed when compared with DMSO-control cells upon early $\mathrm{DhL}$ addition, corresponding to days 1 or 3 of treatment (Figure $4.5 \mathrm{~A}$ and B). However, this inhibitory effect was not apparent when DhL was added on day 5,7 or at day 8 post-induction. These results indicate that DhL may affect early adipocyte gene expression during in vitro differentiation.

These results clearly show that the addition of DhL inhibited differentiation of 3T3-L1 preadipocytes in a dose-dependent manner without a significant effect on cell toxicity (Figure 4.1). However, it has been postulated that the nonsaturated a-methylene- $y$-lactone function of sesquiterpene lactones produces an unspecific toxic effect leading to cell death (Polo et al., 2007). Therefore, it has been investigated the effect of $\mathrm{DH}-\mathrm{DhL}$, which is a derivative of $\mathrm{DhL}$ lacking alkylating function, on the differentiation of 3T3-L1 preadipocytes.

Dehydroleucodine (Figure 4.7, compound 1) can be gently reduced with sodium borohydride to give the corresponding 11,13-dihydro derivative (classical nomenclature; (Giordano et al., 1990). Analysis of the reaction product (DH-DhL) by GC shows that two epimers (Figure 4.7B, compounds 2 and 3 ) are formed in different amounts (Figure 4.7B) due to the generation of a chiral center at C-11 of the molecule during reduction. The 11S- epimer (compound 2) is the major reaction product (Giordano et al., 1992). It is accompanied by the minor 11Repimer (compound 3), and by traces of unreacted DhL (compound 1) (Figure 
4.7B). In the following these epimers are denoted (11S)DH-DhL and (11R)DHDhL, respectively, for simplicity. After separation by preparative HPLC, the epimers were obtained in pure form and confirmed by GC analysis (Figure 4.7C and D). They were studied, in parallel with DhL, for their effect on the differentiation of 3T3-L1 preadipocytes.

Figure 4.8A shows that the addition of $\mathrm{DH}-\mathrm{DhL}$ inhibited the differentiation of 3T3-L1 preadipocytes. The inhibition was dose-dependent and required a higher concentration of DH-DhL to produce a similar inhibitory effect as DhL. Thus, it required 10 times the $\mathrm{DH}-\mathrm{DhL}$ concentration to achieve the same effect as DhL (Figure 4.8A). Furthermore, it was also found that $100 \mu \mathrm{M}$ of $\mathrm{DH}-\mathrm{DhL}$ did not affect cell viability (control cells: $98 \pm 2 \%$ of viability vs. $80 \mu \mathrm{M}$ DH-DhL treated cells: $97 \pm 2 \%$ of viability). These results suggest that the reduction of the a-methylene-y-lactone group of the $\mathrm{DhL}$ was not required to block the differentiation of 3T3- L1 preadipocytes.

To further investigate the role of these epimers of $\mathrm{DH}-\mathrm{DhL}$ on the differentiation of 3T3-L1 preadipocytes, the two methyl epimers at C-11 produced during the in vitro reduction of DhL were separated by preparative HPLC, concentrated, confirmed by GC analysis and then their effect on adipogenesis was examined. For this, 3T3-L1 pre-adipocytes were incubated with $80 \mu \mathrm{M}$ of either (11S)DH-DhL or (11R)DH-DhL during the entire differentiation process. It was found that the addition of (11R)DH-DhL epimer, but not (11S)DH-DhL epimer, inhibited the differentiation of 3T3-L1 preadipocytes (Figure 4.8B). These 
results suggest that $(11 \mathrm{R}) \mathrm{DH}-\mathrm{DhL}$ epimer may be responsible in inhibiting adipocyte differentiation.

Several studies have shown that compounds that have the a-methylene- $\gamma-$ lactone group can react with nucleophiles, especially cysteine sulfhydryl groups. Interestingly, studies indicate that cysteine residues in certain proteins, such as NF-kB, may be direct targets of sesquiterpene lactones (Semenkovich, 1997). Thus, it is logical to speculate that proteins like Rin1 and Rab5 (Chapters 2 and 3), whose activities are required for adipogenesis, may be affected by DhL. Expression of Rab5 and Rin1, as well as Rab5 activity, showed a strong effect on adipogenesis: reducing lipid formation, decreasing the expression of key without affecting the major signaling pathways. To investigate the possible effect of DhL on Rin1 and Rab5 function, it was decided to study whether expression of Rin1 and Rab5 and Rab5 activity were affected by the addition of DhL. Interestingly, expression of Rin1 and Rab5 had shown a detrimental effect on adipogenesis, which is consistent with the inhibitory effect of the active form of Rab5 in adipogenesis (unpublished data Nicole Villaverde, 2009). To this end, $8 \mu \mathrm{M}$ DhL was added to cells and the level of expression of Rab5 and Rin1 were examined by Western blot analysis. Rab5 activity was determined by the formation of enlarged Rab5-positive endosomes in cells overexpressing Rab5:WT and the constitutively active mutant Rab5:Q79L (Barbieri et al., 1996). Overexpression of Rab5:WT promotes endosomes with an average perimeter of $1.2-/+0.01 \mu \mathrm{m}$, while the overexpression of the constitutively active mutant promotes endosomes with an average perimeter of $2.3-/+0.012 \mu \mathrm{m}$ ( $\mathrm{Li}$ and Qian, 2002). Figure 4.9A 
and B shows that DhL did not affect either the expression or activity of Rab5, or the expression of Rin1 (Figure 4.10). Taken together, these observations reveal that DhL inhibited adipogenesis by a Rin1/Rab5 independent mechanism(s). 


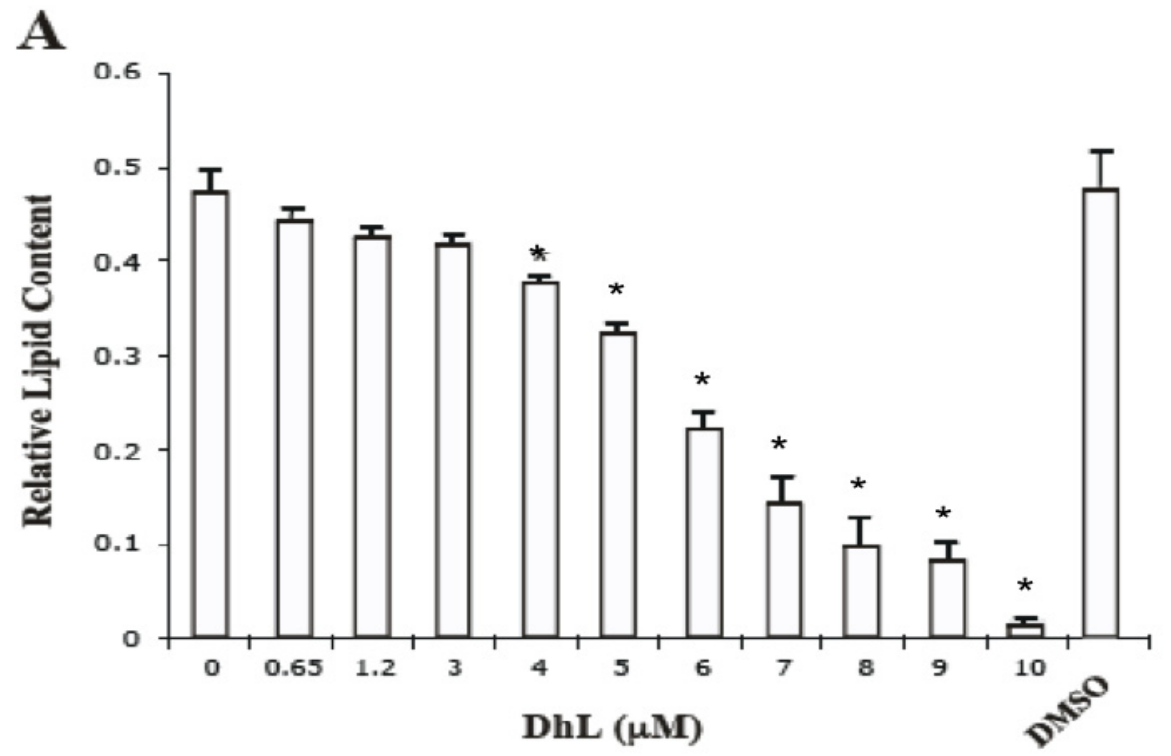

B

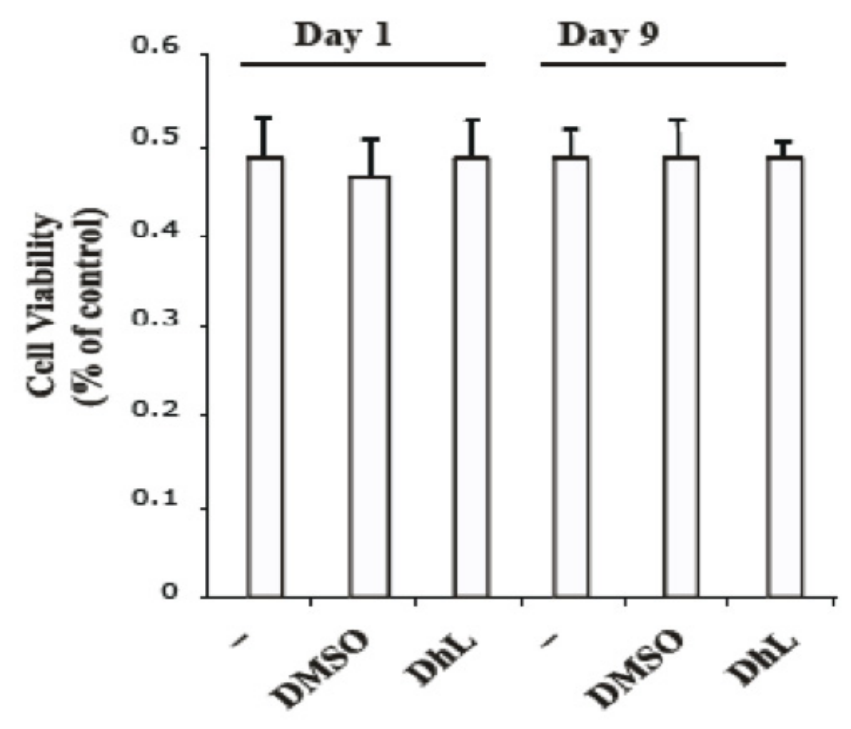

Figure 4.1. Dehydroleucodine inhibited adipogenesis of 3T3-L1 preadipocytes without reducing cell viability.

Dehydroleucodine inhibited adipogenesis of 3T3-L1 preadipocytes without reducing cell viability. (A) 3T3-L1 preadipocytes were differentiated into adipocytes in the absence or in the presence of various amounts of DhL ( 0.65 to $10 \mu \mathrm{M})$ as described in Material and Methods. Results were represented as relative lipid contents. Data represent the mean \pm S.E.M. of three independent experiments. ${ }^{*} P<0.05$ by Student's t-test compared to DMSO and only induction media-treated cells. (B) Cells were treated with $8 \mu \mathrm{M} \mathrm{DhL}$ for either $24 \mathrm{hrs}$ (day 1) or for 9 days (day 9). Cell viability was measured using the MTT assay as described in Material and Methods. Data represent the mean \pm S.E.M. of three independent experiments. 


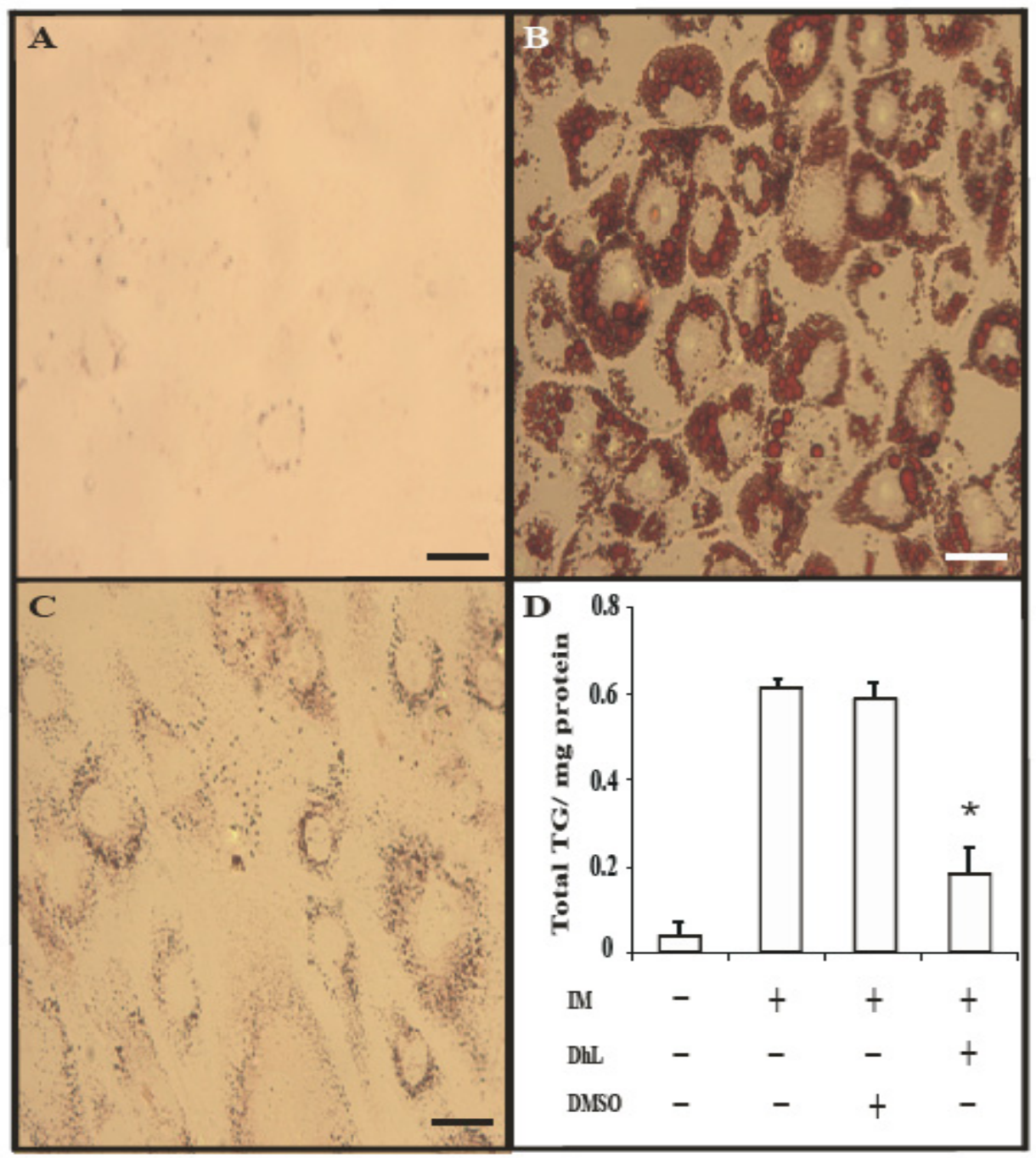

Figure 4.2. Dehydroleucodine blocked the formation of lipid droplet by induction media in 3T3-L1 cells.

Dehydroleucodine blocked the formation of lipid droplet by induction media in 3T3-L1 cells. Adipocyte differentiation was induced by treating confluent 3T3-L1 preadipocytes with induction media in the absence or presence of $8 \mu \mathrm{M} \mathrm{DhL}$. Morphological changes of 3T3-L1 preadipocytes were monitored by a microscope and photographed after 9 days from the onset of differentiation. (A) Vehicle only, (B) cells treated with induction media in the presence of DMSO, or (C) in the presence of DhL. (D) Nine days after induction of differentiation, cells were lysed for triglyceride and protein assays as described in Material and Methods. Vehicle only (line 1), cells treated with induction media alone (line 2), cells treated with induction media in the presence of DMSO (line 3), and cells treated with induction media in the presence of $8 \mu \mathrm{M} \mathrm{DhL}$ (line 4). Bars $=10 \mu \mathrm{m}$. Data represent the mean \pm S.E.M. of three independent experiments. ${ }^{*} P<0.05$ by Student's t-test compared to DMSO-treated cells and only induction mediatreated cells. 

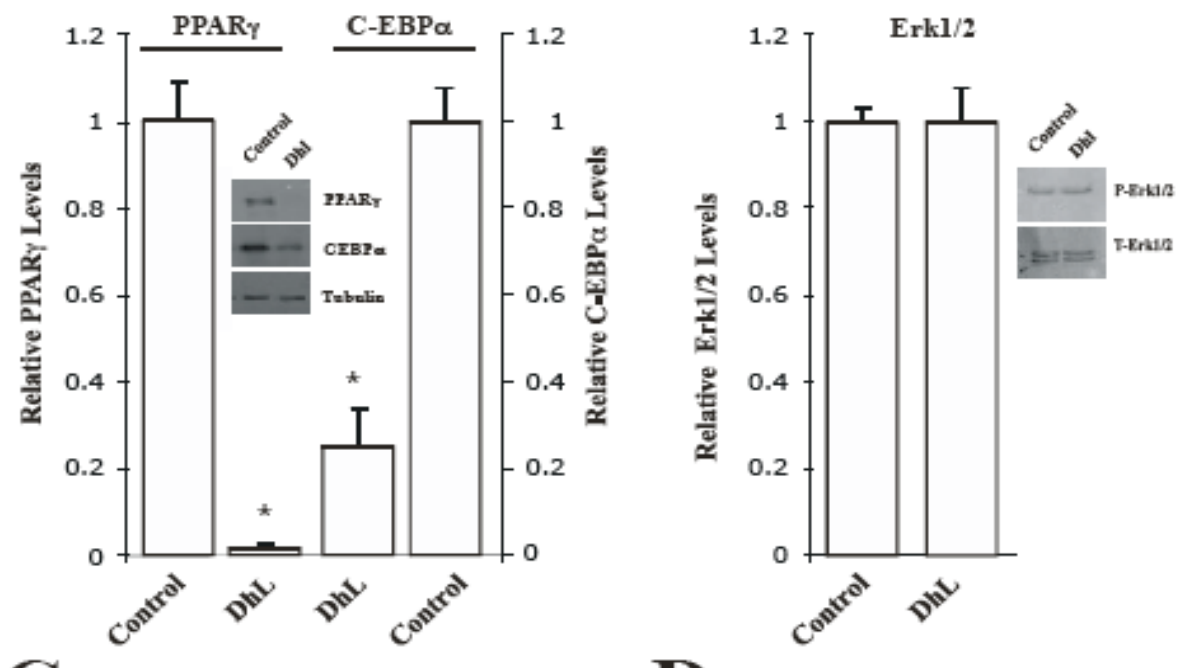

C
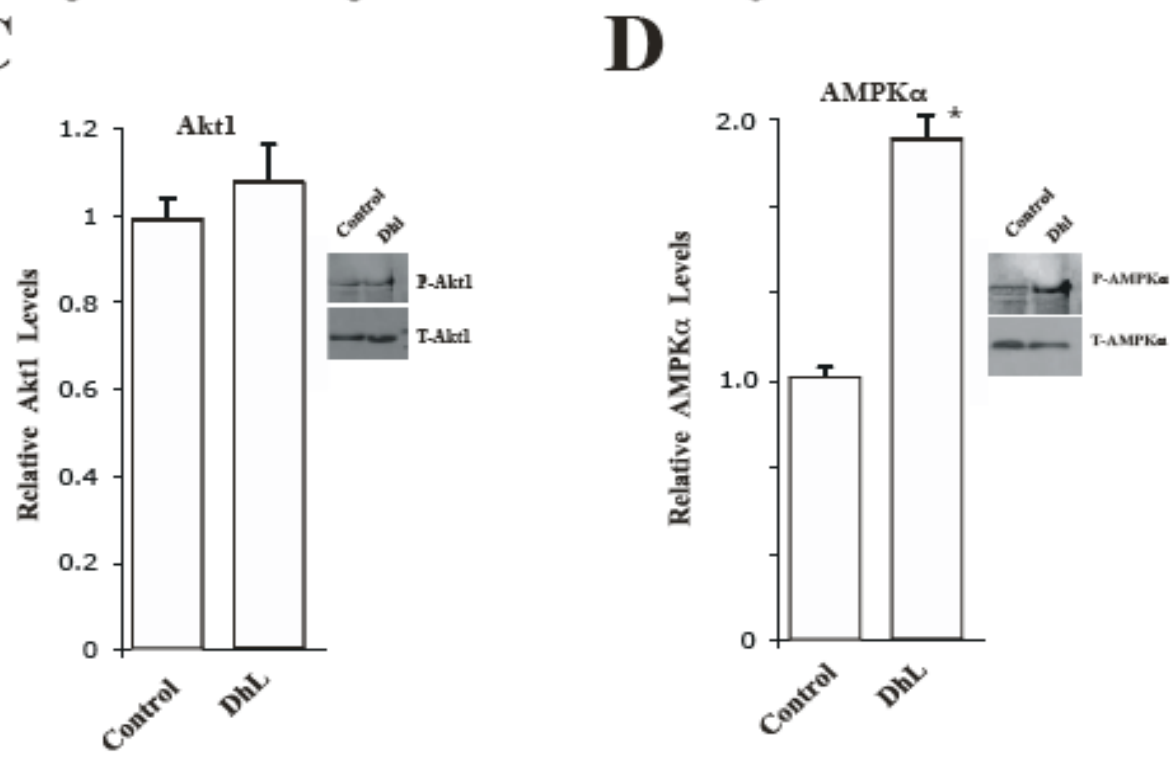

Figure 4.3. Dehydroleucodine attenuated the expression of PPARY during 3T3-L1 preadipocyte differentiation.

Dehydroleucodine attenuated the expression of PPARY during 3T3-L1 preadipocyte differentiation. 3T3-L1 preadipocytes were induced to differentiate by induction media into adipocytes in the absence (inset: -DhL, control) or in the presence (inset: $+\mathrm{DhL}$ ) of $8 \mu \mathrm{M} \mathrm{DhL}$. Total protein extracts were prepared at day 9 from each sample. The proteins were subset to 12\% SDS-PAGE electrophoresis, blotted to a nitrocellulose membrane, and probed with antibodies specific to (A) PPARy, C-EBPa and tubulin, (B) P-Erk1/2, T-Erk1/2, (C) PAkt1, T-Akt1, (D) P-AMPKa and T-AMPKa respectively. Relative levels of proteins were determined by densitometry as described in Material and Methods. Data represent the mean \pm S.E.M. of three independent experiments. ${ }^{*} P<0.05$ by Student's t-test compared to DMSO induction media-treated cells (control). 

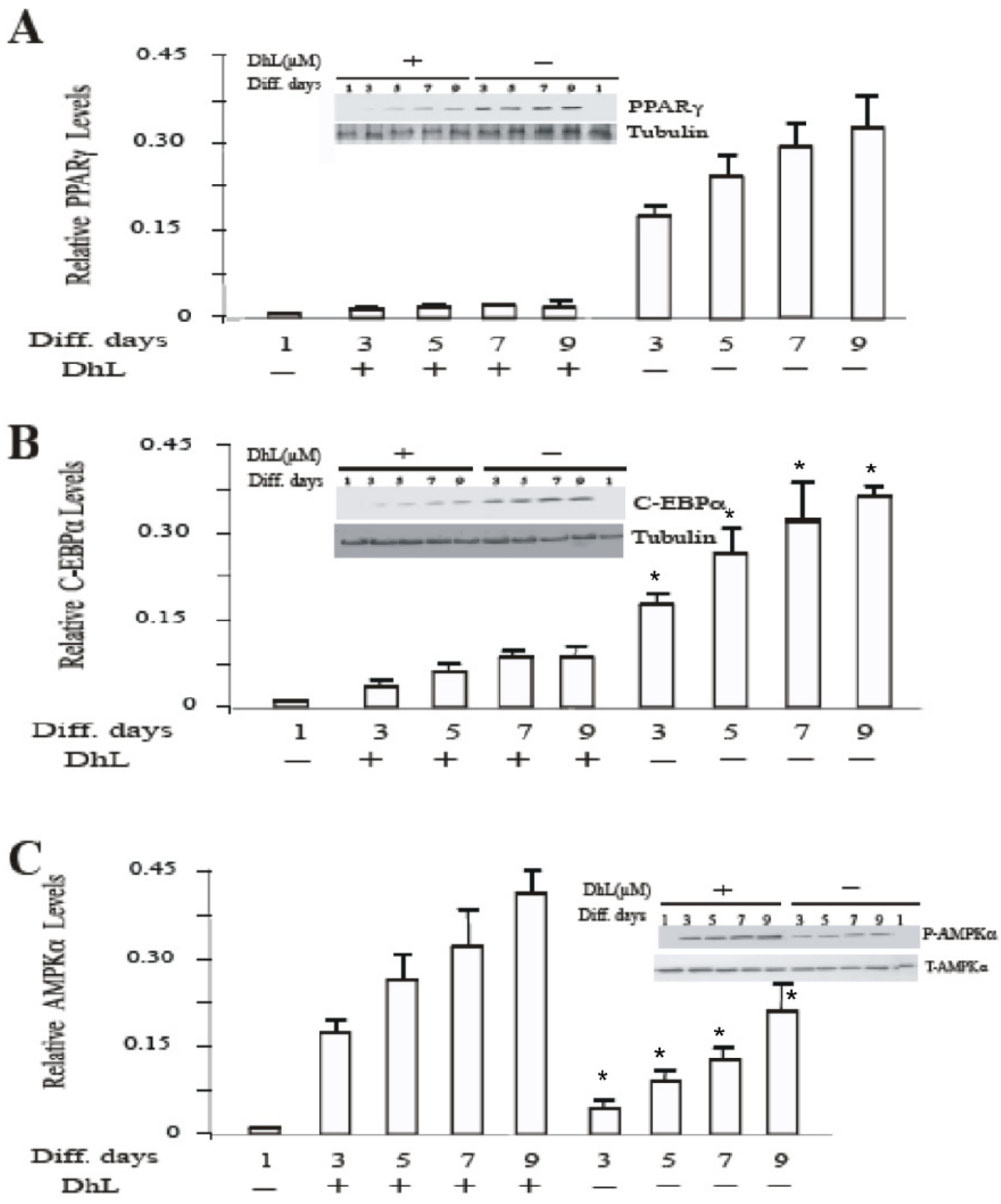

Figure 4.4. Dehydroleucodine selectively alters the expression of PPARY, C-EBPa and AMPKa.

3T3-L1 preadipocytes were induced to differentiate by induction media into adipocytes in the absence (insert: -DhL, control) or in the presence (insert: + DhL) of $8 \mu \mathrm{M}$ DhL. Total protein extracts were prepared at day 1, 3, 5, 7 and 9 from each sample. The proteins were subset to $12 \%$ SDS PAGE electrophoresis, blotted to a nitrocellulose membrane, and probed with anti-bodies specific to PPARY (A), C-EBPa (B), AMPKa (C), and tubulin. Relative levels of proteins were determined by densitometry as described in Material and Methods. Data represent the mean \pm S.E.M. of three independent experiments. ${ }^{*} P<0.05$ by Student's t-test compared to DMSO induction media-treated cells (control). 


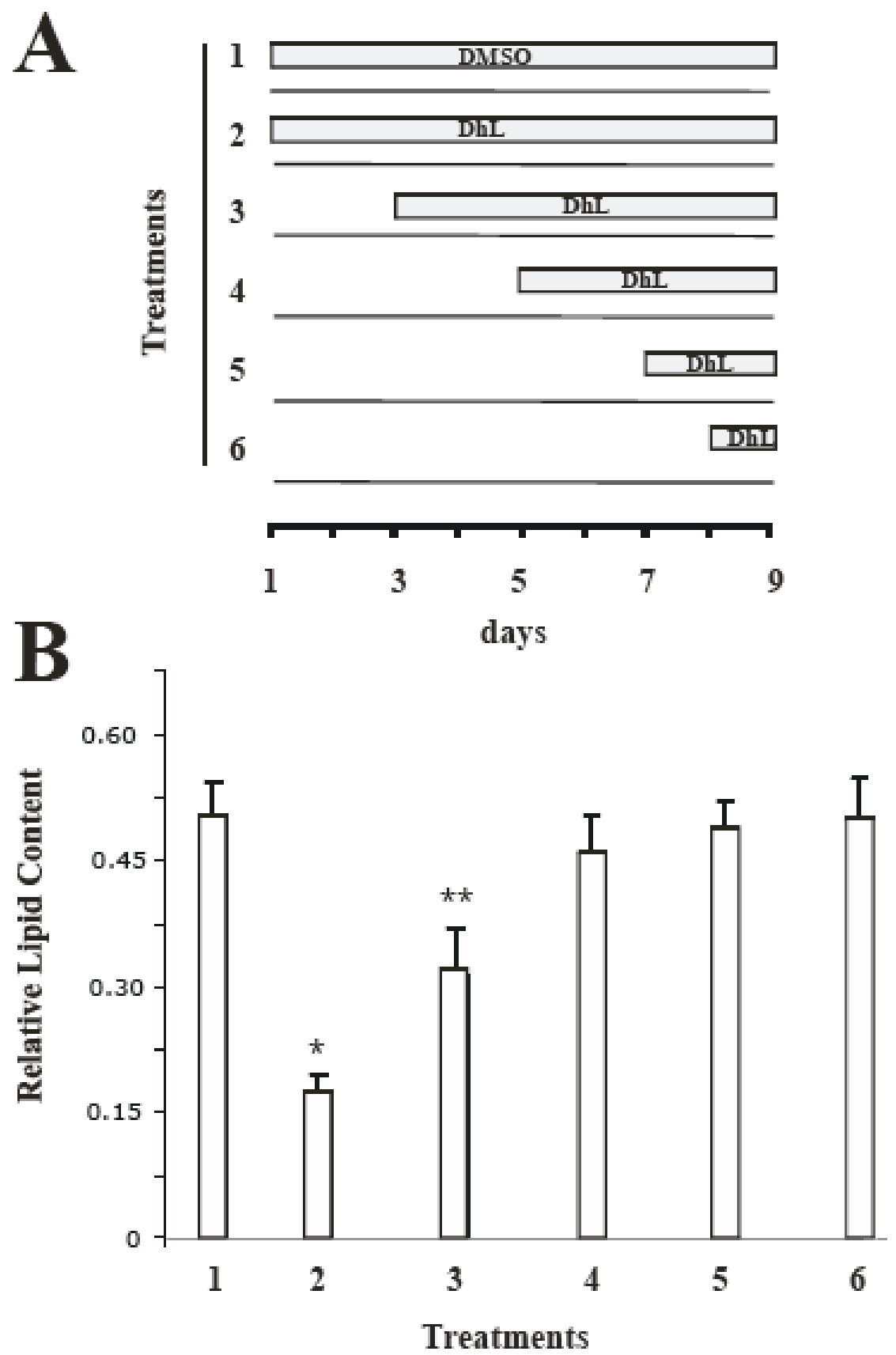

Figure 4.5. Dehydroleucodine blocked adipocyte differentiation in a timedependent manner.

(A) 3T3-L1 preadipocyte cells were treated with $8 \mu \mathrm{M} \mathrm{DhL}$ for the time indicated in the schematic representation of the experiment. (B) In each treatment (1-6), the accumulation of lipid droplets was measured by the incorporation of Oil Red $\mathrm{O}$ as de- scribed in Material and Methods. Data represent the mean \pm S.E.M. of three independent experiments. ${ }^{*} P<0.05$ and ${ }^{* *} P<0.01$ by Student's t-test compared to DMSO induction media-treated cells (control). 


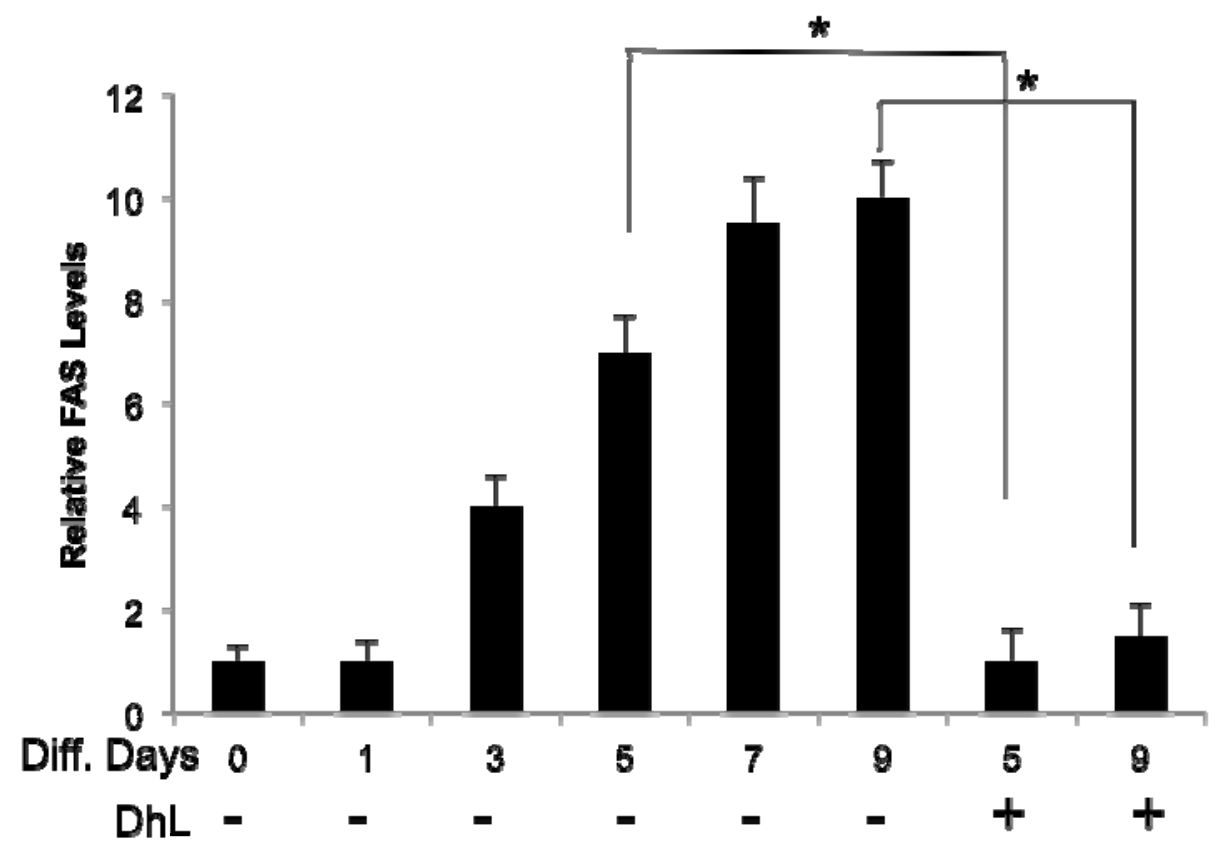

Figure 4.6. Dehydroleucodine alters the expression of FAS.

3T3-L1 preadipocytes were induced to differentiate by induction media into adipocytes in the absence (insert: -DhL, control) or in the presence (insert: + DhL) of $8 \mu \mathrm{M} \mathrm{DhL}$. Total protein extracts were prepared at day 0 (no induction media), $1,3,5,7$ and 9 from each sample. The proteins were subset to $12 \%$ SDS PAGE electrophoresis, blotted to a nitrocellulose membrane, and probed with anti- FAS antibody. Relative levels of proteins were determined by densitometry as described in Material and Methods. Data represent the mean \pm S.E.M. of three independent experiments. ${ }^{*} P<0.05$ by Student's t-test compared to DMSO induction media-treated cells (control). 


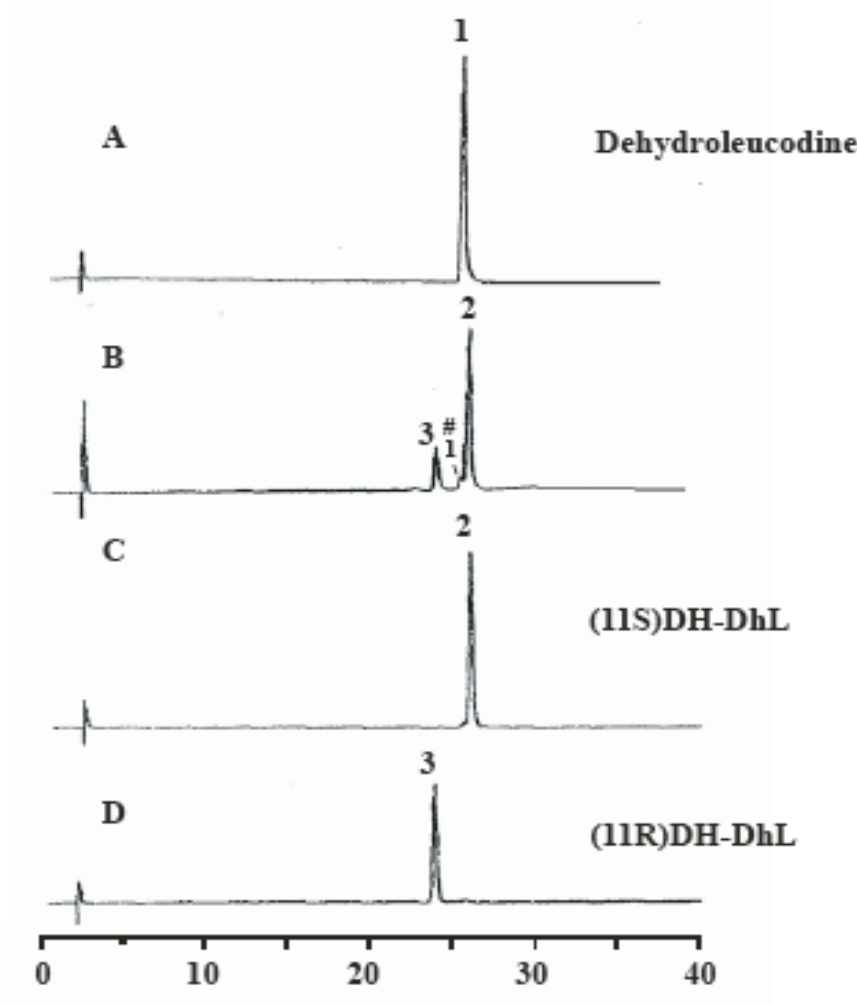

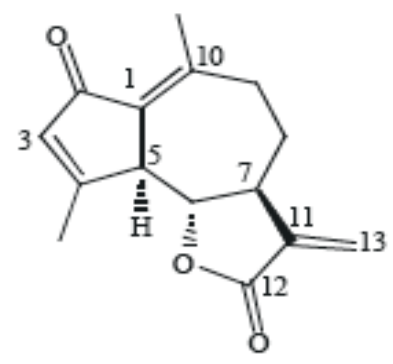

1

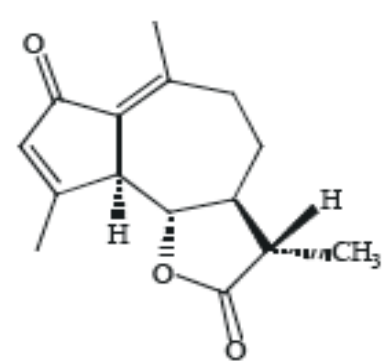

2

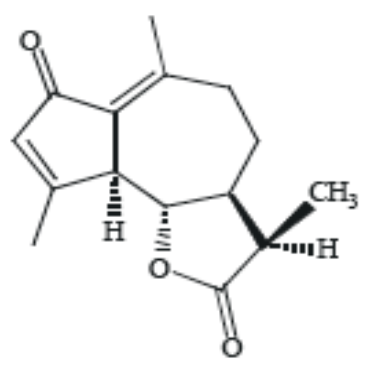

3

Figure 4.7. GC analysis of dehydroleucodine and 11,13dihydrodehydroleucodine epimers.

(A) DhL isolated from Artemisia douglasiana; (B) mixture DH-DhL epimers as obtained by reduction of $\mathrm{DhL}$, (\#) denotes small amount of DhL after the reduction reaction; (C) $\mathrm{DH}-\mathrm{DhL}$ epimer S, and, (D) DH-DhL epimer $\mathrm{R}$ after separation from the mixture. Chemical struc- tures of DhL (compound 1), $\mathrm{DH}-$ DhL epimer 11S (compound 2) and DH-DhL epimer 11R (compound 3) (numbering according to classical nomenclature). 


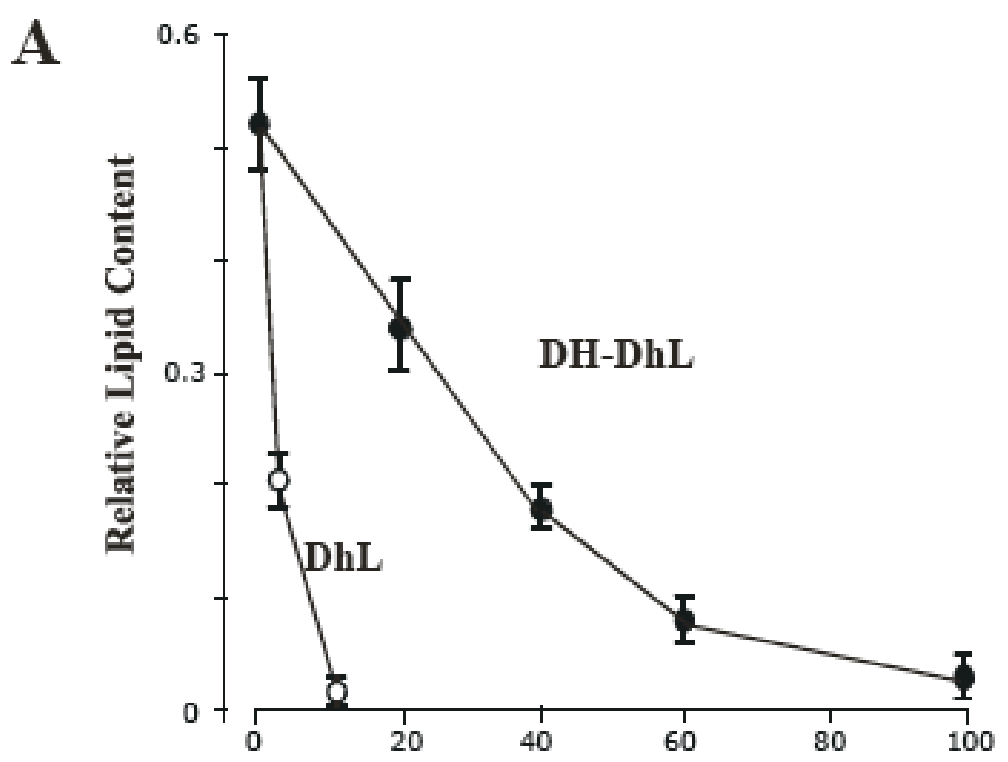

Compound ( $\mu \mathrm{M})$

B

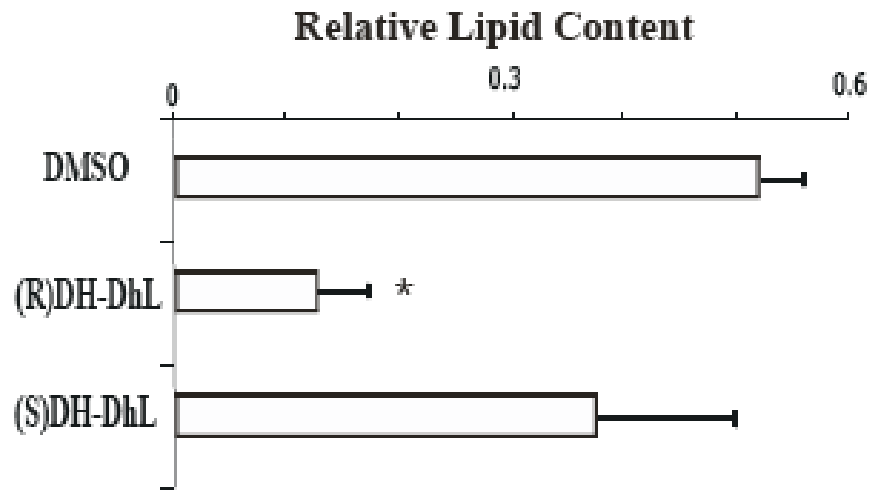

Figure 4.8. 11,13-Dihydro-dehydroleucodine inhibited 3T3-L1 preadipocyte differentiation.

(A) 3T3-L1 preadipocytes were differentiated into adipocytes in the absence or in the presence of either DHL or DH-DhL. Results were represented as relative lipid content. Data represent the mean \pm S.E.M. of three independent experiments. (B) 3T3-L1 preadipocyte cells were incubated with induction media supplemented with either DMSO, $80 \mu \mathrm{M}$ DH-DhL epimer S or $80 \mu \mathrm{M} \mathrm{DH}-\mathrm{DhL}$ epimer $\mathrm{R}$ and the incorporation of Oil Red $\mathrm{O}$ was measured by as described in Material and Methods. Results were represented as relative lipid content. Data represent the mean \pm S.E.M. of three independent experiments. ${ }^{*} P<0.01$ by Student's t-test compared to DMSO-treated cells. 

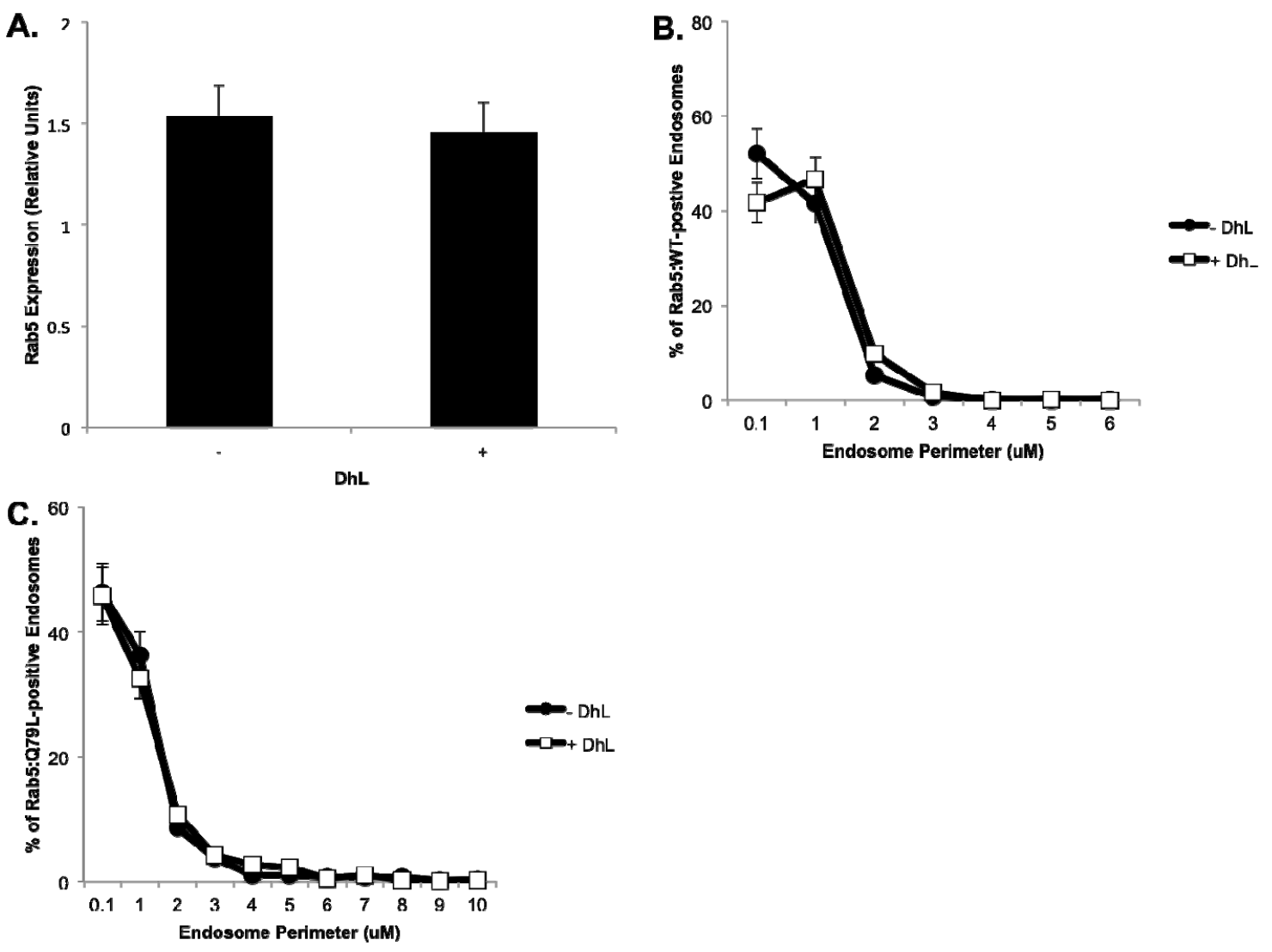

Figure 4.9. Effect of dehydroleucodine in Rab5 expression and activation.

(A) To study Rab5 expression, NIH3T3 cells overexpressing GFP-Rab5 constructs were exposed to $8 \mu \mathrm{M}$ DhL for 6hrs. Then, the cells were lysed and total protein extracts were subset to $12 \%$ SDS-PAGE electrophoresis, blotted to a nitrocellulose membrane, and probed with Rab5 and tubulin antibodies. Relative levels of proteins were determined by densitometry as described in Material and Methods. Data represent the mean \pm S.E.M. of three independent experiments. To study Rab5 activity NIH3T3 cells overexpressing GFP-Rab5 constructs were exposed to $8 \mu \mathrm{M}$ DhL for $6 \mathrm{hrs}$. Then, the cells were fixed and the perimeter of Rab5-positive endosomes was measured, as described in Material and Methods, in cells overexpressing Rab5:WT (B) and Rab5:Q79L (C). 


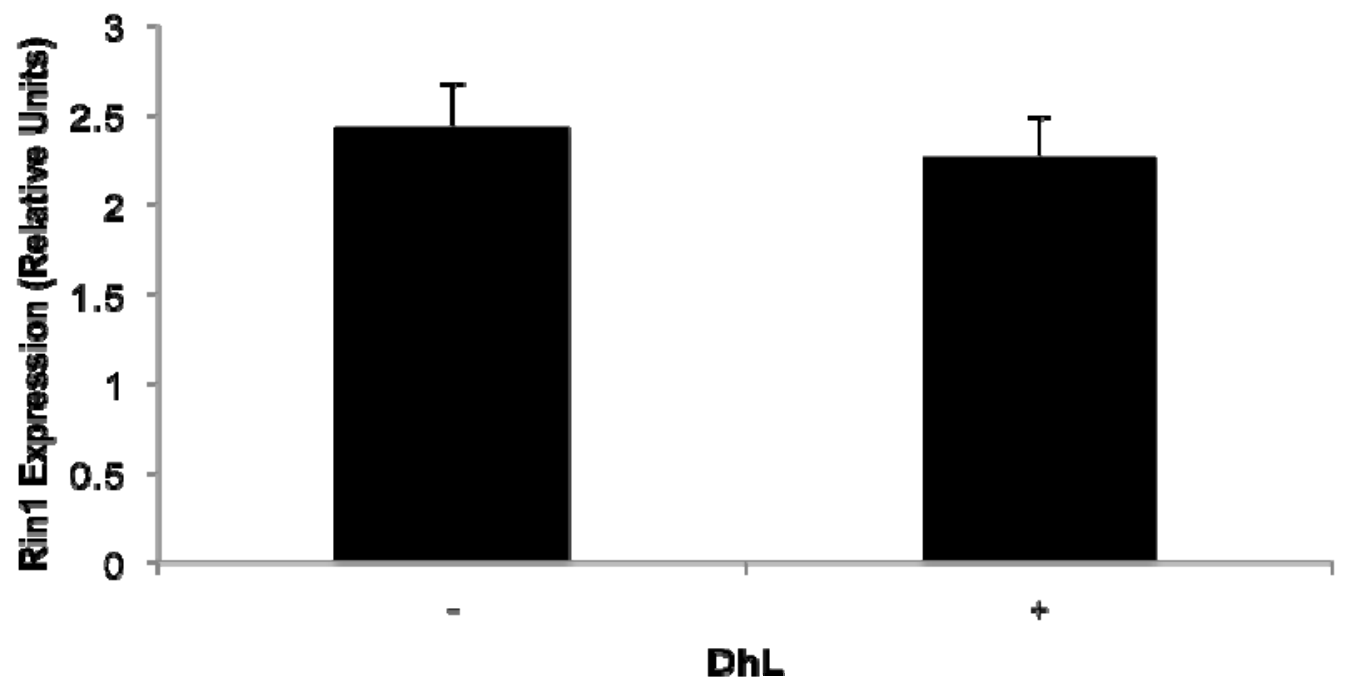

Figure 4.10. Effect of dehydroleucodine in Rin1 expression.

NIH3T3 cells overexpressing Rin1 were exposed to $8 \mu \mathrm{M}$ DhL for 6hrs then lysed and total protein extracts were subset to $12 \%$ SDS-PAGE electrophoresis, blotted to a nitrocellulose membrane, and probed with Rin1 and tubulin antibodies. Relative levels of proteins were determined by densitometry as described in Material and Methods. Data represent the mean \pm S.E.M. of three independent experiments. 


\section{DISCUSSION}

Tyrosine kinase receptors (RTKs) are expressed in many cell types and regulate important biological processes such as cell growth and differentiation, among others (Brodeur et al., 2009; Shaham et al., 2008; Wieduwilt and Moasser, 2008). Even though RTKs are the focus of an extensive research area, its signaling and regulation have not been completely elucidated. Overactivation and/or malfunction of RTKs have been linked to hyperproliferative and other type of diseases. Therefore it is important to understand not only the pathway, but also the proteins involved in RTK signal transduction and trafficking. It is also critical to investigate the molecular mechanism by which these proteins are interconnected.

The scope of this dissertation is a detailed analysis of the function of Rin1, a cytosolic protein involved in RTK signaling and internalization. The aim of this study is to: 1) determine how key residues of Rin1 are responsible for the protein-protein interactions, 2) elucidate how these interactions impact biological processes, mainly cell differentiation, and 3) determine the role of small molecules on intracellular pathways leading to selective inhibitory effects. Misregulation of pathways involved in these biological processes may be a direct cause of certain diseases such as cancer, obesity and neurodegenerative diseases.

The present study shows that Rin 1 , through several domains, directly interacts with EGFR, IR, and NGFR upon ligand stimulation. Rin1-EGFR interaction was only observed when Rin1:WT or Rin1:N-terminal domain were 
utilized, but not with the Rin1:C-terminal domain. Moreover, NGFR showed a similar type of interaction as the one observed for EFGR: through the $\mathrm{SH} 2$ domain. There was no interaction when the C-terminus of Rin1 was utilized. However, the IR-Rin1 interaction was not only through the $\mathrm{SH} 2$ domain, but also with the Vps9 (located at the C-terminal region, suggesting a novel interaction with the Vps9 domain and IR.

The crystal structure of SRC kinase shows the importance of a signature motif composed of Phe-Leu-Val-Arg-Glu-Ser (FLVRES) in SH2 domain function (Campbell and Jackson, 2003). Mutations in the arginine residue prevent almost every interaction with phosphotyrosines (Campbell and Jackson, 2003). In Rin1, residue arginine 94 was mutated to alanine creating Rin1:R94A mutant to investigate its effect in IR interaction and signaling. It can be concluded that even though this residue, does not affect the protein-protein interaction; it is critical for the proper function of the receptor tail.

Next, it was studied how this RTK-Rin1 interaction affected the internalization and signaling processes. Rin1 affects endocytosis and signal transduction via different proteins such as Rab5 and Ras. In the case of Rab5, Rin1 acts as a GEF, promoting the exchange from GDP to GTP (Han and Colicelli, 1995; Tall et al., 2001). As a consequence, the ligand-receptor complex internalization is accelerated, until the complex is separated in the late endosome and they both get delivered to the lysosome. The rate of endocytosis has a direct effect on receptor signaling: the faster the internalization, the shorter the signaling. This observation indicates that Rin1 not only regulates membrane 
receptor signaling by activating Rab5 and accelerating the internalization process, but also by decreasing Ras signaling. Thus, when Rin1 is overexpressed in the cell upon ligand stimulation, Erk and Akt activities are decreased. Directed mutagenesis studies reveal that tyrosine 561 in the Vps9 domain may be one of the key amino acids for Rin1 function (Galvis et al., 2009). It has been shown that point mutation in this residue inhibit Rab5 activation (Galvis et al., 2009). In addition, it was found that tyrosine 561 also has an effect on the interaction of Rin1 with Ras (Galvis et al., 2009). Even though the Rin1:Y561F mutant does not have a direct role in the interaction, it reverses the inhibition of Erk and Akt by overexpression of Rin1:WT. Another residue that regulates Rin1 function is arginine 629 in the RA domain. It reduces the RasRin1 interaction, which inhibits both, Erk and Akt activities. These data suggest a dual role of Rin1 domains: promoting Rab5 activation and decreasing Ras signaling upon ligand stimulation.

Phosphorylation of EGFR and IR also appears to be affected by the overexpression of Rin1, another possible cause of accelerating its internalization, decreasing the signal span. Similarly, when Rin2 and Rin3 are overexpressed, phosphorylation of the receptor decreases; there is an increase in Rab5 activation that may help to explain the effect of the Rin family. In contrast, the overexpression of the other two members of the Rin family (Rin2 and Rin3) seems to have a more cell-specific effect on Ras signaling. Rin2 promotes Erk activation upon EGF stimulation, while decreasing it upon insulin stimulation. 
Consistent with this observation, Rin proteins show a distinctive tissue distribution (Gurkan et al., 2005).

Taken together, Rin proteins have a regulatory role in RTKs internalization and cell signaling. Rin1 shows a selective method of interaction with RTKs. This study describes a novel mechanism of interaction of Rin1 with IR, which is not observed with EGFR or NGFR. It also demonstrates that all domains are required for the regulatory role of Rin1 in RTK signaling.

Next, it was studied the interaction of Rin1 with membrane receptors, and its effect on Rab5 and Ras activation affected some biological processes such as, proliferation and cell differentiation. It has been shown that Rin1 affected cell proliferation as well as thymidine incorporation upon ligand stimulation (Hunker et al., 2006b). To determine the importance of Rin1 function in cell differentiation, it was decided to investigate two different and well-characterized cell differentiation processes: adipogenesis and neurogenesis.

In the case of adipogenesis, overexpression of Rin1 full-length inhibited significantly adipocyte differentiation by decreasing the expression of the key transcription factors PPARY and C/EBPa. Previous studies (unpublished data Nicole Villaverde, 2009) showed that Rab5 overexpression inhibits adipogenesis in vitro in 3T3-L1 preadipocytes. The inhibition by Rab5 may be, at least in part, because its activation promotes receptor degradation terminating its signal. Another explanation could be the role of Rab5 on the endosomal localization of EEA1 (Simonsen et al., 1998), as well as the nuclear localization of AAPL1 (Miaczynska et al., 2004). Inhibition in vitro of adipocyte formation by Rin1 
overexpression confirms and also expands these data, since Rin1 is a Rab5 GEF. Thus, inactivation of Rab5 must be required for the normal process of adipogenesis. Actually, a decrease in adipocytes formation was observed when all members of the Rin family were overexpressed; Rin1 showed the greatest inhibitory effect.

Rab5 activation may not be the only factor explaining the inhibitory effect of Rin1 in preadipocyte differentiation. Each individual domain of Rin1 seems to have the same or similar inhibitory effect, indicating a high level of complexity of Rin1 function. Consistent with this observation, individual mutations in selective domains of Rin1 partially reversed the inhibitory effect of Rin1:WT. These data indicate that all domains of Rin1 and its respective interactions with RTKs, Rab5 and Ras are necessary for its role in adipogenesis.

In the case of neurogenesis, several studies have shown that Rab5 activity inhibits neurite growth, and it has been shown to be related to inactivate Rab5 through RabGap5 interaction (Liu et al., 2007).

Even though each individual RTK signaling pathway has been extensively studied, there is no complete understanding of how signal transduction networks integrate upon simultaneous stimulus (Volinsky and Kholodenko, 2013). Crosstalk between signal transduction pathways occur at different levels: receptors, adaptor proteins, GTPases, and transcription factors can be involved in more than one pathway at a time resulting in different outcomes (Pawson et al., 2001). Some RTKs activate the same signaling pathways with different biological outcomes. Upon NGF stimulation, PC12 cells will differentiate, but 
upon EGF stimulation they will proliferate (Marshall, 1995). The key factor here seems to be the phosphorylation span of Erk. NGF-stimulated Erk lasts for hours, while the EGF-stimulated is just transiently activated (Heasley and Johnson, 1992). Rin1 overexpression in PC12 has no effect in neurite growth upon NGF stimulation. Thus, until now adipogenesis may be the only differentiation process affected by Rin1.

As indicated in Chapter 1, several small molecules have been implicated in different enzymatic activities, for example, RTKs inhibitors (Han et al., 1996). As described above, Rin1 and Rab5 have an effect in adipogenesis. In addition, other proteins (AMPK, C/EBPa and PPARY) have been shown to be required in different steps of the differentiation processes (Hwang et al., 1997).

The small molecule DhL showed a selective inhibitory effect in adipogenesis (Galvis et al., 2011). It attenuated dramatically the production of adipogenic transcriptional factors PPARY and C-EBPa during adipogenesis without altering the activation of Erk and Akt. In addition, it was also found that $\mathrm{DH}-\mathrm{DhL}$, a derivative of $\mathrm{DhL}$ with inactivated $\alpha$ - methylene-y-lactone function, also inhibited the formation of adipocytes. However, it required ten times the $\mathrm{DH}-$ DhL concentration to achieve the same effect as DhL. Based on these observations, it is clear that in the adipocyte differentiation model, the $\alpha$ methylene- $y$-lactone moiety causes a significant decrease of 3T3-L1 preadipocyte differentiation at lower concentrations without altering cell viability. The molecular mechanism by which $\mathrm{DhL}$ and $\mathrm{DH}-\mathrm{DhL}$ inhibit adipogenesis is not completely understood, but based on this work it can be concluded that it is 
independent from the expression and activation of Erk, Akt, Rin1 and Rab5. It is important elucidate the direct target(s) of DhL because it can be utilized as a potential treatment for obesity and other related diseases. 


\section{FUTURE WORK}

Further studies need to be carried out in order to understand the role of Rin1 in diseased cells at both, cellular and animal levels. First, it would be necessary to study the effect of the Rin1-RTK interaction, thought the SH2 domain, in receptor degradation and signal attenuation. Second, study if the role of Rin1 through its interaction with Rab5 and Ras is cell/tissue-specific, by using other isoforms of the GTPases and examine the effect of these interactions in signal transduction and receptor trafficking. Third, to elucidate the molecular mechanisms used by Rin1 (and the small molecule $\mathrm{DhL}$ ) to inhibit adipogenesis. All this knowledge may lead to a possible treatment for adipogenesis regulation and other diseases related to RTKs signaling and trafficking misregulation. 


\section{MATERIALS AND METHODS}

\section{Cloning.}

Full length proteins and their domains (cDNAs) were cloned in the following vectors according to the technique used: pGEX-4T-1 (for the production of GST fusion proteins),t pB42AD and pLexA (for proteins used in the yeast two-hybrid system) and pMX-puro (for retrovirus production).

Point mutations were done using the QuickChange kit by Strategene following the manufacturer's protocol, except for the following mutations that were done by Genscript: Rin1:K642A/K662A/L675A and R702A. Oligonucleotide primers for cloning and mutagenesis were purchased from Sigma.

Construction of recombinant retroviruses and stable cell lines expressing protein constructs.

Rin1:WT, Rin1 mutants, Rin2:WT, Rin3:WT and Rab5:WT were sub-cloned into EcoRI restriction sites of the pMX-puro vector (Schlessinger, 2002; Zhu et al., 2001). To make stable cell lines expressing the constructs mentioned above, Plat-E packaging cells were cultured in Dulbecco's modified Eagle's medium (DMEM) containing 10\% fetal bovine serum (Han and Colicelli, 1995; Wang et al., 2002).

\section{Rin1 depletion in 3T3-L1 cells.}

3T3-L1 cells were transfected with lipofectamin and 100pmol RNAi against Rin1 either for one time (day 1 ) every $24 \mathrm{hrs}$ or every $48 \mathrm{hrs}$ during the differentiation process. At day 10 , cells were either lysed and Western blotting analysis was 
performed to confirm Rin1 depletion, or the cells were fixed for lipid content quantification.

\section{Lysate preparation, SDS-PAGE and Western blotting.}

To prepare whole cell lysates, cell monolayers were washed with phosphate buffer saline (PBS) and lysed in ice-cold lysis buffer (20mM Tris-HCL, 150mM $\mathrm{NaCl}, 1 \%$ Triton-X, $1 \mathrm{mM}$ PMSF, $1 \mathrm{mM} \mathrm{NaF}, 1 \mathrm{mM}$ sodium orhtovanadate). The lysates were clarified by centrifugation, and protein concentrations were determined by band intensities on SDS-PAGE gels stained with Coomassie Blue. Proteins were resolved by SDS-PAGE and transferred to nitrocellulose membranes, blocked and probed with the indicated antibodies. To determine relative protein amounts, three representative exposures for each sample were quantitated by densitometry analysis.

\section{GST-fused protein purification.}

pGEX-4T1 constructs (Rin1 full-length, domains and mutants) expressed in BL21 (DE3) RIPL Escherichia coli were induced with $0.25 \mathrm{mM}$ IPTG for three hours. Bacterial cells were resuspended in extraction buffer $(50 \mathrm{mM}$ Tris- $\mathrm{HCl}, 100 \mathrm{mM}$ $\mathrm{NaCl}, 1 \mathrm{mM}$ EDTA, 1mM EGTA , 1mM DTT, 1mM PMSF, 1mg/ml lysozyme, 10ug/ml DNAse, $2 \mathrm{ug} / \mathrm{ml}$ leupeptin, $2 \mu \mathrm{g} / \mathrm{ml}$ aprotinin) and lysed by sonication and

incubation with $1 \%$ Triton $\mathrm{X}-100$. Protein concentrations were determined by band intensities on SDS-PAGE gels stain with Coomassie Blue.

\section{Pull-down assay.}

For in vitro studies, fusion proteins were expressed and purified as in the protein purification section. For the GST-Pull-down ten $\mu \mathrm{g}$ of immobilized GST alone and 
GST-fused protein to glutathione sepharose beads were blocked with $0.1 \%$ BSA in extraction buffer and then were incubated with different amounts of cell lysate for $1 \mathrm{~h}$ at $4^{\circ} \mathrm{C}$ in binding buffer. After incubation, the beads were washed three times by centrifugation and bound proteins were eluted by the addition of SDS sample buffer. Solubilized proteins were separated by SDS-PAGE, and analyzed by Western blotting using the appropriate antibody.

\section{Rab5 activation assay.}

NR6-EGFR and NIH3T3-IR were stimulated as explained in the section of "Tyrosine kinase receptor-dependent signaling" below. The activation was done using the Rab5 activation assay kit following the manufacturer's protocol (New East Biosciences). Briefly, total cell lysates were incubated with anti-Rab5-GTP mouse monoclonal antibody. Then, protein $A / G$ agarose was used to pull down the bound Rab5-GTP and it was detected by Western blotting using rabbit antiRab5 antibody.

\section{Ras activation assay.}

NR6 cells expressing GFP and Rin1:WT were lysed using lysis buffer supplemented with $1 \mathrm{mM}$ PMSF. Lysates $(1 \mathrm{ml})$ were then incubated with $100 \mu \mathrm{l}$ glutathione beads containing $\sim 10 \mu \mathrm{g}$ of GST-RAF at $4^{\circ} \mathrm{C}$ while rocking for $1 \mathrm{hr}$. After incubation, the beads were washed three times using the lysis buffer. The pull-downs were subjected to SDS-PAGE and analyzed by Western Blotting using an anti-pan Ras antibody. Relative Units (\% of maximum) of proteins were determined by densitometry using the ratio of active Ras to total-Ras. 


\section{Insulin receptor tail phosphorylation.}

Six $\mu$ l of pure recombinant Insulin receptor tail were diluted in a buffer containing $10 \mathrm{mM} \mathrm{MgCl} 2,240 \mathrm{mM} \mathrm{NaCl}, 0.05 \%$ Triton-X 100, 50mM Tris HCL and $20 \mathrm{mM}$ ATP. The reaction was left 30 minutes at room temperature prior to the binding to the GST beads explained above.

\section{Immunoprecipitation assay.}

All immunoprecipitations were performed on cytosol prepared from cells in icecold buffer containing several phosphatase and protein inhibitors as described above. After clarification, protein concentrations were measured and samples were immunoprecipitated by incubation with the appropriate antibodies followed by immobilization on Protein G-Sepharose beads (Amersham Phar-macia Biotech). The beads were washed three times with buffer and the bound proteins were resuspended in sample buffer and analyzed by SDS-PAGE and Western blot with the indicated antibodies.

\section{Yeast Two-Hybrid assay.}

Two-hybrid LexA DNA binding domain (LexA-BD) and B42 transcription activation domain (B42AD) fusion constructs were prepared by ligating cDNAs for different proteins or protein fragments into the pLexA (His) and pB42AD (Trp) plasmids, respectively (Clontech). Mating and transformation of Yeast-EGY48 cells were done as described in the MATCHMAKER two-hybrid manual (Clontech). The Rin1 constructs were expressed as pB42AD fusion constructs whereas Rab5:S34N, HRas:V12, insulin receptor and insulin receptor: kinase dead mutants were expressed as pLexA fusion constructs. Yeast-EGY48 co- 
transformants were plated on medium without His $(H)$, Trp $(W)$, Leu $(L)$ or Ura (U) (-HWUL) to detect LacZ reporter gene activation due to interaction of constructs and on medium without His, Trp, or Ura (-HWU) as a control for loading and growth on galactose containing medium. All Rin1, Rab5, Ras and insulin receptor constructs were detected by Western blot analysis. For liquid $\beta$ galactosidase ( $\beta$-gal) assays, yeast was grown on appropriate selective media and assayed as described in the yeast $\beta$-gal assay manual (Pierce). Results were expressed in Units: one unit of $\beta$-gal was defined as 1000 xOD420/[time $x$ vol xOD660].

\section{Tyrosine kinase receptor-depending signaling.}

NR6-EGFR/ NIH3T3-IR/ PC12 cell monolayers were infected with pMX viruses (alone or Rin1 proteins) and were serum starved for $3 \mathrm{hrs}$ prior to activation with $100 \mathrm{ng} / \mu \mathrm{l} \mathrm{EGF,} \mathrm{100nM} \mathrm{insulin} \mathrm{or} 100 \mathrm{nM}$ NGF respectively, for 5 minutes. Cells were washed with PBS and lysed $(20 \mathrm{mM}$ Tris-HCL, $150 \mathrm{mM} \mathrm{NaCl}, 1 \%$ Triton-X, 1mM PMSF, $1 \mathrm{mM} \mathrm{NaF}, 1 \mathrm{mM}$ sodium orhtovanadate). Cell proteins were separated by SDS-PAGE, and analyzed by Western blotting using the appropriate antibody for different signaling proteins (i.e., phospho and total-Erk, Akt, p38 and Junk). Relative levels of the proteins were determined by densitometry.

\section{T3-L1 preadipocyte differentiation.}

3T3-L1 cells (ATCC) were grown to confluence in DMEM high glucose supplemented with $10 \%$ fetal bovine serum, $1 \%$ penicillin/ streptomycin and $1 \%$ L-glutamine (growth media) in a humidified atmosphere of $5 \% \mathrm{CO}_{2}$ at $37^{\circ} \mathrm{C}$. 
Culture was fed every $48 \mathrm{hrs}$, both for cell growth and differentiation. To trigger differentiation cells were exposed to differentiation medium (growth media supplemented with $670 \mathrm{nM}$ insulin, $65 \mathrm{nM}$ dexamethasone and $0.5 \mathrm{mM} 3$-isobutyl1-methylxanthine [IBMX]) for the first two days, then fed with post-differentiation media (DMEM high glucose supplemented with $5 \%$ fetal bovine serum, $1 \%$ penicillin/streptomycin, 1\% L-glutamine and $670 \mathrm{nM}$ insulin) for the next seven days. DhL treated cells were exposed to the compound the entire process with different concentrations, unless otherwise indicated.

\section{High-performance liquid chromatography analysis.}

The high-performance liquid chromatography (HPLC) equipment consisted of a SpectraSystem SMC1000 solvent delivery system, vacuum membrane degasser, P4000 gradient pumps and AS3000 autosampler (Thermo Electro Corporation). Column effluent was monitored at $254 \mathrm{~nm}$ with Spectra System UV6000LP variable wavelength PDA detector and ChromQuest 4.1 software. DhL, (11S)DHDhL and (11R)DH-DhL were separated using a C18 YMC column (A-302, 150x $4.3 \mathrm{~mm}$ i.d., S-5 $\mu \mathrm{m}, 12 \mathrm{~nm}$; Waters) and the following solvents: A. acetonitrile; and B. $0.1 \%$ TFA in water. System 1: linear gradient $10 \%$ to $100 \%$ A in 120 minutes; flow rate $1 \mathrm{ml} / \mathrm{min}$. Preparative HPLC was performed in the above equipment with a XTerra Prep MS C18 OBD column, $15 \mu \mathrm{m}, 19 \times 50 \mathrm{~mm}$ (Waters) and the solvent system $25 \%$ acetonitrile- $75 \% 0.1 \%$ TFA in water (isocratic); flow rate $3 \mathrm{ml} / \mathrm{min}$. 
Gas chromatography (GC)/flame ionization detector (FID) and GC/ mass spectrometry (MS) analysis of DhL derivatives.

GC/FID analyses were performed on a Trace GC Ultra apparatus (Thermo Electro Corporation) equipped with a flame ionization detector. The output was recorded using a ChromQuest version 4.1 data system. A DB-5MS capillary column (0.25 mm i.d. $\times 30 \mathrm{~m}$; film thickness $0.25 \mu \mathrm{m}$; J \& W Scientific) was employed. The temperature was programmed 105 to $240^{\circ} \mathrm{C}$ at $3^{\circ} \mathrm{C} / \mathrm{min}$ (linear increase) and then the temperature was held at $240^{\circ} \mathrm{C}$ for 10 minutes. The injector temperature was $250^{\circ} \mathrm{C}$ with a split ratio of $1 / 20$. The detector temperature was $270^{\circ} \mathrm{C}$. Helium was used as gas carrier at $1 \mathrm{ml} / \mathrm{min}$. DHL, (11S)DH-DHL and (11R)DH-DhL were dissolved in ethyl acetate and $2 \mu$ of the solution was injected. GC/MS determinations were carried out in a HewlettPackard model 6890 instrument coupled to a Q-Mass 910 quadrupole selective detector at $70 \mathrm{eV}$ and equipped with a DB-5MS capillary column. Temperature program and other conditions were as indicated above.

\section{DhL derivatives: compound identification.}

Dehydroleucodine $\quad\{(1 \mathrm{~S}, 6 \mathrm{~S}, 2 \mathrm{R})-9,13-$ dimethyl-5-methylene-3oxatri- $\quad$ cyclo [8.3.0.0b2,6N] trideca-9,12-diene-4,11-dione, IUPAC nomenclature\}. DhL (compound 1): HPLC (System 1), Rt $27.74 \mathrm{~min}$; GC/MS, Rt 22.72 min; UV/PDA $\lambda \max 256$ nm; MS m/z (rel. int.), 244 (100) M+, 173 (18.2), 145 (19.8), 129 (18.9), 115 (18.5), 105 (18.3), 91 (62.9), 79 (17.7), 77 (28.4), 65 (21.6), 53 (30.8). (1S,2S,5S,6S)-5,9,13-trimethyl-3-oxatricyclo[8.3.0.0b2,6N]trideca-9, 12-diene4,11-dione;11,13-dihydro-dehydroleucodine (IUPAC nomenclature), (11S)DH- 
DhL (compound 2): HPLC (System 1), Rt 28.16 min; GC/MS, Rt 21.87; UV/PDA $\lambda \max 257$ nm; MS, m/z (rel. int.): 246 (100) M+, 217 (26.7), 173 (37.6), 172 (31.2), 145 (26.2), 105 (23.2), 91 (60.7), 77 (26.2), 55 (24.3). (1S,2S,6S,5R)5,9,13-trimethyl-3-oxatricyclo[8.3.0.0b2,6N]trideca-9, 12-diene-4,11-dione, 11,13dihydro-dehydroleucodine (IUPAC nomenclature), (11R)DH-DhL (compound 3): HPLC (System 1), Rt 26.23 min; GC/MS, Rt 22.84; UV/PDA Amax 257 nm; MS, m/z (rel. int.): 246 (100) M+, 217 (31.5), 173 (35.5), 172 (33.1), 145 (27.5), 105 (26.1), 91 (67.1), 77 (29.0), 55 (25.8).

\section{Effect of DhL in Rin and Rab5 expression and activation.}

$\mathrm{NIH} 3 \mathrm{~T} 3$ cells overexpressing GFP-Rab5 or Rin1 were exposed to $8 \mu \mathrm{M}$ DhL for 6hrs. For protein expression, the cells were lysed and total protein extracts were subset to $12 \%$ SDS-PAGE electrophoresis, blotted to a nitrocellulose membrane, and probed with Rab5 or Rin1, and tubulin antibodies. For Rab5 activity, the cells were fixed with $2 \%$ paraformaldehyde for 20 minutes, and the diameter and perimeter of Rab5-positive endosomes were measured using the ImageJ64 software.

\section{Adipogenesis quantification.}

On the tenth day of differentiation cells were fixed with $10 \%$ formalin in PBS $1 \mathrm{hr}$ at $4^{\circ} \mathrm{C}$. Oil Red $\mathrm{O}$ (Allied Chemical) stock solution $(0.6 \mathrm{~g}$ in $100 \mathrm{ml}$ of isopropanol) was diluted with 0.6 parts of water, filtered and added to the fixed cells for 15 minutes at room temperature. Cells were washed with water and analyzed in an inverted microscope (photos of lipid droplets were taken). To quantify the lipid droplets, Oil Red O was eluted with $100 \%$ isopropanol for 10 minutes at $37^{\circ} \mathrm{C}$, 
collected, and its optical density was measured at $540 \mathrm{~nm}$. Lipid quantification was verified by studying the expression levels of adipogenic differentiation markers, such as of AMPK, FAS, PPARY, and C-EBPa by Western blotting as explained above.

\section{Neurogenesis.}

PC12 cells were grown to confluence in DMEM high glucose supplemented with $5 \%$ fetal bovine serum, $10 \%$ horse serum, $1 \%$ penicillin/streptomycin and $1 \% \mathrm{~L}$ glutamine (growth media) in a humidified atmosphere of $5 \% \mathrm{CO}_{2}$ at $37^{\circ} \mathrm{C}$. Culture was fed every 48hrs, both for cell growth and differentiation. To trigger neurogenesis cells were exposed to differentiation medium (DMEM, 1\% horse serum, $1 \%$ penicillin/streptomycin and $100 \mathrm{ng} / \mathrm{ml} \mathrm{NGF)} \mathrm{during} \mathrm{the} 10$ days treatment. Neurite outgrowth was monitored daily and cell processes longer than one cell body in diameter was counted as neurites.

\section{Statistical analysis.}

All experiments presented were repeated a minimum of 3 times. The data represent the mean \pm SEM. Student's $t$ test was performed to calculate statistical significance. 


\section{REFERENCES}

Abdipranoto, A., S. Wu, S. Stayte, and B. Vissel. 2008. The role of neurogenesis in neurodegenerative diseases and its implications for therapeutic development. CNS Neurol Disord Drug Targets. 7:187-210.

Abidov, M.T., M.J. del Rio, T.Z. Ramazanov, A.L. Klimenov, S. Dzhamirze, and O.V. Kalyuzhin. 2006. Effects of Aralia mandshurica and Engelhardtia chrysolepis extracts on some parameters of lipid metabolism in women with nondiabetic obesity. Bull Exp Biol Med. 141:343-346.

Adebajo, A.C., E.O. Olawode, O.R. Omobuwajo, S.A. Adesanya, F. Begrow, A. Elkhawad, M.A. Akanmu, R. Edrada, P. Proksch, T.J. Schmidt, M. Klaes, and E.J. Verspohl. 2007. Hypoglycaemic constituents of Stachytarpheta cayennensis leaf. Planta medica. 73:241-250.

Agola, J., P. Jim, H. Ward, S. Basuray, and A. Wandinger-Ness. 2011. Rab GTPases as regulators of endocytosis, targets of disease and therapeutic opportunities. Clin Genet.

Ahn, I.S., M.S. Do, S.O. Kim, H.S. Jung, Y.I. Kim, H.J. Kim, and K.Y. Park. 2006. Antiobesity effect of Kochujang (Korean fermented red pepper paste) extract in 3T3-L1 adipocytes. J Med Food. 9:15-21.

Albert, S., E. Will, and D. Gallwitz. 1999. Identification of the catalytic domains and their functionally critical arginine residues of two yeast GTPase-activating proteins specific for Ypt/Rab transport GTPases. EMBO J. 18:5216-5225.

Alleva, E., and D. Santucci. 2001. Psychosocial vs. "physical" stress situations in rodents and humans: role of neurotrophins. Physiol Behav. 73:313-320.

Aravindaram, K., and N.S. Yang. 2010. Anti-inflammatory plant natural products for cancer therapy. Planta medica. 76:1103-1117.

Arteaga, C.L. 2002. Epidermal growth factor receptor dependence in human tumors: more than just expression? Oncologist. 7 Suppl 4:31-39.

Auld, C.A., R.G. Hopkins, K.M. Fernandes, and R.F. Morrison. 2006. Novel effect of helenalin on Akt signaling and Skp2 expression in 3T3-L1 preadipocytes. Biochemical and biophysical research communications. 346:314-320.

Avraham, R., and Y. Yarden. 2011. Feedback regulation of EGFR signalling: decision making by early and delayed loops. Nat Rev Mol Cell Biol. 12:104-117.

Balandrin, M.F., J.A. Klocke, E.S. Wurtele, and W.H. Bollinger. 1985. Natural plant chemicals: sources of industrial and medicinal materials. Science. 228:1154-1160. 
Balunas, M.J., and A.D. Kinghorn. 2005. Drug discovery from medicinal plants. Life Sci. 78:431-441.

Barbieri, M.A., C. Kong, P.I. Chen, B.F. Horazdovsky, and P.D. Stahl. 2003. The SRC homology 2 domain of Rin1 mediates its binding to the epidermal growth factor receptor and regulates receptor endocytosis. The Journal of biological chemistry. 278:32027-32036.

Barbieri, M.A., G. Li, M.I. Colombo, and P.D. Stahl. 1994. Rab5, an early acting endosomal GTPase, supports in vitro endosome fusion without GTP hydrolysis. The Journal of biological chemistry. 269:18720-18722.

Barbieri, M.A., G. Li, L.S. Mayorga, and P.D. Stahl. 1996. Characterization of Rab5:Q79L-stimulated endosome fusion. Arch Biochem Biophys. 326:64-72.

Barbieri, M.A., R.L. Roberts, A. Gumusboga, H. Highfield, C. AlvarezDominguez, A. Wells, and P.D. Stahl. 2000. Epidermal growth factor and membrane trafficking. EGF receptor activation of endocytosis requires Rab5a. $J$ Cell Biol. 151:539-550.

Basel-Vanagaite, L., O. Sarig, D. Hershkovitz, D. Fuchs-Telem, D. Rapaport, A. Gat, G. Isman, I. Shirazi, M. Shohat, C.D. Enk, E. Birk, J. Kohlhase, U. MatysiakScholze, I. Maya, C. Knopf, A. Peffekoven, H.C. Hennies, R. Bergman, M. Horowitz, A. Ishida-Yamamoto, and E. Sprecher. 2009. RIN2 deficiency results in macrocephaly, alopecia, cutis laxa, and scoliosis: MACS syndrome. Am J Hum Genet. 85:254-263.

Beekman, A.C., H.J. Woerdenbag, W. van Uden, N. Pras, A.W. Konings, H.V. Wikstrom, and T.J. Schmidt. 1997. Structure-cytotoxicity relationships of some helenanolide-type sesquiterpene lactones. Journal of natural products. 60:252257.

Belfiore, A., F. Frasca, G. Pandini, L. Sciacca, and R. Vigneri. 2009. Insulin receptor isoforms and insulin receptor/insulin-like growth factor receptor hybrids in physiology and disease. Endocr Rev. 30:586-623.

Berger, T.G., D. Dieckmann, T. Efferth, E.S. Schultz, J.O. Funk, A. Baur, and G. Schuler. 2005. Artesunate in the treatment of metastatic uveal melanoma--first experiences. Oncol Rep. 14:1599-1603.

Besterman, J.M., and R.B. Low. 1983. Endocytosis: a review of mechanisms and plasma membrane dynamics. Biochem J. 210:1-13.

Biocca, S., A. Cattaneo, and P. Calissano. 1983. A macromolecular structure favouring microtubule assembly in NGF-differentiated pheochromocytoma cells (PC12). EMBO J. 2:643-648. 
Blanco, J.G., R.R. Gil, C.I. Alvarez, L.C. Patrito, S. Genti-Raimondi, and A. Flury. 1997. A novel activity for a group of sesquiterpene lactones: inhibition of aromatase. FEBS Lett. 409:396-400.

Bohlmann, F., and C. Zdero. 1972. Zwei neue Sesquiterpenlactone aus Lidbeckia pectinata Berg. und Pentzia elegans DC. Tetrahedron Letters. 13:621-624.

Brengio, S.D., S.A. Belmonte, E. Guerreiro, O.S. Giordano, E.O. Pietrobon, and M.A. Sosa. 2000. The sesquiterpene lactone dehydroleucodine (DhL) affects the growth of cultured epimastigotes of Trypanosoma cruzi. The Journal of parasitology. 86:407-412.

Brodeur, G.M., J.E. Minturn, R. Ho, A.M. Simpson, R. Iyer, C.R. Varela, J.E. Light, V. Kolla, and A.E. Evans. 2009. Trk receptor expression and inhibition in neuroblastomas. Clin Cancer Res. 15:3244-3250.

Bublil, E.M., and Y. Yarden. 2007. The EGF receptor family: spearheading a merger of signaling and therapeutics. Curr Opin Cell Biol. 19:124-134.

Bucci, C., R.G. Parton, I.H. Mather, H. Stunnenberg, K. Simons, B. Hoflack, and M. Zerial. 1992. The small GTPase rab5 functions as a regulatory factor in the early endocytic pathway. Cell. 70:715-728.

Campbell, S.J., and R.M. Jackson. 2003. Diversity in the SH2 domain family phosphotyrosyl peptide binding site. Protein Eng. 16:217-227.

Cannon, B., and J. Nedergaard. 2004. Brown adipose tissue: function and physiological significance. Physiol Rev. 84:277-359.

Carney, D.S., B.A. Davies, and B.F. Horazdovsky. 2006. Vps9 domain-containing proteins: activators of Rab5 GTPases from yeast to neurons. Trends in cell biology. 16:27-35.

Carpenter, C.L., and L.C. Cantley. 1996. Phosphoinositide 3-kinase and the regulation of cell growth. Biochim Biophys Acta. 1288:M11-16.

Carpenter, G. 1987. Receptors for epidermal growth factor and other polypeptide mitogens. Annu Rev Biochem. 56:881-914.

Cazzaniga, G., S. Tosi, A. Aloisi, G. Giudici, M. Daniotti, P. Pioltelli, L. Kearney, and A. Biondi. 1999. The tyrosine kinase abl-related gene ARG is fused to ETV6 in an AML-M4Eo patient with a $\mathrm{t}(1 ; 12)(\mathrm{q} 25 ; \mathrm{p} 13)$ : molecular cloning of both reciprocal transcripts. Blood. 94:4370-4373. 
Ceresa, B.P., A.W. Kao, S.R. Santeler, and J.E. Pessin. 1998. Inhibition of clathrin-mediated endocytosis selectively attenuates specific insulin receptor signal transduction pathways. Molecular and cellular biology. 18:3862-3870.

Cheng, C.H., B. Costall, M. Hamburger, K. Hostettmann, R.J. Naylor, Y. Wang, and P. Jenner. 1992. Toxic effects of solstitialin A 13-acetate and cynaropicrin from Centaurea solstitialis L. (Asteraceae) in cell cultures of foetal rat brain. Neuropharmacology. 31:271-277.

Cheng, Z., Y. Tseng, and M.F. White. 2010. Insulin signaling meets mitochondria in metabolism. Trends Endocrinol Metab. 21:589-598.

Chotard, L., A.K. Mishra, M.A. Sylvain, S. Tuck, D.G. Lambright, and C.E. Rocheleau. 2010. TBC-2 regulates RAB-5/RAB-7-mediated endosomal trafficking in Caenorhabditis elegans. Mol Biol Cell. 21:2285-2296.

Christensen, S.B., D.M. Skytte, S.R. Denmeade, C. Dionne, J.V. Moller, P. Nissen, and J.T. Isaacs. 2009. A Trojan horse in drug development: targeting of thapsigargins towards prostate cancer cells. Anticancer Agents Med Chem. 9:276-294.

Colicelli, J. 2004. Human RAS superfamily proteins and related GTPases. Sci STKE. 2004:RE13.

Connor, B., and M. Dragunow. 1998. The role of neuronal growth factors in neurodegenerative disorders of the human brain. Brain Res Brain Res Rev. 27:139.

Costantino, V.V., S.F. Mansilla, J. Speroni, C. Amaya, D. Cuello-Carrion, D.R. Ciocca, H.A. Priestap, M.A. Barbieri, V. Gottifredi, and L.A. Lopez. 2013. The sesquiterpene lactone dehydroleucodine triggers senescence and apoptosis in association with accumulation of DNA damage markers. PLoS One. 8:e53168.

Daval, M., F. Foufelle, and P. Ferre. 2006. Functions of AMP-activated protein kinase in adipose tissue. $J$ Physiol. 574:55-62.

Denmeade, S.R., and J.T. Isaacs. 2005. The SERCA pump as a therapeutic target: making a "smart bomb" for prostate cancer. Cancer Biol Ther. 4:14-22.

Downward, J., P. Parker, and M.D. Waterfield. 1984. Autophosphorylation sites on the epidermal growth factor receptor. Nature. 311:483-485.

Dulloo, A.G. 1993. Ephedrine, xanthines and prostaglandin-inhibitors: actions and interactions in the stimulation of thermogenesis. Int $\mathrm{J}$ Obes Relat Metab Disord. 17 Suppl 1:S35-40. 
Dunn, W.A., and A.L. Hubbard. 1984. Receptor-mediated endocytosis of epidermal growth factor by hepatocytes in the perfused rat liver: ligand and receptor dynamics. J Cell Biol. 98:2148-2159.

Efferth, T. 2006. Molecular pharmacology and pharmacogenomics of artemisinin and its derivatives in cancer cells. Curr Drug Targets. 7:407-421.

Eriksson, P.S., E. Perfilieva, T. Bjork-Eriksson, A.M. Alborn, C. Nordborg, D.A. Peterson, and F.H. Gage. 1998. Neurogenesis in the adult human hippocampus. Nat Med. 4:1313-1317.

Evans, R.M., G.D. Barish, and Y.X. Wang. 2004. PPARs and the complex journey to obesity. Nat Med. 10:355-361.

Faigle, R., and H. Song. 2013. Signaling mechanisms regulating adult neural stem cells and neurogenesis. Biochim Biophys Acta. 1830:2435-2448.

Fernandez-Medarde, A., and E. Santos. 2011. Ras in cancer and developmental diseases. Genes Cancer. 2:344-358.

Fischer, O.M., S. Hart, A. Gschwind, and A. Ullrich. 2003. EGFR signal transactivation in cancer cells. Biochem Soc Trans. 31:1203-1208.

Friedman, E., P.V. Gejman, G.A. Martin, and F. McCormick. 1993. Nonsense mutations in the C-terminal $\mathrm{SH} 2$ region of the GTPase activating protein (GAP) gene in human tumours. Nat Genet. 5:242-247.

Galvis, A., H. Giambini, Z. Villasana, and M.A. Barbieri. 2009. Functional determinants of ras interference 1 mutants required for their inhbitory activity on endocytosis. Exp Cell Res. 315:820-835.

Galvis, A., A. Marcano, C. Stefancin, N. Villaverde, H.A. Priestap, C.E. Tonn, L.A. Lopez, and M.A. Barbieri. 2011. The effect of dehydroleucodine in adipocyte differentiation. European journal of pharmacology. 671:18-25.

Garlid, K.D., M. Jaburek, and P. Jezek. 1998. The mechanism of proton transport mediated by mitochondrial uncoupling proteins. FEBS Lett. 438:10-14.

Ghantous, A., H. Gali-Muhtasib, H. Vuorela, N.A. Saliba, and N. Darwiche. 2010. What made sesquiterpene lactones reach cancer clinical trials? Drug Discov Today. 15:668-678.

Giordano, O.S., E. Guerreiro, M.J. Pestchanker, J. Guzman, D. Pastor, and T. Guardia. 1990. The gastric cytoprotective effect of several sesquiterpene lactones. Journal of natural products. 53:803-809. 
Giordano, O.S., M.J. Pestchanker, E. Guerreiro, J.R. Saad, R.D. Enriz, A.M. Rodriguez, E.A. Jauregui, J. Guzman, A.O. Maria, and G.H. Wendel. 1992. Structure-activity relationship in the gastric cytoprotective effect of several sesquiterpene lactones. Journal of medicinal chemistry. 35:2452-2458.

Goedert, M. 2001. Alpha-synuclein and neurodegenerative diseases. Nat Rev Neurosci. 2:492-501.

Goldstein, J.L., M.S. Brown, R.G. Anderson, D.W. Russell, and W.J. Schneider. 1985. Receptor-mediated endocytosis: concepts emerging from the LDL receptor system. Annu Rev Cell Biol. 1:1-39.

Gopal, Y.N., E. Chanchorn, and M.W. Van Dyke. 2009. Parthenolide promotes the ubiquitination of MDM2 and activates p53 cellular functions. Mol Cancer Ther. 8:552-562.

Gorvel, J.P., P. Chavrier, M. Zerial, and J. Gruenberg. 1991. rab5 controls early endosome fusion in vitro. Cell. 64:915-925.

Gotz, M., and W.B. Huttner. 2005. The cell biology of neurogenesis. Nat Rev Mol Cell Biol. 6:777-788.

Grimes, M.L., J. Zhou, E.C. Beattie, E.C. Yuen, D.E. Hall, J.S. Valletta, K.S. Topp, J.H. LaVail, N.W. Bunnett, and W.C. Mobley. 1996. Endocytosis of activated TrkA: evidence that nerve growth factor induces formation of signaling endosomes. J Neurosci. 16:7950-7964.

Gschwind, A., E. Zwick, N. Prenzel, M. Leserer, and A. Ullrich. 2001. Cell communication networks: epidermal growth factor receptor transactivation as the paradigm for interreceptor signal transmission. Oncogene. 20:1594-1600.

Guillausseau, P.J., T. Meas, M. Virally, M. Laloi-Michelin, V. Medeau, and J.P. Kevorkian. 2008. Abnormalities in insulin secretion in type 2 diabetes mellitus. Diabetes Metab. 34 Suppl 2:S43-48.

Gurkan, C., H. Lapp, C. Alory, A.I. Su, J.B. Hogenesch, and W.E. Balch. 2005. Large-scale profiling of Rab GTPase trafficking networks: the membrome. Mol Biol Cell. 16:3847-3864.

Haas, A.K., E. Fuchs, R. Kopajtich, and F.A. Barr. 2005. A GTPase-activating protein controls Rab5 function in endocytic trafficking. Nat Cell Biol. 7:887-893.

Hama, H., G.G. Tall, and B.F. Horazdovsky. 1999. Vps9p is a guanine nucleotide exchange factor involved in vesicle-mediated vacuolar protein transport. The Journal of biological chemistry. 274:15284-15291. 
Han, L., and J. Colicelli. 1995. A human protein selected for interference with Ras function interacts directly with Ras and competes with Raf1. Molecular and cellular biology. 15:1318-1323.

Han, Y., C.G. Caday, A. Nanda, W.K. Cavenee, and H.J. Huang. 1996. Tyrphostin AG 1478 preferentially inhibits human glioma cells expressing truncated rather than wild-type epidermal growth factor receptors. Cancer Res. 56:3859-3861.

Hancock, J.F. 2003. Ras proteins: different signals from different locations. Nat Rev Mol Cell Biol. 4:373-384.

Hannink, M., and D.J. Donoghue. 1989. Structure and function of platelet-derived growth factor (PDGF) and related proteins. Biochim Biophys Acta. 989:1-10.

Hardy, J., and D.J. Selkoe. 2002. The amyloid hypothesis of Alzheimer's disease: progress and problems on the road to therapeutics. Science. 297:353-356.

Harmon, A.W., and J.B. Harp. 2001. Differential effects of flavonoids on 3T3-L1 adipogenesis and lipolysis. Am J Physiol Cell Physiol. 280:C807-813.

Harris, R.C., E. Chung, and R.J. Coffey. 2003. EGF receptor ligands. Exp Cell Res. 284:2-13.

Hartwell, J.L., and B.J. Abbott. 1969. Antineoplastic principles in plants: recent developments in the field. Adv Pharmacol. 7:117-209.

Hassan, M., N. Latif, and M. Yacoub. 2012. Adipose tissue: friend or foe? Nat Rev Cardiol. 9:689-702.

Hay, A.J., M. Hamburger, K. Hostettmann, and J.R. Hoult. 1994. Toxic inhibition of smooth muscle contractility by plant-derived sesquiterpenes caused by their chemically reactive alpha-methylenebutyrolactone functions. British journal of pharmacology. 112:9-12.

Hayashi, K., T. Hayashi, K. Ujita, and Y. Takaishi. 1996. Characterization of antiviral activity of a sesquiterpene, triptofordin C-2. The Journal of antimicrobial chemotherapy. 37:759-768.

Heasley, L.E., and G.L. Johnson. 1992. The beta-PDGF receptor induces neuronal differentiation of PC12 cells. Mol Biol Cell. 3:545-553.

Heath, C.M., P.D. Stahl, and M.A. Barbieri. 2003. Lipid kinases play crucial and multiple roles in membrane trafficking and signaling. Histol Histopathol. 18:989998. 
Hehner, S.P., M. Heinrich, P.M. Bork, M. Vogt, F. Ratter, V. Lehmann, K. Schulze-Osthoff, W. Droge, and M.L. Schmitz. 1998. Sesquiterpene lactones specifically inhibit activation of NF-kappa B by preventing the degradation of I kappa B-alpha and I kappa B-beta. The Journal of biological chemistry. 273:1288-1297.

Heinrich, M., M. Robles, J.E. West, B.R. Ortiz de Montellano, and E. Rodriguez. 1998. Ethnopharmacology of Mexican asteraceae (Compositae). Annu Rev Pharmacol Toxicol. 38:539-565.

Henson, E.S., and S.B. Gibson. 2006. Surviving cell death through epidermal growth factor (EGF) signal transduction pathways: implications for cancer therapy. Cell Signal. 18:2089-2097.

Holbro, T., and N.E. Hynes. 2004. ErbB receptors: directing key signaling networks throughout life. Annu Rev Pharmacol Toxicol. 44:195-217.

Hoppener, J.W., P. de Pagter-Holthuizen, A.H. Geurts van Kessel, M. Jansen, S.D. Kittur, S.E. Antonarakis, C.J. Lips, and J.S. Sussenbach. 1985. The human gene encoding insulin-like growth factor I is located on chromosome 12. Hum Genet. 69:157-160.

Hsu, C.L., and G.C. Yen. 2006. Induction of cell apoptosis in 3T3-L1 preadipocytes by flavonoids is associated with their antioxidant activity. Mol Nutr Food Res. 50:1072-1079.

Hu, H., M. Milstein, J.M. Bliss, M. Thai, G. Malhotra, L.C. Huynh, and J. Colicelli. 2008. Integration of transforming growth factor beta and RAS signaling silences a RAB5 guanine nucleotide exchange factor and enhances growth factor-directed cell migration. Molecular and cellular biology. 28:1573-1583.

Hua, Q. 2010. Insulin: a small protein with a long journey. Protein Cell. 1:537551.

Hubbard, S.R., and W.T. Miller. 2007. Receptor tyrosine kinases: mechanisms of activation and signaling. Curr Opin Cell Biol. 19:117-123.

Hunker, C.M., A. Galvis, I. Kruk, H. Giambini, M.L. Veisaga, and M.A. Barbieri. 2006a. Rab5-activating protein 6 , a novel endosomal protein with a role in endocytosis. Biochemical and biophysical research communications. 340:967975.

Hunker, C.M., A. Galvis, M.L. Veisaga, and M.A. Barbieri. 2006b. Rin1 is a negative regulator of the IL3 receptor signal transduction pathways. Anticancer Res. 26:905-916. 
Hunter, T., and J.A. Cooper. 1985. Protein-tyrosine kinases. Annu Rev Biochem. 54:897-930.

Hwang, C.S., T.M. Loftus, S. Mandrup, and M.D. Lane. 1997. Adipocyte differentiation and leptin expression. Annu Rev Cell Dev Biol. 13:231-259.

Hwang, D., N.H. Fischer, B.C. Jang, H. Tak, J.K. Kim, and W. Lee. 1996. Inhibition of the expression of inducible cyclooxygenase and proinflammatory cytokines by sesquiterpene lactones in macrophages correlates with the inhibition of MAP kinases. Biochemical and biophysical research communications. 226:810-818.

Hwang, J.T., I.J. Park, J.I. Shin, Y.K. Lee, S.K. Lee, H.W. Baik, J. Ha, and O.J. Park. 2005. Genistein, EGCG, and capsaicin inhibit adipocyte differentiation process via activating AMP-activated protein kinase. Biochemical and biophysical research communications. 338:694-699.

Inoue, T., T. Goi, Y. Hirono, K. Katayama, and A. Yamaguchi. 2011. RIN1-RasERK pathway plays an important role in carcinogenesis in colon cancer cell line LoVo. Oncol Res. 19:527-534.

Janson, C., N. Kasahara, G.C. Prendergast, and J. Colicelli. 2012. RIN3 is a negative regulator of mast cell responses to SCF. PLoS One. 7:e49615.

Jordan, C.T. 2006. Searching for leukemia stem cells--not yet the end of the road? Cancer Cell. 10:253-254.

Kajiho, H., K. Saito, K. Tsujita, K. Kontani, Y. Araki, H. Kurosu, and T. Katada. 2003. RIN3: a novel Rab5 GEF interacting with amphiphysin II involved in the early endocytic pathway. Journal of cell science. 116:4159-4168.

Kaksonen, M., C.P. Toret, and D.G. Drubin. 2006. Harnessing actin dynamics for clathrin-mediated endocytosis. Nat Rev Mol Cell Biol. 7:404-414.

Kawasaki, B.T., E.M. Hurt, M. Kalathur, M.A. Duhagon, J.A. Milner, Y.S. Kim, and W.L. Farrar. 2009. Effects of the sesquiterpene lactone parthenolide on prostate tumor-initiating cells: An integrated molecular profiling approach. Prostate. 69:827-837.

Kong, C., X. Su, P.I. Chen, and P.D. Stahl. 2007. Rin1 interacts with signaltransducing adaptor molecule (STAM) and mediates epidermal growth factor receptor trafficking and degradation. The Journal of biological chemistry. 282:15294-15301.

Koppen, A., and E. Kalkhoven. 2010. Brown vs white adipocytes: the PPARgamma coregulator story. FEBS Lett. 584:3250-3259. 
Kruttgen, A., I. Schneider, and J. Weis. 2006. The dark side of the NGF family: neurotrophins in neoplasias. Brain Pathol. 16:304-310.

Lane, M.D., Q.Q. Tang, and M.S. Jiang. 1999. Role of the CCAAT enhancer binding proteins (C/EBPs) in adipocyte differentiation. Biochemical and biophysical research communications. 266:677-683.

Lee, K.H., E.S. Huang, C. Piantadosi, J.S. Pagano, and T.A. Geissman. 1971. Cytotoxicity of sesquiterpene lactones. Cancer Res. 31:1649-1654.

Li, G., M.A. Barbieri, M.I. Colombo, and P.D. Stahl. 1994. Structural features of the GTP-binding defective Rab5 mutants required for their inhibitory activity on endocytosis. The Journal of biological chemistry. 269:14631-14635.

Li, G., and H. Qian. 2002. Kinetic timing: a novel mechanism that improves the accuracy of GTPase timers in endosome fusion and other biological processes. Traffic. 3:249-255.

Li, G., and P.D. Stahl. 1993. Structure-function relationship of the small GTPase rab5. The Journal of biological chemistry. 268:24475-24480.

Lim, J.P., and P.A. Gleeson. 2011. Macropinocytosis: an endocytic pathway for internalising large gulps. Immunol Cell Biol. 89:836-843.

Liu, J., D. Lamb, M.M. Chou, Y.J. Liu, and G. Li. 2007. Nerve growth factormediated neurite outgrowth via regulation of Rab5. Mol Biol Cell. 18:1375-1384.

Lu, L. 2002. [Study on effect of Cordyceps sinensis and artemisinin in preventing recurrence of lupus nephritis]. Zhongguo Zhong Xi Yi Jie He Za Zhi. 22:169-171.

Lyss, G., A. Knorre, T.J. Schmidt, H.L. Pahl, and I. Merfort. 1998. The antiinflammatory sesquiterpene lactone helenalin inhibits the transcription factor NFkappaB by directly targeting p65. The Journal of biological chemistry. 273:3350833516.

MacLean, D.B., and L.G. Luo. 2004. Increased ATP content/production in the hypothalamus may be a signal for energy-sensing of satiety: studies of the anorectic mechanism of a plant steroidal glycoside. Brain Res. 1020:1-11.

Marion, E., P.J. Kaisaki, V. Pouillon, C. Gueydan, J.C. Levy, A. Bodson, G. Krzentowski, J.C. Daubresse, J. Mockel, J. Behrends, G. Servais, C. Szpirer, V. Kruys, D. Gauguier, and S. Schurmans. 2002. The gene INPPL1, encoding the lipid phosphatase SHIP2, is a candidate for type 2 diabetes in rat and man. Diabetes. 51:2012-2017. 
Marshall, C.J. 1995. Specificity of receptor tyrosine kinase signaling: transient versus sustained extracellular signal-regulated kinase activation. Cell. 80:179185.

Maxfield, F.R., J. Schlessinger, Y. Shechter, I. Pastan, and M.C. Willingham. 1978. Collection of insulin, EGF and alpha2-macroglobulin in the same patches on the surface of cultured fibroblasts and common internalization. Cell. 14:805810.

Mendoza, P., R. Ortiz, J. Diaz, A.F. Quest, L. Leyton, D. Stupack, and V.A. Torres. 2013. Rab5 activation promotes focal adhesion disassembly, migration and invasiveness in tumor cells. Journal of cell science. 126:3835-3847.

Merlino, G.T., Y.H. Xu, N. Richert, A.J. Clark, S. Ishii, S. Banks-Schlegel, and I. Pastan. 1985. Elevated epidermal growth factor receptor gene copy number and expression in a squamous carcinoma cell line. J Clin Invest. 75:1077-1079.

Miaczynska, M., S. Christoforidis, A. Giner, A. Shevchenko, S. UttenweilerJoseph, B. Habermann, M. Wilm, R.G. Parton, and M. Zerial. 2004. APPL proteins link Rab5 to nuclear signal transduction via an endosomal compartment. Cell. 116:445-456.

Milstein, M., C.K. Mooser, H. Hu, M. Fejzo, D. Slamon, L. Goodglick, S. Dry, and J. Colicelli. 2007. RIN1 is a breast tumor suppressor gene. Cancer Res. 67:11510-11516.

Moch, H., G. Sauter, N. Buchholz, T.C. Gasser, L. Bubendorf, F.M. Waldman, and M.J. Mihatsch. 1997. Epidermal growth factor receptor expression is associated with rapid tumor cell proliferation in renal cell carcinoma. Hum Pathol. 28:1255-1259.

Moreno, L.A., B. Tresaco, G. Bueno, J. Fleta, G. Rodriguez, J.M. Garagorri, and M. Bueno. 2003. Psyllium fibre and the metabolic control of obese children and adolescents. J Physiol Biochem. 59:235-242.

Nair, P. 2005. Epidermal growth factor receptor family and its role in cancer progression. Curr Sci. 88:890-898.

Nakase, I., B. Gallis, T. Takatani-Nakase, S. Oh, E. Lacoste, N.P. Singh, D.R. Goodlett, S. Tanaka, S. Futaki, H. Lai, and T. Sasaki. 2009. Transferrin receptordependent cytotoxicity of artemisinin-transferrin conjugates on prostate cancer cells and induction of apoptosis. Cancer Lett. 274:290-298.

Nelson-Dooley, C., M.A. Della-Fera, M. Hamrick, and C.A. Baile. 2005. Novel treatments for obesity and osteoporosis: targeting apoptotic pathways in adipocytes. Curr Med Chem. 12:2215-2225. 
Nicholson, R.I., J.M. Gee, and M.E. Harper. 2001. EGFR and cancer prognosis. Eur J Cancer. 37 Suppl 4:S9-15.

Oben, J.E., D.M. Enyegue, G.I. Fomekong, Y.B. Soukontoua, and G.A. Agbor. 2007. The effect of Cissus quadrangularis (CQR-300) and a Cissus formulation (CORE) on obesity and obesity-induced oxidative stress. Lipids Health Dis. 6:4.

Olivier, J.P., T. Raabe, M. Henkemeyer, B. Dickson, G. Mbamalu, B. Margolis, J. Schlessinger, E. Hafen, and T. Pawson. 1993. A Drosophila SH2-SH3 adaptor protein implicated in coupling the sevenless tyrosine kinase to an activator of Ras guanine nucleotide exchange, Sos. Cell. 73:179-191.

Ornitz, D.M., and N. Itoh. 2001. Fibroblast growth factors. Genome Biol. 2:REVIEWS3005.

Otomo, A., R. Kunita, K. Suzuki-Utsunomiya, H. Mizumura, K. Onoe, H. Osuga, S. Hadano, and J.E. Ikeda. 2008. ALS2/alsin deficiency in neurons leads to mild defects in macropinocytosis and axonal growth. Biochemical and biophysical research communications. 370:87-92.

Pajak, B., B. Gajkowska, and A. Orzechowski. 2008. Molecular basis of parthenolide-dependent proapoptotic activity in cancer cells. Folia Histochem Cytobiol. 46:129-135.

Pareek, A., M. Suthar, G.S. Rathore, and V. Bansal. 2011. Feverfew (Tanacetum parthenium L.): A systematic review. Pharmacogn Rev. 5:103-110.

Patapoutian, A., and L.F. Reichardt. 2001. Trk receptors: mediators of neurotrophin action. Curr Opin Neurobiol. 11:272-280.

Pawson, T., G.D. Gish, and P. Nash. 2001. SH2 domains, interaction modules and cellular wiring. Trends in cell biology. 11:504-511.

Penissi, A.B., T.H. Fogal, J.A. Guzman, and R.S. Piezzi. 1998. Gastroduodenal mucosal protection induced by dehydroleucodine: mucus secretion and role of monoamines. Digestive diseases and sciences. 43:791-798.

Perona, R. 2006. Cell signalling: growth factors and tyrosine kinase receptors. Clin Transl Oncol. 8:77-82.

Perry, N.B., and L.M. Foster. 1995. Sesquiterpene/quinol from a New Zealand liverwort, Riccardia crassa. Journal of natural products. 58:1131-1135.

Pfeffer, S. 2005. Filling the Rab GAP. Nat Cell Biol. 7:856-857.

Polo, L.M., C.M. Castro, M.C. Cruzado, C.J. Collino, F.D. Cuello-Carrion, D.R. Ciocca, O.S. Giordano, M. Ferrari, and L.A. Lopez. 2007. 11,13-dihydro- 
dehydroleucodine, a derivative of dehydroleucodine with an inactivated alkylating function conserves the anti-proliferative activity in G2 but does not cause cytotoxicity. European journal of pharmacology. 556:19-26.

Ponting, C.P., and D.R. Benjamin. 1996. A novel family of Ras-binding domains. Trends Biochem Sci. 21:422-425.

Priestap, Galvis, Rivero, Costantino, Lopez, and Barbieri. 2012. Dehydroleucodine and dehydroparishin-B inhibit proliferation and motility of B16 melanoma cells. Phytochemistry Letters. 5:581-585.

Qiang, L., R. Fujita, and A. Abeliovich. 2013. Remodeling neurodegeneration: somatic cell reprogramming-based models of adult neurological disorders. Neuron. 78:957-969.

Racotta, I.S., J. Leblanc, and D. Richard. 1994. The effect of caffeine on food intake in rats: involvement of corticotropin-releasing factor and the sympathoadrenal system. Pharmacol Biochem Behav. 48:887-892.

Rayalam, S., M.A. Della-Fera, and C.A. Baile. 2008. Phytochemicals and regulation of the adipocyte life cycle. $J$ Nutr Biochem. 19:717-726.

Reaven, G., and P.S. Tsao. 2003. Insulin resistance and compensatory hyperinsulinemia: the key player between cigarette smoking and cardiovascular disease? J Am Coll Cardiol. 41:1044-1047.

Riese, D.J., 2nd, and D.F. Stern. 1998. Specificity within the EGF family/ErbB receptor family signaling network. Bioessays. 20:41-48.

Roberts, R.L., M.A. Barbieri, K.M. Pryse, M. Chua, J.H. Morisaki, and P.D. Stahl. 1999. Endosome fusion in living cells overexpressing GFP-rab5. Journal of cell science. 112 ( Pt 21):3667-3675.

Robles, M., M. Aregullin, J. West, and E. Rodriguez. 1995. Recent studies on the zoopharmacognosy, pharmacology and neurotoxicology of sesquiterpene lactones. Planta medica. 61:199-203.

Rogers, S.J., K.J. Harrington, P. Rhys-Evans, O.C. P, and S.A. Eccles. 2005. Biological significance of c-erbB family oncogenes in head and neck cancer. Cancer Metastasis Rev. 24:47-69.

Rosen, E.D., and O.A. MacDougald. 2006. Adipocyte differentiation from the inside out. Nat Rev Mol Cell Biol. 7:885-896.

Rosen, E.D., and B.M. Spiegelman. 2000. Molecular regulation of adipogenesis. Annu Rev Cell Dev Biol. 16:145-171. 
Rosen, E.D., and B.M. Spiegelman. 2006. Adipocytes as regulators of energy balance and glucose homeostasis. Nature. 444:847-853.

Ross, J.J., J.T. Arnason, and H.C. Birnboim. 1999. Low concentrations of the feverfew component parthenolide inhibit in vitro growth of tumor lines in a cytostatic fashion. Planta medica. 65:126-129.

Sato, M., K. Sato, P. Fonarev, C.J. Huang, W. Liou, and B.D. Grant. 2005. Caenorhabditis elegans RME- 6 is a novel regulator of RAB-5 at the clathrincoated pit. Nat Cell Biol. 7:559-569.

Schlessinger, J. 1981. Dynamics of hormone receptors on cell membrane. Ann N Y Acad Sci. 366:274-284.

Schlessinger, J. 2002. Ligand-induced, receptor-mediated dimerization and activation of EGF receptor. Cell. 110:669-672.

Schmid, S.L. 1997. Clathrin-coated vesicle formation and protein sorting: an integrated process. Annu Rev Biochem. 66:511-548.

Sebastian, S., J. Settleman, S.J. Reshkin, A. Azzariti, A. Bellizzi, and A. Paradiso. 2006. The complexity of targeting EGFR signalling in cancer: from expression to turnover. Biochim Biophys Acta. 1766:120-139.

Semenkovich, C.F. 1997. Regulation of fatty acid synthase (FAS). Prog Lipid Res. 36:43-53.

Shaham, O., R. Wei, T.J. Wang, C. Ricciardi, G.D. Lewis, R.S. Vasan, S.A. Carr, R. Thadhani, R.E. Gerszten, and V.K. Mootha. 2008. Metabolic profiling of the human response to a glucose challenge reveals distinct axes of insulin sensitivity. Mol Syst Biol. 4:214.

Siddle, K. 2011. Signalling by insulin and IGF receptors: supporting acts and new players. J Mol Endocrinol. 47:R1-10.

Siegel, G.J., and N.B. Chauhan. 2000. Neurotrophic factors in Alzheimer's and Parkinson's disease brain. Brain Res Brain Res Rev. 33:199-227.

Sigismund, S., E. Argenzio, D. Tosoni, E. Cavallaro, S. Polo, and P.P. Di Fiore. 2008. Clathrin-mediated internalization is essential for sustained EGFR signaling but dispensable for degradation. Dev Cell. 15:209-219.

Simonsen, A., R. Lippe, S. Christoforidis, J.M. Gaullier, A. Brech, J. Callaghan, B.H. Toh, C. Murphy, M. Zerial, and H. Stenmark. 1998. EEA1 links PI(3)K function to Rab5 regulation of endosome fusion. Nature. 394:494-498. 
Singh, N.P., and V.K. Panwar. 2006. Case report of a pituitary macroadenoma treated with artemether. Integr Cancer Ther. 5:391-394.

Sofroniew, M.V., C.L. Howe, and W.C. Mobley. 2001. Nerve growth factor signaling, neuroprotection, and neural repair. Annu Rev Neurosci. 24:1217-1281.

Stein, M.P., J. Dong, and A. Wandinger-Ness. 2003. Rab proteins and endocytic trafficking: potential targets for therapeutic intervention. Adv Drug Deliv Rev. 55:1421-1437.

Stumvoll, M., B.J. Goldstein, and T.W. van Haeften. 2005. Type 2 diabetes: principles of pathogenesis and therapy. Lancet. 365:1333-1346.

Su, X., I.J. Lodhi, A.R. Saltiel, and P.D. Stahl. 2006. Insulin-stimulated Interaction between insulin receptor substrate 1 and p85alpha and activation of protein kinase B/Akt require Rab5. The Journal of biological chemistry. 281:2798227990.

Summers, S.A., L.A. Garza, H. Zhou, and M.J. Birnbaum. 1998. Regulation of insulin-stimulated glucose transporter GLUT4 translocation and Akt kinase activity by ceramide. Molecular and cellular biology. 18:5457-5464.

Suo, Z., and J.M. Nesland. 2002. Type 1 protein tyrosine kinases in breast carcinoma: a review. Ultrastruct Pathol. 26:125-135.

Suzuki, K., R. Konno, T. Shimzu, T. Nagashima, and A. Kimura. 2007. A fermentation product of phytosterol including campestenone reduces body fat storage and body weight gain in mice. J Nutr Sci Vitaminol (Tokyo). 53:63-67.

Tall, G.G., M.A. Barbieri, P.D. Stahl, and B.F. Horazdovsky. 2001. Ras-activated endocytosis is mediated by the Rab5 guanine nucleotide exchange activity of RIN1. Dev Cell. 1:73-82.

Tomshine, J.C., S.R. Severson, D.A. Wigle, Z. Sun, D.A. Beleford, V. Shridhar, and B.F. Horazdovsky. 2009. Cell proliferation and epidermal growth factor signaling in non-small cell lung adenocarcinoma cell lines are dependent on Rin1. The Journal of biological chemistry. 284:26331-26339.

Trayhurn, P. 2005. Endocrine and signalling role of adipose tissue: new perspectives on fat. Acta Physiol Scand. 184:285-293.

Ueda, S., K. Hatsuse, H. Tsuda, S. Ogata, N. Kawarabayashi, T. Takigawa, T. Einama, D. Morita, K. Fukatsu, Y. Sugiura, O. Matsubara, and H. Mochizuki. 2006. Potential crosstalk between insulin-like growth factor receptor type 1 and epidermal growth factor receptor in progression and metastasis of pancreatic cancer. Mod Pathol. 19:788-796. 
Vasudeva, N., N. Yadav, and S.K. Sharma. 2012. Natural products: a safest approach for obesity. Chin J Integr Med. 18:473-480.

Volinsky, N., and B.N. Kholodenko. 2013. Complexity of receptor tyrosine kinase signal processing. Cold Spring Harb Perspect Biol. 5:a009043.

Wang, Y., B. Su, and Z. Xia. 2006. Brain-derived neurotrophic factor activates ERK5 in cortical neurons via a Rap1-MEKK2 signaling cascade. The Journal of biological chemistry. 281:35965-35974.

Wang, Y., R.T. Waldron, A. Dhaka, A. Patel, M.M. Riley, E. Rozengurt, and J. Colicelli. 2002. The RAS effector RIN1 directly competes with RAF and is regulated by 14-3-3 proteins. Molecular and cellular biology. 22:916-926.

Wang, Y.X. 2010. PPARs: diverse regulators in energy metabolism and metabolic diseases. Cell Res. 20:124-137.

Werner, H., D. Weinstein, and I. Bentov. 2008. Similarities and differences between insulin and IGF-I: structures, receptors, and signalling pathways. Arch Physiol Biochem. 114:17-22.

Wiedhopf, R.M., M. Young, E. Bianchi, and J.R. Cole. 1973. Tumor inhibitory agent from Magnolia grandiflora (Magnoliaceae). I. Parthenolide. J Pharm Sci. 62:345.

Wieduwilt, M.J., and M.M. Moasser. 2008. The epidermal growth factor receptor family: biology driving targeted therapeutics. Cell Mol Life Sci. 65:1566-1584.

Woynarowski, J.M., and J. Konopa. 1981. Inhibition of DNA biosynthesis in HeLa cells by cytotoxic and antitumor sesquiterpene lactones. Mol Pharmacol. 19:97102.

Wu, C., F. Chen, J.W. Rushing, X. Wang, H.J. Kim, G. Huang, V. Haley-Zitlin, and G. He. 2006. Antiproliferative activities of parthenolide and golden feverfew extract against three human cancer cell lines. J Med Food. 9:55-61.

Yang, J.Y., M.A. Della-Fera, D.L. Hartzell, C. Nelson-Dooley, D.B. Hausman, and C.A. Baile. 2006. Esculetin induces apoptosis and inhibits adipogenesis in 3T3L1 cells. Obesity (Silver Spring). 14:1691-1699.

Zerial, M., and H. McBride. 2001. Rab proteins as membrane organizers. Nat Rev Mol Cell Biol. 2:107-117.

Zhang, S., C.N. Ong, and H.M. Shen. 2004. Critical roles of intracellular thiols and calcium in parthenolide-induced apoptosis in human colorectal cancer cells. Cancer Lett. 208:143-153. 
Zhang, S., Y.K. Won, C.N. Ong, and H.M. Shen. 2005. Anti-cancer potential of sesquiterpene lactones: bioactivity and molecular mechanisms. Curr Med Chem Anticancer Agents. 5:239-249.

Zhang, Z.Y., S.Q. Yu, L.Y. Miao, X.Y. Huang, X.P. Zhang, Y.P. Zhu, X.H. Xia, and D.Q. Li. 2008. [Artesunate combined with vinorelbine plus cisplatin in treatment of advanced non-small cell lung cancer: a randomized controlled trial]. Zhong Xi Yi Jie He Xue Bao. 6:134-138.

Zhou, J., and Y. Zhang. 2008. Cancer stem cells: Models, mechanisms and implications for improved treatment. Cell Cycle. 7:1360-1370.

Zhou, Q., G.S. Lee, J. Brady, S. Datta, M. Katan, A. Sheikh, M.S. Martins, T.D. Bunney, B.H. Santich, S. Moir, D.B. Kuhns, D.A. Long Priel, A. Ombrello, D. Stone, M.J. Ombrello, J. Khan, J.D. Milner, D.L. Kastner, and I. Aksentijevich. 2012. A hypermorphic missense mutation in PLCG2, encoding phospholipase Cgamma2, causes a dominantly inherited autoinflammatory disease with immunodeficiency. Am J Hum Genet. 91:713-720.

Zhou, Y.J., K.S. Magnuson, T.P. Cheng, M. Gadina, D.M. Frucht, J. Galon, F. Candotti, R.L. Geahlen, P.S. Changelian, and J.J. O'Shea. 2000. Hierarchy of protein tyrosine kinases in interleukin-2 (IL-2) signaling: activation of syk depends on Jak3; however, neither Syk nor Lck is required for IL-2-mediated STAT activation. Molecular and cellular biology. 20:4371-4380.

Zhu, Z., J.J. Dumas, S.E. Lietzke, and D.G. Lambright. 2001. A helical turn motif in Mss4 is a critical determinant of Rab binding and nucleotide release. Biochemistry. 40:3027-3036. 


\section{APPENDICES}

\section{Appendix 1}

Primers used to do the point mutations in Rin1.

1) Rin1: W69E

5' - CTCACCCGGCCCGTGGAGCTGCAGCTGCAAGCCAAC - 3'

2) Rin1: A76E

$$
\text { 5' - CTGCAGCTGCAAGCCAACGAAGCGGCCGCACTGCAC - 3' }
$$

3) Rin1: R94A

$$
\text { 5' - CCGGGGACGTTCCTCGTGGCGAAATCTAACACCCGCCAG - 3' }
$$

4) Rin1:Y561F

$$
\text { 5' - GAGCTGCTGCTGGCGGCCGAGTTCATGTCGGAGCTGCTGGAGCCCAG }
$$

5) Rin1:T580A

$$
\text { 5' - GAGGGTGGCTACTACCTGGCCAGCCTCTCTGCCAGCCTG - 3' }
$$

6) Rin1:R629A

$$
\text { 5' - CACCTCCTCGCAGTAGCCTATC - 3' }
$$

7) Rin1: H120L

$$
\text { 5' - CCCTCCTTCGTCTCCAGCCTCTACATCCTGGAGAGCCCTGGC - 3' }
$$

8) Rin1: Y121F

$$
\text { 5'- CCCTCCTTCGTCTCCAGCCACTTCATCCTGGAGAGCCCTGGC - 3' }
$$

9) Rin1: Y148F

$$
\text { 5' - CCCTCCTTCGTCTCCAGCCACTTCATCCTGGAGAGCCCTGGC - 3' }
$$


VITA

ADRIANA GALVIS

Born, Bogota, Colombia

2003-2005

B.S., Biology

Minor in Chemistry

Florida International University, Miami, Florida

2007-2009

M.S., Biology

Florida International University, Miami, Florida

2009-2014

Doctoral Candidate

Florida International University

Miami, Florida

2007-2009

Teaching Assistant,

Dept. of Biology

Florida International University

Miami, Florida

2009-2012

Teaching Assistant,

Dept. of Biology

Florida International University

Miami, Florida

\section{PUBLICATIONS AND PRESENTATIONS}

Villaverde N, Galvis A, Marcano A, Priestap HA, Bennett BC, Barbieri MA. Saw palmetto ethanol extract inhibits adipocyte differentiation. Journal of Natural Medicines. 2012.

Priestap HA, Priestap, Galvis A, Rivero N, Consantino V, Lopez LA, Barbieri MA. Dehydroleucodine and dehydroparishin-B inhibit proliferation and motility of B16 melanoma cells. Phytochemistry Letters. 2012; 3:581-585.

Galvis A, Marcano A, Villaverde N, Priestap HA, Tonn CE, Lopez LA and Barbieri MA. The effect of dehydroleucodine in adipocytes differentiation. European Journal of Pharmacology. 2011; 671:18-25. 
Galvis A, Giambini H, Villasana Z, and Barbieri MA. Functional determinants of Ras interference 1 mutants required for their inhibitory activity on endocytosis. Experimental Cell Research. 2009; 315:820-35.

Galvis A, Balmaceda V, Giambini H, Conde A, Villasana Z, Fornes M and Barbieri MA. Inhibition of early endosome fusion by Rab5-binding defective Ras interference 1 mutants. Archives of Biochemistry and Biophysics. 2009; 482:8395.

Hunker CM, Galvis A, Veisaga ML and Barbieri MA. Rin1 is a negative regulator of the IL3 receptor signal transduction pathways. Anticancer Research. 2006; 26:905-16.

Hunker CM, Giambini H, Galvis A, Kruk I, Veisaga ML and Barbieri MA. Rab5 activating protein 6 (RAP6), a novel endosomal protein with a role in endocytosis. Biochemical and Biophysical Research Communications. 2006; 340: 967-75.

Hunker CM, Giambini H, Galvis A, Hall J, Kruk I, ML, and Barbieri MA. Rin1 regulates insulin receptor signal transduction pathways. Experimental Cell Research. 2006; 312:1106-18.

Galvis A, and Barbieri A. The role of Rin1 in insulin receptor signaling. Presented on the 53th Annual Meeting of The American Society for Cell Biology. December 14 - 18, 2013, New Orleans, LA.

Galvis A, and Barbieri A. Adipogenesis regulation: from the inside or from the outside? Presented at the MBRS RISE Mini-Symposium, FIU, October 82013.

Galvis A, and Barbieri A. Rin1, via activation of Rab5, is a key regulator of the preadipocyte 3T3-L1 differentiation. Presented at the Biology Research Symposium, FIU, February 22013.

Galvis A, and Barbieri A. The regulatory role of Rin1 in preadipocyte differentiation. Presented at the MBRS RISE Mini-Symposium, FIU, October 8 2012.

Galvis A, and Barbieri A. The Effect of Dehydroleucodine in Adipocyte Differentiation. Presented at the Biology Research Symposium, FIU, January 29 2011.

Galvis A, Marcano A, Priestap H, Lopez L, and Barbieri A. The Effect of Dehydroleucodine in Adipocyte Differentiation. Presented on the 50th Annual Meeting of The American Society for Cell Biology. December 11 - 15, 2010, Philadelphia, PA. 